\title{
IDENTITY IN TRANSITION: WOMEN'S NARRATIVE IDENTITY WORK ON THE PATH TO PROFESSIONAL AND MOTHER
}

\author{
Christine Deborah Bataille \\ Desautels Faculty of Management \\ McGill University, Montreal
}

December, 2014

A thesis submitted to McGill University in partial fulfillment of the requirements of the degree of Doctor of Philosophy in Management

Copyright (C) by Christine D. Bataille 


\begin{abstract}
Although numerous scholars claim that identity is an integral aspect of engaging in work and family, the extant literature falls short of explaining how women's identities evolve over time through the significant transitions involved in pursuing professional careers and raising families. In fact, much of the literature is grounded in the assumption that work and family represent competing identities for women. Missing from this body of literature is a conceptualization of pursuing a professional/managerial career and having a family as a complex set of transitions that provoke the questions, "Who am I?” and "Who/what do I want to be?” Through a narrative study of 35 professional/managerial women, I uncover novel forms of narrative identity work that illuminate how women construct, revise and present their identities as they transition from university students to young professionals, from non-mothers to mothers, and from childless employees to those with childcare responsibilities. Further, I posit that these forms of narrative identity work reflect three higher-order identity processes: identity exploration, identity adaptation, and identity expression. Through a within and between-case examination of the configurations of identity processes across the three transitions, I uncover four dominant patterns that provide novel insights into how women's identities evolve over time on the path to professional and mother.
\end{abstract}




\section{Résumé}

Bien que de nombreux chercheurs affirment que l'identité est une partie intégrante dans l'engagement au travail et avec la famille, la littérature existante est loin d'expliquer comment l'identité des femmes évolue dans le temps à travers les transitions importantes impliquées dans la poursuite de leur carrière professionnelle et élever une famille. En fait, une grande partie de la littérature est fondée sur la présomption que le travail et la famille représentent identités concurrentes pour les femmes. Absent de cette littérature est une conceptualisation de la poursuite d'une carrière professionnelle/gestionnaire et avoir une famille comme un ensemble complexe de transitions qui provoquent les questions suivantes: «Qui suis-je? » et « Qui/quoi veux-je être? » Grâce à une étude narrative de 35 femmes professionnelles/gestionnaires, je découvre de nouvelles formes de travail de l'identité narrative qui éclairent la façon dont les femmes construisent, modifient et présentent leurs identités lors de la transition comme étudiantes universitaires aux jeunes professionnelles, de non-mères à mères, et des employées sans enfant à ceux qui ont des enfants à charge. En outre, je pose que ces formes de travail de l'identité narrative reflètent trois processus identitaires d'ordre supérieur: l'exploration de l'identité, de l'adaptation de l'identité, et de l'expression de l'identité. Grâce à un examen des configurations de processus identitaires à travers les trois transitions, je découvre quatre modèles dominants qui fournissent de nouveaux aperçus sur la façon dont les identités des femmes évoluent au fil du temps sur le chemin de professionnel et de mère. 


\section{Dedication}

This thesis is dedicated to Olivier, Emmy, and Benoit. You are my hope, my joy, and my inspiration in all that I do. 


\section{Acknowledgements}

There are a number of people that I would like to thank for supporting me over the past seven years. First, I thank my family: my husband, Olivier, my daughter, Emmy, and my son, Benoit; your love, encouragement and patience have kept me going through this long and challenging process. I also thank my parents, Raymond R. Lapointe and Deborah J. Fleming for

always believing that I could accomplish anything I set my mind to, and for coming to my rescue more times than I could possibly count. I would like to extend a special thank you to my stepfather, Richard Fleming, for his unconditional support during those crucial final hours.

I thank my PhD supervisor, chair of my dissertation committee, and mentor, Dr. Mary Dean Lee, without whom my life and career would have taken a very different direction. There are no words to express the depth of my gratitude; somehow I hope that you understand how much your constant support and belief in me have meant over the past seven years. Thank you for constantly pushing me outside of my comfort zone, for challenging my ideas and how I express them, and for allowing me to learn and grow through perseverance. Your dedication to me and my work throughout the PhD program, and in particular during this past year, go above and beyond what any doctoral student could possibly expect from a supervisor. I am eternally grateful.

I would like to thank the members of my dissertation committee, Dr. Heather Vough and Dr. Tracy Hecht, who helped me to bring my research ideas to life. Dr. Vough, in particular, pushed me repeatedly to look beyond my data and to craft a dissertation that offers novel theoretical insights. I also thank the members of my Phase II Committee, Dr. Roxana Barbulescu and Dr. Caroline Aube, for their suggestions and feedback pertaining to my earlier 
work that helped inspire the direction I have taken with this thesis. I also thank Stella Scalia for helping me to navigate the $\mathrm{PhD}$ program from beginning to end.

There are also several members of the Desautels Faculty of Management that I would like to thank. First, I thank the doctoral students who helped me along this journey, especially Sungsoo Kim, Russel Siedel, and Sung Chul Noh. I also thank my first year DDSS “buddy,” Stephanie Berger, with whom I spent countless hours studying statistics during my first semester in the program, and without whom I would not have submitted my first (accepted!) paper to AOM. I thank Pamela Lirio for championing my research and for modeling exceptional networking skills. I also thank the faculty members who guided, supported and encouraged me throughout the past seven years, in particular Dr. Nancy Adler, Dr. Alfred Jaeger, and Dr. Suzanne Gagnon. I also thank my Teaching Assistant, Simon Blanchette, whose exceptional skills and unwavering support allowed me to progress with my writing while teaching.

I would like to thank the McGill Women's Alumni Association (MWAA) for awarding me a three-year scholarship that helped to fund my data collection. In particular, I thank Sonia Mata, MWAA President, for her constant encouragement and friendship.

I thank Leticia, Kelly, Susan, Jeff, and Delia for providing vital support during the final year of completing my PhD. I am forever grateful. I also thank my dear personal friends, Toula Kottis, Susanne Bevacqua and Esther Baston. You ladies have been a tremendous source of love, laughter, and unconditional friendship over the past several years.

Finally, I thank my grandfather, George Bertrand, who passed away just two months after I received my letter of acceptance to the PhD program. His last words to me were, "May I be the first to call you Doctor,” leaving me no choice but to finish what I had started. 


\section{Table of Contents}

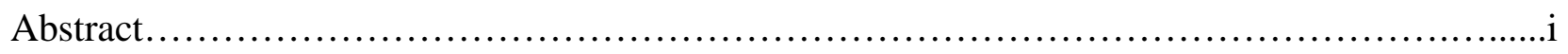

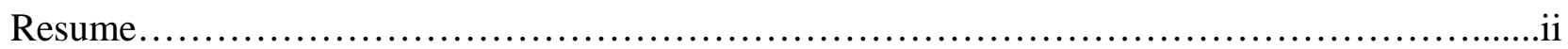

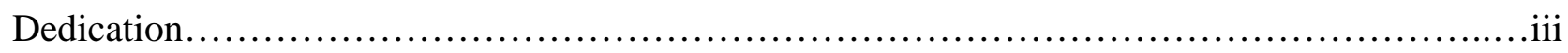

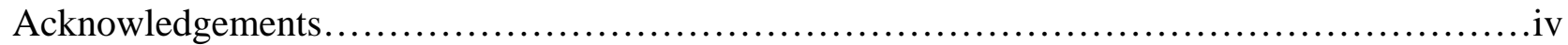

Table of Contents

Chapter 1: $\quad$ Introduction and purpose of the study

Chapter 2: $\quad$ Literature review and research questions

Chapter 3: Methodology

Chapter 4: Findings

Chapter 5: Discussion

References

Tables and Figures

Appendices 


\section{CHAPTER 1: INTRODUCTION AND PURPOSE OF THE STUDY}

\section{Problem and Focus of this Dissertation}

Women's engagement in career and family has attracted the attention of scholars, practitioners and policy makers for decades, stemming from a dramatic shift in the demographic make-up of the North American workforce. While fewer than half of all women with children under the age of 18 were in the paid U.S. workforce in the mid-1970s, more than $70 \%$ are employed outside the home today (Galinsky, Sakai, \& Wigton, 2008). Moreover, in both the United States and Canada, 60\% of women with children under the age of 6 are in the workforce (U.S. Department of Labor, 2006; Human Resources and Social Development Canada, 2003). The growing number of working mothers and dual-earner households has had a tremendous impact on family life, sparking a gendered conceptualization of work and family as separate, competing domains (Lewis \& Cooper, 1999; R. Rapoport, Bailyn, Fletcher, \& Pruitt, 2002; R Rapoport \& Rapoport, 1971) For women in particular, combining career and family has been viewed as problematic, compromising the time and energy available for the roles of wife, mother and worker (Bielby \& Bielby, 1989) and requiring a "second shift” (Hochschild \& Machung, 1989) to meet the demands of both paid work outside the home and unpaid work inside it.

The movement of so many women into the paid workforce, including the pursuit of careers once dominated by men, has provided fertile ground for scholarly inquiry as well as practical debate. In the scholarly realm, the conceptualization of work and family as separate, competing domains provided support for the work-family conflict (Greenhaus \& Beutell, 1985) perspective that overshadowed the literature throughout the1980s and 1990s. However, the new millennium gave birth to a fresh academic outlook in which engagement in work and family came to be viewed as mutually beneficial. In fact, the introduction of constructs such as work- 
family facilitation (Frone, 2003) and work-family enrichment (Greenhaus \& Powell, 2006) served to shift scholarly attention away from conflict and towards an appreciation for the benefits of combining career and family. Yet, while the scholarly literature experienced a flurry of research in support of this positive outlook on work and family, the popular press ignited a new debate over the "hard choices" (K. Gerson, 1985) that women face. Based on the discovery that one-third of successful, middle-aged career women are childless and often regret being so, readers of the Harvard Business Review were informed that, for women, "having it all” is a “myth” (Hewlett, 2002). This conclusion was supported when Lisa Belkin’s (2003) “The OptOut Revolution” announced a new trend of highly successful women stepping out of the corporate rat race and into part-time positions, self-employment or full-time motherhood. A few months later, “The Case for Staying Home” (Wallis et al., 2004) appeared on the cover of Time Magazine, clearly calling into question women's choices in the work/family realm. Nearly a decade later, the message that little has changed was announced by the Atlantic Monthly article, “Why Women Still Can’t Have It All” (Slaughter, 2012).

The ensuing debate over the validity of the picture painted by the media of women rejecting the boardroom in favour of the playroom, or being forced to choose one over the other, brought an identity lens to the forefront of work and family research. Some scholars concluded that women who "opt-out" of their careers experience a shift in identity priorities, such as the increasing importance of the motherhood role, which leads them to leave prestigious, demanding jobs and enter full-time motherhood (Anderson, Vinnicombe, \& Singh, 2010; Volpe \& Murphy, 2011); while others uncovered identity loss as an important consequence of this decision (Stone, 2007). Scholars who focus instead on women who continue to pursue careers while raising children conclude that identity, in addition to autonomy and control, is an integral part of 
combining career and family (Cohen, Duberley, \& Musson, 2009). These discoveries support the claim that, "integrating work and family life is intimately tied to constructions of identities" (Emslie \& Hunt, 2009). However, the extant literature does not explain how women engage in constructing their identities as they pursue demanding professional/managerial careers, and start and raise families. While investigations into the transition to motherhood have exposed the potential for this particular life event to be identity transforming, scholarly knowledge is limited regarding how women’s identities evolve over time and through significant turning points, beginning prior to the transition to motherhood and continuing beyond it.

At present, we are sorely lacking research in which pursuing a professional/managerial career, becoming a mother, and crafting a life that combines career and family is conceptualized as a complex set of life transitions that provoke the questions, "Who am I?” and, “What do I really want?” In the words of Powell and Graves, “women’s careers are more complex than those of men and involve a wide panorama of choices, as well as constraints. Issues of balance, connectedness, and interdependence, in addition to issues of achievement and individuality, permeate women’s lives” (2003, p. 201). Although scholarly endeavours have surfaced identity as a key aspect of women’s careers, there remains much to be learned about how women’s identities develop as they leave university, enter the world of professional work, make decisions regarding the pursuit of graduate degrees, become mothers, and navigate the complex landscape of combining career and family.

\section{Research Approach and Contribution}

In this dissertation, I seek to advance our knowledge of how professional/managerial women with young children develop a sense of who they are, and what they want to be and do, by examining the narrative identity work at particular junctures in their lives, as well as patterns 
in their narrative identity work over time. My study is designed to uncover identity work in selfnarratives of three significant transitions that are common to all professional and managerial women who combine career and family: the early career transition, the transition to motherhood, and the transition to combining career and family. Taking a narrative perspective, I examine patterns of identity work through and across these transitions in order to paint a more nuanced picture of professional and managerial women's identity journeys.

My goal in pursuing this line of research is three-fold. First, while scholars have advanced our understanding of the link between identity and professional/managerial women’s experiences and decision-making in the work/family realm, most studies perpetuate the conceptualization of career and family as competing identities. Researchers continue to categorize women along a career identity salience/family identity salience spectrum. Therefore, I seek to demonstrate that the belief that women are inherently oriented toward one domain or the other is limiting at best; that is, it frames identity as static rather than taking into account the dynamic nature of identity that is clearly established in the literature. Accordingly, I focus on professional/managerial women who pursue high-powered professional careers, because they are heavily invested in education and work experience; therefore, professional identity is likely to be an important element of their sense of self. While much of the extant research would suggest that such women are likely to experience conflict between their professional/career identities and family identities, some scholars posit that self-complexity (i.e., conceiving of oneself in terms of multiple roles/identities) is beneficial to well-being (Barnett \& Hyde, 2001; Baruch \& Barnett, 1986, 1987). Therefore, I seek to challenge the orientation and conflict perspectives by studying women that some would assume are a) inherently career-oriented based on their decision to pursue professional/ managerial careers, and b) conflicted due to the competing demands of their 
high-powered careers and family responsibilities. This is not to imply that nonprofessional/managerial women's identity work is less worthy of scholarly inquiry; it is simply not the focus of the present study.

Second, I seek to advance our understanding of women's identity development in the present social context. That is, I question the assumption that women's identities are fundamentally rooted in relationship and connection; that work is something to do, rather than something to be (Gallos, 1989). In North America, women are now on par or surpassing men in professions once exclusive to men, and are also becoming more highly educated than their male counterparts (Russell Sage Foundation, 2013). In addition, many of today’s young professional women have mothers who role model the pursuit of both career and family. Accordingly, career is likely becoming an increasingly important element of women's identity, and yet this perspective is underrepresented in the extant literature. This gap in the literature is important because identity has been linked to work/family behaviours (Cohen et al., 2009; Honeycutt \& Rosen, 1997; Rothbard \& Edwards, 2005). Therefore, by increasing our understanding of the evolution of a woman's sense of self in the present context we may gain important insights into why professional/managerial women combine career and family in the variety of ways in which they do.

Finally, by taking a narrative approach and focusing on the evolution of identity, I build on and extend the concept of narrative identity work and employ it to investigate how women articulate the continuities and disjunctures in their sense of self as they navigate three significant transitions. Further, while the majority of identity work studies focus on single episodes of macro occupational role transitions (e.g., Ibarra, 1999), I examine narrative identity work over time in the context of three significant work and family transitions. In so doing, I answer the 
scholarly call for, "greater attention on identity’s dynamism over the course of an increasingly discontinuous professional life (Ashforth et al, 2008)” (Ibarra \& Barbulescu, 2010, p. 136). Overview of the Dissertation

This dissertation is organized as follows. Chapter 2 situates the thesis in the relevant literature, thus providing a theoretical framework for the present research. This chapter also identifies the specific gaps the present study seeks to address, and presents the specific research questions it proposes to answer. Chapter 3 includes details of the qualitative methodology I employed to carry out this study, including a detailed explanation of the data collection and analysis. Chapter 4 presents the results of this analysis, including ten different forms of narrative identity work that were uncovered in stories of the three transitions. In this chapter, I demonstrate how particular forms of narrative identity work reflect three higher-order identity processes: identity exploration, identity adaptation, and identity expression. Further, I identify four dominant within-case patterns of identity processes across the three transitions and explain what these patterns indicate about the evolution of women's identity. Finally, I conclude in Chapter 5 with a discussion of theoretical and practical implications, limitations of the study, and directions for future research. 


\section{CHAPTER 2: LITERATURE REVIEW}

The purpose of this chapter is to present and integrate the extant literature and theory informing this study. First, I discuss the women's adult, identity and career development literature, demonstrating the existence of a variety of perspectives on how women's careers and identities unfold. In particular, I highlight how the changing social context warrants taking a closer look at women's identity development given the significant strides women have made on career paths once exclusive to men. Second, I examine the identity theory and narrative identity literatures to provide an appropriate theoretical frame for examining how women come to understand who they are as professionals/managers with children. I then review the literature that pertains to identity work in order to provide a theoretical lens and empirical approach through which we may study the evolution of women's identity. In so doing, I broaden the concept of narrative identity work beyond self-narration in a social context to legitimize macro role transitions (Ibarra \& Barbulescu, 2010), to the retrospective, storied version of the tactics individuals use to form, maintain, repair, or revise their sense of self (Sveningsson \& Alvesson, 2003) during significant transitions. I then discuss the literature that pertains to three specific transitions that are common to all women who combine professional/managerial careers and family: the early career transition, the transition to motherhood, and the transition to combining career and family. In reviewing the literature on this third transition, I discuss the competing identities perspective that has thus far dominated the research on how women approach work and family. Finally, I identify the specific gaps this thesis seeks to fill. In particular, I explain how my research aims to provide a fresh perspective on women's work/family choices by focusing on women's own life stories about how they come to understand who they are, and who/what they wish to become. 


\section{Women's Identity and Career Development}

Women's identity and adult development. The study of identity and adult development is often traced back to Erik H. Erikson, who is credited as the founding father of identity research and the first to have coined the term, "identity crisis” (Singer, 2004). In fact, Levinson (1978), also recognized as an influential adult development scholar, credits Erikson as, "the most influential developmental theorist of the time” (Levinson \& Levinson, 1996, p. 16). Erikson was the first to conceive of identity as a lifelong process: “... while the end of adolescence thus is the stage of an overt identity crisis, identity formation neither begins nor ends with adolescence: it is a lifelong development largely unconscious to the individual and his society” (E. H. Erikson \& Rapaport, 1959). Erikson’s theory distinguishes between ego identity and identity diffusion, and posits that individuals face the task of developing a self-definition in late adolescence. During this life stage, a man (Erikson's subjects were exclusively male) faces the tasks of choosing an occupation and becoming a citizen; in essence, ego identity is achieved by establishing one’s place in society while maintaining a feeling of continuity within oneself (Marcia, 1966). Erikson (1959) believed that the task of ego identity achievement had to be accomplished before intimacy could be attained in young adulthood.

Advancing Erikson’s work from theory to empirical research, James Marcia (1966) identified two dimensions of late adolescent identity status, exploration and commitment, and developed a method to categorize adolescents at the ego identity/identity diffusion stage according to their identity development (Josselson, 1996). The first dimension, exploration, involves trying out different identities, or ways of being, while the second dimension, commitment, refers to devoting oneself to a particular identity (Marcia, 1966; Josselson, 1996). Based on these dimensions, Marcia proposed four categories that psychologists could use to 
classify adolescents into one of four categories: Identity Achieved (exploration followed by commitment), Foreclosure (commitment with no exploration), Moratorium (exploration with no commitment), or Identity Diffusion (no exploration, no commitment) (Josselson, 1996). However, as Josselson (1996) explains, Marcia conferred with Erikson that identity is a lifelong process, not a one-time task, and that late adolescence represents, “.... an initial formulation, subject to reformation and reintegration throughout the lifecycle” (p.277). In fact, in his later research, Marcia examined the development of identity throughout all stages of adulthood (Marcia, 2002). In so doing, Marcia proposes a model in which he contends that individuals experience an identity re-formulation period at least three times during their lives, based on Erikson's stage model of adult development. That is, as an individual comes to the end of one stage and the beginning of the next, he/she experiences an achievement-moratoriumachievement-moratorium (MAMA) cycle in which active exploration and consideration of alternatives is followed by tentative commitments until a re-formulated adult identity is achieved in the next stage of development. Marcia also posits that MAMA cycles will occur during what he refers to as, “disequilibrating circumstances," such as divorce, losing a job, getting a promotion, and retirement.

The perspective that identity development occurs in particular age-based stages or phases has dominated the adult development literature, as many scholars regarded Erikson’s seminal work as providing a fundamental theoretical foundation from which to build. Levinson (1978) provided further support for this approach with his intensive study of 40 men between the ages of 35 and 45. Based on this research, he developed a model of the life cycle that articulates the major eras, periods and transition points from age 17 through old age. In accord with Erikson, Levinson concluded that individuals must accomplish tasks in each period of the life cycle before 
successfully moving on to the next one. However, although Erikson, Levinson and Marcia made considerable contributions to the study of adult development and identity formation, their theories have come under scrutiny by feminist and careers scholars who question the use of exclusively male subjects in this area of research (Gallos, 1989; Harrington \& Hall, 2007; Roberts \& Newton, 1987). In fact, several adult development scholars, from Erikson (1968) and Levinson (1978) to Gould (1978) and Kolhberg (1976), have been criticized for establishing a male standard for what it means to be an adult and deeming women's divergence from this standard as a reflection of immaturity (Gallos, 1989). Building on the work of several influential feminist scholars, including Miller (1976, 1986), Gilligan (1982, 1993), and Bardwick (1980), Gallos (1989) argues that men’s identity is strengthened through increased autonomy and separation whereas women's identity formation is grounded in attachments and relationships. In fact, Bardwick (1980), Gilligan (1980) and Giele (1980) all viewed the extension of male models of adult development to women as inappropriate, believing instead that women face unique struggles to combine achievement and attachment: “even for accomplished professional and career women, traditional roles and interpersonal commitments remain a core part of female identity,” (Cytrynbaum \& Crites, 1989, p. 73).

In response to the feminist critique, Levinson extended his research to women in Season's of a Woman's Life (Levinson \& Levinson, 1996), where he sought to replicate his original study with a sample of 45 women between the ages of 35 to 45, 15 of whom were homemakers, and 30 of whom had careers in either finance or academia. He concludes that women's lives can be mapped to the same sequence of eras and periods, and at the same ages, as men’s. However, he also discovered an inner battle between what he terms, the Anti-Traditional Figure, an image that supports a woman's right to have a career and to expect household help 
from her husband, and the Traditional Homemaker Figure, an opposing image who makes a woman feel that she is primarily responsible for childcare and housework. He writes, "By the late 30s, many career women carried the individual Dream of the Successful Career woman, which was helped by the Anti-Traditional Figure, who co-existed in every career woman with the opposing internal Traditional Homemaker Figure” (Levinson \& Levinson, 1996, p. 369). While the relative strength of these two "Figures" differed by woman, this inner struggle emerged as an important theme in the personal stories of all 30 career women in his study. These findings imply that all women who pursue professional careers are burdened by a conflicting sense of self in terms of who one should be (i.e., traditional homemaker) and who one wishes to be (i.e., independent career woman). However, while this may have been the experience of the trailblazing women who challenged the male breadwinner/female homemaker model of the 1950s by pursuing higher education and traditionally male-dominated careers, today's professional/managerial women may be less inclined to see themselves as conflicted by competing, gendered roles.

Although the feminist perspective continues to dominate the women's identity literature, it is not without its critics. Some scholars argue that categorizing adult development stages and identity formation according to gender results in a narrow perspective in which there is little room to conceptualize the experiences of men who display feminine tendencies or women who display masculine tendencies (Cote \& Levine, 2002). In fact, the writings of feminist scholars in the 1970s, 1980s, and early 1990s reinforced the conclusion that relationship and connection are fundamental to women's identity. For example, based on a study of women managers in the early 1980s, Marshall (1989) concludes that women see themselves in terms of relationship, and that their careers are reflective of communion, a "feminine" modality of acceptance and personal 
adjustment, rather than agency, a more "masculine" expression of independence and selfassertion (p. 279). This perspective minimizes the importance some women may place on challenge, achievement and career as fundamental to their sense of self. Indeed, Gallos (1989) writes: "Research has shown that even with career and professional achievements, traditional roles remain a central part of women's identity, and their occupational commitments are based on a different psychological stance than men. Work is something important to do rather than something to be.” Such an outlook makes a sweeping generalization, ignoring the possibility that work/professional identity may be central to some women's self-definition. In the present North American context, many women pursue continuous, full-time professional and managerial careers, consciously opting for high-powered organizational positions over marriage and family, while others pursue both demanding careers and motherhood. Other professional/managerial women have discontinuous careers, reducing work hours at particular points in their lives such as during their children's early years, yet they may still see their work/career as essential to their sense of self. As such, there remains much to be learned about how women answer the questions, "Who am I?” and "What do I really want?” at different points in their lives. In order to tackle the question, "How does a woman come to be who she is?” Josselson (1996) conducted a longitudinal study of women's identity development. She followed a randomly selected group of 30 women from four different colleges and universities and interviewed them at three points in time: first, as college seniors, second, twelve years after the first interview when they were in their 30s, and third, ten years later when they were in their 40s. Following the first round of data collection and analysis when the women were in college, Josselson categorized her informants according to Marcia’s (1966) four identity status groups. However, she explains that she re-named Marcia's categories to be more descriptive and less 
evaluative: Pathmakers (i.e., Achieved), Guardians (i.e., Foreclosure), Searchers (Moratorium), and Drifters (Diffusion). Although Josselson re-interviewed her subjects ten years later, when they were in their 30s, and again when they were in their 40s, she maintained the categorization she established after the first interview. Despite the significant changes she observed in the women within each group, she argues that attempts to re-group at each time period resulted in unmanageable complexity.

Based on her findings, Josselson confirms that Marcia’s dimensions of exploration and commitment are useful for defining four distinct identity pathways from young adulthood to midlife, and concludes that, "identity resides at the intersection of competence and connection" (p. 178). However, for Josselson, competence refers to how effective a woman feels in the world, not just in her work, and connection refers to how she is linked to others. However, while she acknowledges competence as a key component of women's identity, her conceptualization of competence is relational rather than intrapersonal, thus overlapping with connection. For example, Josselson posits that competence at work is experienced primarily through generativity and feeling part of an interconnected web of work relationships. As such, while apparently recognizing that a woman's sense of self is derived from more than just her relationships, she essentially confirms the status quo feminist perspective that women's identities differ from men's in that they are primarily relational: "a woman forms her sense of herself through connections with others" (Josselson, 1996, p.32).

While the extant literature continues to support the perspective that women's identity development is rooted in relationship and connection, and that work is something to do rather than something to be (Gallos, 1989), it is important to recognize that women's place in North American society continues to advance. In fact, in the present North America context in which 
women hold more graduate degrees than men, are expected to dominate such professions as medicine and law, and make up an increasing percentage of students enrolled in top MBA programs (Davidson \& Burke, 2011), it is likely that many women have come to view their work as central to their sense of self. Further, although working mothers today must contend with a culture of "helicopter parents" who micromanage and overschedule their children's lives (Gibbs, 2009), professional and managerial women now have role models and mentors that were nearly non-existent just a few decades ago. Accordingly, theories of women's identity development need to be reexamined if we are to paint a more accurate picture of how today's professional/ managerial women develop an understanding of themselves, and how this evolving sense of self influences the work/family choices that they make at different points in their lives.

Women's careers. The study of adult development and identity is inextricably linked to career development research. However, while this has always been the case for men's careers, the study of women's careers only gained traction as a rapidly increasing number of women began working outside the home after getting married, and after having children. For men, choosing an occupation/career has always represented the preeminent task following the resolution of the late adolescent "identity crisis" assumed in models of adult development; however, just a few decades ago women were expected to work only until they were married, at which point homemaking would become their chosen career (Gutek \& Larwood, 1989). In an early attempt to devise a theory of women's career development, Gutek and Larwood (1989) identified five elements as impacting an individual's career path: career preparation, opportunities available, marriage, pregnancy and children, and timing and age. Based on these elements, they propose three potential career paths for women. The first reflects the traditional male career, and the authors posit that this path is the most likely to lead to hierarchical success. 
Herein the adolescent prepares for her career with the appropriate training and education, recognizes and takes advantage of available career opportunities, continues working whether or not she marries and has children, and experiences no timing delays; that is, she embarks on her career at the same time a man would. The second path reflects the traditional female career path of the 1960s and 1970s, when women did not expect to work after getting married. As such, they did not engage in preparing for a career, nor were there many interesting career opportunities available. In this path, if she did decide to return to work after having children, both her years of being out of the workforce and her age served as significant disadvantages to advancement. The third path represents those women who prepared for careers and continued to work after marriage and childbirth; however, whether due to post WWII policies that forced women to give up their jobs to men returning from war, or sensing a lack of opportunity for advancement in their organizations, their careers were delayed and ultimately stagnated.

Demonstrating the impact of social trends on women's career and identity development, Gutek and Larwood's model reflects the nature of women's careers from the 1960s to the mid1980s. Throughout this time period, women's career opportunities were significantly constrained by legislation, overt discrimination by employers, and social norms that shaped female adolescents' expectations of marriage and homemaking as defining their adulthood (Gutek \& Larwood, 1989). However, as women began to remain in the paid workforce after getting married and having children, to pursue higher education, and to begin making strides in careers that were formed and dominated by men, scholars began to uncover important nuances in women's careers. Based on a review of the previous decade's research on women's career development, Phillips and Imhoff (1997) conclude that, "interpersonal and family domains appear to be uniquely central to the development of identity for women” (p. 33). This deduction 
resonates with the feminist perspective regarding the significance that relationships and connection play in women's development. Providing insight into one of the reasons why relationship has been found to be so central to women's identity and career development in previous research, Gutek and Larwood argue, “...because their jobs provided little responsibility and challenge or opportunities for advancement, many peaked early and thus found interests outside of their careers or focused on interpersonal relationships at work rather than trying to advance from a job with little opportunity” (p. 180).

As women continued to advance in the professional and managerial arena, research also advanced and new discoveries were made regarding how women's career patterns differed from those of men. For one, the careers of women who choose to become mothers often include interruptions, such as multiple leaves of absence and/or periods of reduced work-load arrangements (Buzzanell \& Lucas, 2006; Powell \& Mainiero, 1992). Based on a review of the women’s careers literature, Powell and Mainiero (1992) concluded that women express two distinct concerns: “concern for career,” which represents women’s concerns with career and personal achievement, and the second, “concern for relationships,” or “concern for others,” which represents women’s concerns about family and personal, non-work relationships (p.219). These scholars explain that emphasis on these two concerns will vary at different times in women's lives, which results in women presenting one of three working statuses: presently working, considering working, and temporarily not working (1992, p.219). In conclusion, Powell and Mainiero posit that, “women are subject to multiple influences, factors, and constraints in making decisions regarding career and relationships with others” (p.231). One of these constraints is the difficulty that dual-career couples face in maintaining two demanding careers while raising a family and the tendency for women to be the ones who make career 
sacrifices. For example, Moen and Sweet (2004) found that as dual-earner couples start families one partner usually scales back on career goals and work hours, and it tends to be the woman who does the scaling back.

In an attempt to provide an explanation for how women's careers unfold, some scholars have examined the difference between men's and women's career development. For example, Mainiero and Sullivan (2005) developed the Kaleidoscope Career Model (KCM) to demonstrate how career patterns differ between the sexes (Sullivan \& Baruch, 2009). The KCM, based on the results of five studies with more than 3000 U.S. professionals, explains how life/career patterns change focus over the course of the life span based on three core aspects of career: authenticity (making choices that permit the individual to be true to him/herself), balance (striving for equilibrium between work and non-work domains) and challenge (pursuing stimulation and career advancement). Mainiero and Sullivan discovered that the majority of men follow the "alpha kaleidoscope career" in which challenge is prominent in the early to midcareer, followed by authenticity and then balance in the later career; the women, on the other hand, overwhelmingly followed the "beta kaleidoscope career" in which challenge is followed by balance, with authenticity the focus of late career (Sullivan \& Mainiero, 2007). Mainiero and Sullivan (2005) posit that women’s careers follow this “beta” pattern based on caring responsibilities that wax and wane over the lifespan.

Beyond demonstrating that women's careers differ from men's, the KCM's indication of authenticity as a ‘pivotal life parameter’ speaks to women’s identity development. Mainiero and Sullivan explain that authenticity begs the question, "Can I be myself in the midst of all this and still be authentic?” In other words, these scholars uncover the need for finding and maintaining a sense of self in the midst of pursuing a career and raising a family. However, they also claim 
that it is not until a woman reaches her late 40s/early 50s that she begins to ask, "What about me?” and/or, “What about what I want to be?” This conclusion suggests that women do not engage in active identity work until they reach the mid- to late career stage.

While some scholars have focused on comparing and contrasting the careers of men and women, others have set out to develop models that are specific to women’s careers. For example, O’Neil and Bilimoria (2005) proposed a three-phase, age-based model of women’s careers based on a qualitative study of 60 women aged 24 to 60 years old, including married and unmarried women, as well as those with and without children. These scholars claim that in Career Phase 1 (ages 24-35), labeled idealistic achievement, women see themselves in charge of their careers and make career choices based on a desire for achievement and success. In Career Phase 2 (ages 36-45), labeled pragmatic endurance, women are managing multiple personal and professional responsibilities, may be questioning the centrality of career in their lives, and, for those who do not have children, are contemplating parenthood. In Career Phase 3 (ages 46-60), labeled re-inventive contribution, women are focused on contributing to their organizations, families and communities. In summary, O’Neil and Bilimoria describe the three phases as moving from positive career experiences in phase 1, to more negative career experiences in phase 2, and returning to positive career experiences in phase 3. Interestingly, O’Neil and Bilimoria found that the women in Phase 2, "see their careers as extensions of themselves, and their identities are inextricably linked with what they do for a living.” The authors posit that the career centrality that surfaced in this phase is likely due to the number of childless women in their sample at the time of the study. Although this conclusion perpetuates the perception that women with children are less likely to be identified with their careers than women without 
children, it does challenges the perspective that for women, "work is something important to do rather than something to be” (Gallos,1989).

Based on a review and analysis of the adult development and women's careers literature, Pringle and McCulloch Dixon (2003) developed a life-career model that takes a holistic view of how women's lives evolve. These scholars argue that women's career theorists have placed too much emphasis on the role of relationships in women's lives and careers, while male career theorists have placed too much emphasis on the role of paid work in men's lives. As an alternative, Pringle and McCulloch Dixon propose an evolutionary process model of women's careers that includes four consecutive facets: explore, focus, rebalance, and revive. The explore facet involves testing limits and possibilities, the focus facet involves concentrating on predominantly one aspect of life (e.g., family, study, paid work, etc.), the rebalance facet comprises involvement in things that complement one's existing self. Drawing on the work of Judi Marshall (1989), they describe the final facet, revive, as a struggle to find a balance between agency, which they explain as the "doing” of things related to self-protection and self-expansion, and communion, which involves "being" open to and flexible with other entities in the environment. The authors posit that transitions between the facets may be subtle and go by almost unnoticed, or may be experienced as abrupt and chaotic. Regardless of the manner in which these transitions occur, Pringle and McCulloch Dixon contend that before a woman moves from one facet to the next, she engages in reassessment. They explain, "Reassessment may be summed up in the question, Where to from here?” and posit that this period may be an incremental process or an agentic choice (p. 295).

Based on the preceding review, it is evident that there are a variety of perspectives regarding how women's identity and careers unfold. In fact, although scholars continue to 
develop and present models of women’s adult and career development, none seems to fully capture the dynamism and diversity in how women's careers are currently unfolding. For example, adult development scholars posit that identity development may be linked to particular life stages and age-based transitions. In fact, Levinson (1996) posits that women reassess their focus on career and shift to a focus on family as they near the age of 30. Many careers scholars (e.g., Mainiero \& Sullivan, 2005; O’Neil \& Bilimoria, 2005; Powell \& Mainiero, 1992) also argue that women's identity development is linked to particular career phases/stages, and conclude that women who combine career and family generally seek "balance," rather than challenge or authenticity as soon as they become mothers (Mainiero \& Sullivan, 2005). This perspective suggests that all women who pursue careers and start families generally want the same things at particular points in their lives, and address issues of identity in essentially the same way. However, some scholars recognize that women's identities evolve and change, through re-formulation (Marcia, 2002) or reassessment (Pringle \& McCulloch Dixon, 2003) during transitional periods that are not necessarily linked to particular ages/phases. Finally, while feminists continue to suggest that women’s identity is rooted in relationship and connection, scholars have found that some women see their careers as extensions of themselves (e.g., O’Neil \& Bilimoria, 2005).

These various perspectives and insights indicate that women’s identity development and career development processes are complex and multifaceted. While scholarly advancements have been made in both of these areas of research, a clear picture of how women's identities and careers are presently unfolding has yet to emerge. In the domain of women's identity theory and research, significant advancements were made in 1970s and 1980s by feminist scholars who challenged adult development theories that were based on studies of men and extrapolated to 
women. Today, scholars generally agree that women's identity development is distinct from men's, with men's identity assumed to be rooted in independence and women's in relationship and connection (Gallos, 1989). While these assumptions continue to dominate the literature, it is worth noting that this perspective emerged at a point in time when women's career opportunities were limited, and marriage was a key factor in determining the role a woman would assume in society (Gutek \& Larwood, 1989). Given that women are now outpacing men in their pursuit of professional and graduate degrees (Davidson \& Burke, 2011), questioning these basic assumptions is warranted. That is, scholars need to consider that work/career may be playing a more central role in women's identity development than previously recognized. Accordingly, further research is needed to further our understanding of how women figure out who they are, and who/what they wish to become, in a social context in which career opportunities for women continue to advance while gendered roles persist. That is, women are still assumed to be responsible for care of the home and children (Moen \& Roehling, 2005) and doubt that they will achieve an egalitarian partnership/ marriage (Gerson, 2010). Accordingly, much remains to be learned about how women develop a sense of self as they pursue professional/managerial careers and motherhood.

In the area of women's career development, there are a multitude of perspectives, and scholars differ on the fundamental assumptions that guide the development of their theoretical models. For one, age and stage-based models are rooted in studies of men's careers. That is, male careers historically followed a relatively predictable pattern, beginning with choosing an occupation in early adulthood and following a linear progression through mid-career and into retirement (Hall, 1996; Levinson, 1978). In more recent years, scholars have converged on the perspective that both men's and women's careers have become discontinuous and non-linear 
(Hall, 2002). However, the variability in women's careers is assumed to stem from the same factor that differentiates men's and women's identity; that is, concern for relationship and connection. Specifically, these relational concerns are believed to impact women's labor force participation, as women are more likely than men to opt for part-time work or to take a career break to care for their families (Powell \& Mainiero, 1992; Powell \& Graves, 2003; Hakim, 2006). Accordingly, a pivotal assumption made in recent age/phase-based models of women’s careers is that a woman's focus on career wanes with the transition to motherhood, and waxes with the onset of mid/late career when her caregiving responsibilities lessen (Mainiero \& Sullivan, 2006). However, there is disagreement regarding the appropriateness of linking women's careers to age/life stages, and placing so much emphasis on relationships in women's choices and career patterns (O’Neil \& Bilimoria, 2005; Pringle \& McCulloch Dixon, 2003).

The result of this body of research is a mix of compelling insights that fails to provide a clear understanding of how women develop a sense of who they are as they pursue careers and raise families. While the feminist perspective aided in advancing scholarly knowledge that women's identity development is distinct from men's, the result has been an overemphasis on relationship in women's career development (Pringle \& Bilimoria, 2005). Accordingly, further research is warranted if we are to understand how women's identities are evolving over time in a way that captures the vast diversity that scholars have observed in how women's lives and careers unfold.

In the following section, I review the identity literature in order to demonstrate how the concepts of narrative identity and identity work provide a compelling theoretical framework for investigating how women develop a sense of self in the context of the significant transitions involved in pursuing a professional career and raising a family. I also examine what we have 
learned from scholars who apply an identity lens to women's choices in the work/family realm, as well as the limitations of this perspective that the present study seeks to address.

\section{Identity Theory and Narrative Identity}

"The stories we construct to make sense of our lives are fundamentally about our struggle to reconcile who we imagine we were, are and might be in our heads and bodies with who we were, are and might be in the social contexts of family, community, the workplace, ethnicity, religion, gender, social class and culture writ large."

-Dan P. McAdams, 1999

Identity is a fairly ubiquitous term that is studied from various perspectives across multiple disciplines (Stryker \& Burke, 2000). However, scholars generally agree that identity is a cognitive construct that provides answers to the question, “Who am I?” (Ashforth, Harrison, \& Corley, 2008; McAdams, 1999). While this question is so seemingly parsimonious when posed, the responses it evokes range from personality and physical characteristics to social roles to group memberships (B.E. Ashforth \& Mael, 1989; Ibarra, 1999). The multiple categories available for self-reference are captured in what scholars have termed, self-concept, "the concept the individual has of himself as a physical, social, and spiritual or moral being” (Gecas, 1982). However, different theoretical perspectives exist as to how identity and self-concept are interrelated. Gecas distinguishes between these two constructs by arguing that identities are the content of self-conception (1982: 4). In other words, individuals have multiple identities that may be labeled and characterized, such as professional identity and mother identity, and these provide input to one's core sense of self, or self-concept.

While multiple scholarly perspectives view the self-concept as a container of multiple identities, there is a lack of agreement regarding the nature of those identities and how they relate to each other. For example, identity theory (Stryker,1968) posits that the self-concept is comprised of multiple identities that exist in a hierarchy of salience (Shamir, House, \& Arthur, 
1993; Stryker, 1980). These identities are conceptualized as social roles, such that the more salient the role (e.g., mother, worker, friend), the more an individual will seek out opportunities to perform in roles which represent that identity (Callero, 1985). This perspective is somewhat limited, however, for it ignores individual characteristics not represented by social roles but nevertheless important to “a person’s unique sense of self” (Postmes \& Jetten, 2006).

Social identity theory (Tajfel \& Turner, 1985), on the other hand, posits that the selfconcept is comprised of a personal identity and a social identity (B. E. Ashforth, 2001; B.E. Ashforth \& Mael, 1989). Whereas personal identity is comprised of individual characteristics such as one’s physical attributes, abilities, interests and psychological traits (B.E. Ashforth, et al., 2008), social identity consists of salient memberships in social categories such as gender, culture and occupation (B.E. Ashforth \& Mael, 1989; Tajfel \& Turner, 1985). However, although this perspective is inclusive of personal characteristics and social roles, the notion of "self-concept" as a container of personal identity and social identity is somewhat elusive. Quoting Turner (1968), Gecas (1982) attempts to provide a more specific definition: "Typically my selfconception is a vague but vitally felt idea of what I am like in my best moments, of what I am striving toward and have some encouragement to believe I can achieve, or of what I can do when the situation supplies incentives for unqualified effort (1968:98).” This conceptualization includes both a present evaluation of one's capabilities, as well as a consideration of future possibilities and realizing one's potential. From this perspective, the self-concept is present and future-focused; continuous, yet open to the possibility of change.

An alternative approach to identity theory's focus on role-identities and social identity theory's distinction between personal and social identities, is offered by scholars who conceptualize identity as, “a life story” (McAdams, 1999). This narrative identity perspective 
moves beyond individual traits, social roles and memberships in social categories to provide a holistic understanding of identity as a person’s autobiography (Giddens, 1991). As Singer (2004) explains, narrative identity research is concerned with how individuals craft their life stories, and tell these stories to themselves and others, to form an identity that provides, "unity to their past, present, and anticipated future” (p.445), connecting disjunctive episodes into a coherent plot. Whereas identities based on social categorizations make an inappropriate presumption of stability over the life span, "the narrative identity approach embeds the actor within relationships and stories that shift over time and space” (Somers, 1994, p. 621). Thus, rather than a hierarchy of role identities, identity may be more comprehensively conceptualized as an evolving story in which particular episodes in one's past and present, as well as envisioned future episodes, are pieced together in an internalized autobiography (McAdams, 1999).

In addition to providing a more holistic view of identity, the narrative perspective recognizes the dynamic nature of identity: "self-identity formation involves the person negotiating passages through life and reflecting on her or his actions during these passages” (Cote \& Levine, 2002, p.44). In other words, individuals are continually claiming and adapting their identities in each chapter of their lives by negotiating who they are with themselves and those around them. Some scholars conceptualize this process as social interactions. For example, Ibarra explains: "people make identity claims by conveying images that signal how they view themselves or hope to be viewed by others. By observing their own behavior as well as the reactions of others, who accept, reject, or renegotiate these public images, they maintain or modify their private self-conceptions ” (1999, p.766). Others have uncovered intrapsychic processes, such as producing tentative mental images of who one hopes to be after making a role transition (Ladge, Clair \& Greenberg, 2012). 
These various perspectives demonstrate the lack of a clear scholarly perspective regarding the precise relationship between identity and self-concept. Further, while scholars generally agree that individuals have multiple identities, the existence of an immutable "self" remains open to debate (Ibarra, 1999). In this dissertation, I adopt the viewpoint that there is a distinction between identities that may be given specific labels, such as "professional identity" and "mother identity", and the holistic assessment an individual has of who she is (i.e., "selfconcept" or "sense of self”). By applying a narrative identity lens, I seek to investigate the evolution of a professional/managerial woman's sense of self. By "sense of self" and "selfconcept”, I refer to the summative assessment a woman holds of the various identities she ascribes to herself in the past, present and future, as well as the multiple roles encompassed by each of those identities (e.g., an academic’s "professional identity” comprises the roles of teacher, scholar, mentor, colleague, etc.). Through this research, I aim to increase scholarly understanding of how a woman's sense of self changes and/or persists over time as she pursues a professional identity, takes on a mother identity, and crafts a life in which she combines career and family. Accordingly, I incorporate the concept of identity work, which scholars apply to the study of the active construction, maintenance, and revision of "identity."

\section{Identity Work}

Known in the literature as identity work, the process of claiming and modifying one's identity is essential to "creating and maintaining a coherent identity narrative” (Musson \& Duberley 2007, p. 147). The concept of identity work, defined as, “forming, repairing, maintaining, strengthening or revising the constructions that are productive of a sense of coherence and distinctiveness” (Sveningsson \& Alvesson, 2003), has allowed scholars to investigate the strategies and behaviours individuals use to construct and modify their identities 
(DeRue \& Ashford, 2010; Ibarra \& Petriglieri, 2010). Over the past decade or so, scholars have studied identity work in a variety of contexts, including professionals transitioning to more senior roles (Ibarra, 1999), new and seasoned managers adapting to changing organizations (Sveningsson \& Alvesson, 2003; Watson, 2008) and medical residents completing their specialization training (Pratt, Rockman and Kaufmann, 2006). This body of literature has helped to illuminate identity construction processes as more complex than adopting a new role or category (Pratt et al., 2006). In fact, scholars contend that individuals engage in identity work throughout the life cycle, especially during times of crisis or significant transition (McAdams, 1999; Sveningsson \& Alvesson, 2003). However, the majority of studies have focused on understanding how individuals conduct identity work in the context of micro and macro sequential role transitions at work, with little attention paid to the identity work involved in making transitions in other life domains (Ladge et al., 2012).

Beyond providing a theoretical framework for conceptualizing and investigating identity construction, the identity work literature has also supplied empirical support for the concept of narrative identity. For example, Sveningsson and Alvesson's (2003) case study of a newlyminted senior manager struggling with conflicting managerial identities resulted in the identification of three narrated, divergent self-identity constructions. These scholars conclude that identity work is a key activity in the process of crafting a narrative identity, and continually modifying it over the lifespan. Providing further support for the narrative identity perspective, Pratt, Rockman and Kaufmann (2006) conclude that, “stories are important to identity construction, as they are the raw materials of a wide 'identity set' that individuals can draw upon to construct identity” (p. 255). Pratt and his colleagues explain that these raw materials refer to 
internalized beliefs and external elements from an organizational context that individuals use to customize their identities (Pratt et al., 2006, p. 246).

In a recent conceptual piece, Ibarra and Barbulescu (2010) define narrative identity work as, “social efforts to craft self-narratives that meet a person’s identity aims.” These scholars describe "self-narratives" as simply stories about the self, and posit that individuals use them to bridge gaps between old and new, or modified, identities during times of significant transition: "stories help people articulate provisional selves, link the past and the future into a harmonious, continuous sense of self” (p. 138). These scholars argue that individuals are most likely to engage in narrative identity work during macro role transitions, such as work role changes, that require changes in behaviours, attitudes and interactions with others. For example, a professor who leaves her academic position to become a money manager would engage in narrative identity work when explaining this seemingly bizarre career move to her colleagues (2010: 147). Ibarra and Barbulescu propose a dynamic model of narrative identity work that goes beyond much of the, "empirical and conceptual work on identity work (that) offers a static picture of how people respond to the identity challenges they experience at a particular point in their lives” and considers, “...the interplay between these day-to-day negotiations and the accumulated understandings of a whole life’s experiences” (Ibarra \& Barbulescu, 2010, p. 149). However, the authors do not address macro life transitions such as marriage/partnering, transitioning to motherhood or returning to a professional/managerial position after maternity leave. They also constrain their conceptualization of narrative identity work to the use of storytelling to achieve particular identity aims in a social context. Missing from this perspective is the notion that narrative identity work is also undertaken in the stories individuals tell, both to themselves and to 
others, to make sense of the changes and disjunctures in how they see themselves during times of significant transition.

As emphasized by the identity theory, narrative identity, and identity work literatures, scholars agree that identity is a life-long process, one that endures transformations over time and through important life transitions (Erikson \& Rapaport, 1959; Levinson \& Levinson, 1996; McAdams, 1999; Sveningsson \& Alvesson, 2003). Research indicates that individuals are likely to engage in active identity work during major life events, such as marriage and the birth of a first child, in order to incorporate new circumstances and a changing sense of self into their personal narratives (McAdams, 1999). Sveningsson and Alvesson posit, “...specific events, encounters, transitions and surprises, as well as more constant strains, serve to heighten awareness of the constructed quality of self-identity and compel more concentrated identity work” (2003, p. 1165). However, the identity work literature has primarily focused on macro, occupational role transitions (Ladge et al., 2012). Women who pursue professional/ managerial careers, become mothers, and combine career and family experience a complex set of life transitions and decision-points; however, how a woman understands and explains the changes and/or continuity in her sense of self through and across these transitions is far from wellunderstood. As a theoretical frame, narrative identity work is fitting for such a context; yet it has not yet been applied in an empirical study. As such, there is an opportunity to elicit "selfnarratives" of major work and family role transitions in the lives of professional and managerial women in order to increase our understanding of the evolution of a woman's sense of self as she journeys from university student to professional/manager with children. 


\section{Identity Work at Key Transitions}

As noted by Petriglieri \& Petriglieri, "identity work is an ongoing process; however, it is undertaken most intensely and consciously during specific junctures and transitions” (2010, p.45). Accordingly, we would expect women to engage in active identity work during the major transitional periods in their lives. In particular, scholars have examined the transition to motherhood as a turning point in which many women experience a change in their personal identities. Making the transition from university student to young professional has also been identified in the literature as a significant, identity-laden turning point in an individual's life (Ng \& Feldman, 2007), and one that occurs during the developmental period in which identity is a core aspect (Levinson, 1996). Less attention, however, has been paid to the transition to combining career and family. While scholars have examined the liminal period of pregnancy (e.g., Ladge et. al, 2012) and the transition from maternity leave back to workforce, combining career and family is a longer transitional period. That is, how women craft their lives to include a professional/managerial career, as well as a family, likely changes over time as they determine what works, and what doesn’t. Having additional children, changing employment status, and perhaps even changing careers are ongoing decisions that women face as they wrestle with such questions as, "Who am I?" “Who do I want to be?” and "How do I get there?” All of these transitions, from university student to young professional, from non-mother to mother, and from childless professional/ manager to facing decisions about how to combine career and family, are some of the most significant turning points that all educated, career-minded women who start families will face.

The Early Career Transition. Scholars conceptualize the time when a young adult separates from his/her family of origin and sets out to become an independent citizen in society 
as a significant life transition that involves defining one’s adult identity (Erikson, 1959;

Levinson, 1978; 1996). Levinson labeled this period the "early adult transition," and defined it terms of a precise age range (i.e., 17 to 22), while other scholars refer to it as the, "school to work transition” (Ng \& Feldman, 2007), focusing specifically on the role transition from student to employee. For the purposes of the present study, I label this transition the "early career transition,” as I focus on my informants' decisions and experiences related to choosing a path in life and embarking on a professional/ managerial career. That is, this transition represents a woman's first experience in the working world and the start of her professional career. Ng and Feldman (2007) conceptualize this period in an individual's life as a transition from the role of student to the role of worker. In other words, this period represents a macro role transition and as such, we would expect individuals to engage in active identity work at this point in their lives. In her study of women's identity development, Josselson (1996) found that her informants looked to the world of work with both hope and trepidation as they prepared to graduate from college.

Adult development and careers scholars have long recognized the phase of late adolescence to early adulthood as a significant transitional period. For one, this period includes the ending of one's student status and the beginning of one's status as worker or professional. Further, theorists contend that individuals are not prepared to tackle the question, "Who am I?" until they are about to enter the life stage of adulthood (E. Erikson, 1950; 1958). It is at this time that the individual begins to create his/her narrative identity, or "internalized story of the self" (McAdams, 1999). Levinson (1978;1996) labeled this period the early adult transition, when the era of childhood draws to a close and early adulthood begins; as such, this transition represents the starting point of adult identity formation. From this perspective, Super (1980) 
proposed a life-span, life-stage model of career development in which life/career could be divided into five stages: growth, exploration, establishment, maintenance and decline. He argues that the growth stage involves recognizing that one needs to choose a career, while the exploration phase involves gathering information about one's options, weighing the alternatives, and making a decision about which path to pursue. Super's model shows the exploration phase occurring approximately between the ages of 15 and 25 . Accordingly, this time in a woman's life may be conceptualized as an extended transitional period rather than a single role transition from student to professional. Further, in the context of professional/managerial women's careers, this period often includes a return to student status in the pursuit of graduate degrees, followed by a transition back to work.

The Transition to Motherhood. The transition to motherhood is viewed by scholars as a critical turning point in career-oriented women's lives, with some scholars conceptualizing this transition as an identity-transforming event (e.g., Lee, MacDermid, Dohring, \& Kossek, 2005). This transition includes both the experience of being pregnant, as well as the experience of living as a new mother. The majority of identity-based studies of the transition to motherhood focus on one or the other of these before/after childbirth experiences, though there are some exceptions (e.g., Millward, 2006). In a study of 30 middle-class working women in the third trimester of a first pregnancy, Bailey (1999) found that while her informants expressed a stronger sense of continued selves than of disjunctive selves, they did experience a sense of altered identity. Using discourse analysis, Bailey concludes that this sense of identity change was expressed from a place of agency, albeit limited, in which the women experienced pregnancy as an opportunity for change. However, there was variation along the change versus continuity spectrum, with some women intending to make very few changes in their lives and others anticipating significant 
change. Taking a narrative identity perspective, Bailey conceptualizes her subjects' experience of the transition to motherhood as, "a narrative pivot in the construction of a reflexive biography” (p. 351); that is, pregnancy provides an opportunity for women to change how they see themselves.

For professional and managerial women, the experience of a first pregnancy is a time when identity work is focused on adapting to the new status of mother while maintaining one's status as professional (Millward, 2006; Ladge et al., 2012). In a recent study, Ladge, Clair and Greenberg (2012) explore how women construct, and respond to, multiple intra-psychic images of themselves as professionals and mothers during a first pregnancy. Through interviews with 30 pregnant professional and managerial women who planned to return to work at the end of their maternity leaves, these scholars demonstrate how women start to build their future identities as working mothers. Ladge and her colleagues found that $17 \%$ of the women in their sample rejected any changes in their professional identities; in other words, they engaged in protecting their professional identities. In 27\% of the cases, their informants engaged in identity inaction; that is, they did not see a need to work through any identity changes prior to actually having the baby and experiencing life as a mother. In the majority of cases, however, women actualized their working mother identities by making changes to their identities. For example, some of these women began to embrace their maternal identities and relax their professional identities, while others envisioned maintaining their professional identities while simultaneously making room for their maternal identities in the hopes of finding a balance between the two. Ladge and her colleagues conclude that this latter group did not believe that their emerging maternal identities posed a threat to their identities as professionals. 
While scholars have demonstrated that many women experience identity changes during a first pregnancy, others do not experience any significant changes until after the baby is born. For professional and managerial women, the birth of a first child is often followed by a struggle to maintain a sense of self as professional while striving to be a "good mother" (P. M. Buzzanell \& Liu, 2005; Frenkel, 2008; Millward, 2006). For example, Buzzanell and Liu (2005) interviewed 15 women of varying occupational status about their experiences with workplace pregnancy and returning to work post-maternity leave. These researchers discovered a clear identity struggle in their informant's discourse regarding their attempts to construct productive identities while pregnant at work and upon return from maternity leave. Stories of coming to terms with backlash in the form of demotion or denial of promotion led Buzzanell and Liu to conclude, “the gendered social order undermines women's identity work to construct themselves as normal workers who just happen to be pregnant and, later, mothers” (2005, p.18). In an investigation of gender-identity construction in the Israeli context in which middle-class women are expected to pursue high-profile careers while simultaneously upholding traditional family values, Frenkel (2008) discovered that women professionals craft masculine, "ideal worker" preparenthood identities that are defied by the birth of a child: “these ‘surrogate men’ start categorizing themselves as 'feminine' and reconstruct normative femininity in a new way” (2008, p. 359). While this context is perhaps extreme, the notion of the "ideal worker" in the developed world continues to be imbued with masculine traits (Bailyn, 2006; Rappoport et al., 2002), leaving professional and managerial women to make sense of who they have become as workers and mothers.

In a study that provides key insights into the before and after childbirth aspects of the transition to motherhood, Millward (2006) followed 8 professional/managerial women from their 
pregnancy through their return to work. Using interviews rather than surveys, she gleaned detailed information about the transition to motherhood experience in an organizational context, concluding that the challenges faced by these women are, "primarily identity-driven" (2006, p.317). Throughout the course of this study, Millward noted significant identity changes in the women stemming from internal sense-making about self-identity and self-worth. She describes the identity-driven transition process as, “...feelings of gradual invisibility as a valued employee during preparation for leave, acquisition of a mother identity (upon childbirth) creating return dilemmas, and efforts (on return to work) to revalidate oneself upon re-entry as both a valued employee and a mother” (2006, p. 322).

Providing further insight into how becoming a parent impacts the identities of professional and managerial women, Lee, MacDermid, Dohring and Kossek (2005) conducted a qualitative study of 78 professionals and managers, 74 of whom were women, who were taking advantage of a flexibility benefit known as "reduced load.” These scholars build on sociology's processual interactionist approach, which emphasizes the ongoing process of negotiation of identity in a social context, to explain the identity transformations experienced by their informants: "These new selves represent more than just adding an additional role, because the overall essence of the individual is fundamentally altered as he or she continues to negotiate identity but in a new context and social structure that includes the workplace, family and community” (p.297). By comparing how these individuals retrospectively described their preparenthood selves, including their career and family aspirations, to how they described their present selves, Lee and her colleagues uncovered distinct pre- and post-parenthood identities. Pre-parenthood identities range from "career defined," those women who were very ambitious and career-oriented, to "career pursued in context," reflecting a malleable professional identity 
grounded in a life-centered context. The post-parenthood identities reflected a range of identity transformations, from the "career figure/family ground” identity in which professional identity was preserved as primary, to the "trapeze artist” identity in which the new parent identity joined the professional identity on center stage, requiring a "new highly orchestrated performance" (p. 311). While these findings provide important insights into the identity-laden issues of the transition to motherhood, all of the women in this study had chosen to work reduced load. Thus, this study cannot speak to the identity work of professional/managerial women who choose to continue working full-time after the birth of a child, nor that of those who take a break from their careers to become full-time mothers.

Although scholars have identified the transition to motherhood as a critical, identityaltering transition point for professional/managerial women, the research in this area falls short of explaining how women conduct identity work after the birth of a first child as they make decisions about whether to return to work full or part-time or to take a break from career to become stay-at-home mothers. Further, this body of literature examines only one, albeit it highly significant, transition point in a woman's experience of combining career and family. Surely, the birth of a second or third child, as well as major career transitions such as switching from fulltime to part-time/reduced load status and/or taking a career break, present circumstances that have implications for women's ongoing identity work. Therefore, in order to paint a more complete picture of how a woman's sense of self evolves over time, research that examines identity work through multiple career and family transition points is warranted. While there is much progress to be made in this arena, past research and scholarly theorizing on the topic has laid an important foundation on which the present study builds. In the following section, I 
consider the literature that provides some clues about the relationship between identity and how women navigate the complexities of combining career and family.

The Transition to Combining Career and Family. While pregnancy and childbirth are recognized as a significant, identity-altering transition in women's lives and have received substantial scholarly attention, combining career and family has not been conceptualized in this way. Identity-based investigations of combining career and family have been grounded in the assumption that, for women, work and family represent separate, competing identities (Bielby \& Bielby, 1989), assuming that women are oriented toward one identity domain over the other, rather than conceptualizing the crafting of a combined career and family life as identity work. The dominant competing identities perspective is supported by studies that indicate women are much more likely to make work-family identity trade-offs than men (Aryee \& Luk, 1996; Bielby \& Bielby, 1989; Rothbard \& Edwards, 2003). For example, Lobel and St-Clair (1992) conceptualize and measure career identity salience and family identity salience as occupying opposite ends of a single spectrum. Honeycutt and Rosen (1997) argue that "social identity theory helps explain the relative importance an individual places on career versus family” and aids our understanding of why "career identity is most salient for one individual while family identity is most salient for another” (p.273). The segmentation-integration perspective (NippertEng, 1995) also conceptualizes work and home as distinct role identities that individuals transition between on a daily basis (Ashforth et al. 2000; Cohen et al., 2009). In sum, incorporating an identity lens in work-family research has led to a perpetuation of the workfamily conflict perspective, as well as the belief that women are inherently drawn to one sphere or the other. In the following sections, I discuss the literature that supports this orientation perspective, argue that this outlook has constrained our understanding of women's ongoing 
identity development, and provide some examples of studies that highlight the need to further investigate women’s identity work in the context of combining career and family.

The Competing Identities Perspective. To make sense of women's choices regarding their engagement in work and family, some scholars have attempted to chart and categorize women's orientation toward each domain. For example, building on Lobel and St. Clair's (1992) concept of “career identity salience,” Rothbard and Edwards (2003) examine the psychological motivation for investment in work and family roles. By operationalizing role identity as the psychological importance of a role, they found evidence to support both utilitarian and identitybased motives for role investment. They conclude that: a) people invest in roles that they find pleasurable; and b) investing time in work and family roles increases identification with those roles. While these scholars are clearly interested in the antecedents of work and family role identification, others are more intrigued by its consequences. In another study, Hecht and Allen (2009) hypothesize that role identification is an antecedent to boundary strength. They posit that strong identification with a work or family role increases boundary strength in that role's domain, and decreases boundary strength in domains unrelated to the role. For example, strong family identification should predict stronger boundaries at home: "an individual who is strongly connected to his/her family might try to avoid thinking about, or doing, work at home” (p. 842). The results of their empirical study indicate that strong personal life identification predicts stronger boundaries at home while strong work role identification predicts weaker boundaries at home. However, there was no support for role identification as a predictor of boundary strength at work, a finding that Hecht and Allen argue may indicate that individuals have more control over setting boundaries at home than they do at work. 
Researchers who have explored how women shape their lives to include career and family often categorize women by orientation toward one domain or the other. For example, Gerson (1985) sought to understand how women choose between work and family commitments and categorized the women she interviewed on the basis of "work-committed," "domestically oriented" or "reluctant mother" orientation. Hochschild (1989) argued that dual-earner couples enact three types of marital ideology that reflect a woman's identification with either work or home; in the "traditional" ideology, the woman is primarily identified with home activities, in the "transitional” ideology the woman wants to identify with her role at work and her role at home, and in "egalitarian" ideology Hochschild found men and women who jointly prioritized either their careers or the home, or some balance between work and family. Finally, building on Lee (1993), Burke and McKeen (1993) conducted a quantitative study of 792 female graduates of a Canadian university, classifying them as, “career-primary,” "modified career-family,” and "career-family.” These scholars argue that, "at the present time companies seem to prefer that all managerial and professional women be career-primary, thus giving the implicit message that to make it to senior management a woman must give up partner and family” (p. 342).

In a more recent qualitative study of women who started out as highly successful, careeroriented professionals, Blair-Loy (2003) also uncovered distinct patterns that she used to classify women into one of two groups. The first group of women had never taken a step back from their careers even after the birth of a child whereas the second group of women left their demanding careers after transitioning to motherhood. Blair-Loy captures this phenomenon in what she calls "schemas ${ }^{1}$ of devotion." The family devotion schema "assigns primary responsibility for home and family to women... a model of motherhood that is intensive, emotionally absorbing, childcentered"; the work devotion schema is "traditionally masculine, demands that one give an

\footnotetext{
${ }^{1}$ Blair-Loy defines schemas as, "shared cultural models we employ to make sense of the world" (2003, p.5)
} 
immense time commitment and strong emotional allegiance to one’s firm or career” (pp. 6-7). In a quantitative study based on a 1999 national British survey, Hakim (2006) also categorized women based on their commitments to the two domains of work and family. Examining women's combinations of work and family, Hakim classified them as, “work-centered," "homecentered” and “adaptive lifestyle preferences.” The "work-centered” women were more likely to return to work after the birth of a child whereas the "home-centered" women were less likely to return to work after the birth of a child. However, Hakim classified the majority of the women in her study as “adaptive,” or committed to both work and family, who were more likely to work part-time to "balance" their work and family roles.

While all of these studies have contributed to our recognition of identity as an important lens through which to study how women combine career and family, this body of research perpetuates the perspective that career and family represent competing identities for women. These studies also leave one wondering how women develop one pattern, schema or ideology over another. Further, Garey (1999) warns that applying an "orientation model of work and family” to the study of women’s pursuit of work and motherhood perpetuates a gendered ideology that economic life and domestic life are separate, mutually exclusive spheres (p. 7). The competing identities and orientation approaches perpetuate the assumption that women who have both a career and a family experience their lives as a "teeter-totter” or "zero-sum game.” What is needed is research that conceptualizes combining career and family as an opportunity for women to engage in identity work as they confront the questions, "Who am I?” and, "What do I really want?”

Combining Career and Family as Identity Work. Based on a qualitative study of working mothers employed in various jobs in a hospital, Anita Garey offers an alternative 
conceptualization of combining career and family as "weaving” (1999). She claims that, "weaving...illuminates the meaning that the women I interviewed gave to their life stories by capturing the interconnectedness of work and family within women's lives” (1999, p.14). In this study of 37 women, Garey sought to understand, "What kinds of strategies do employed women with children use to indicate themselves?” (Garey, 1999); that is, "to be taken seriously as workers and to 'be there' as mothers” (Dellinger, 2000, p. 1166). She uncovered four employment strategies for combining work and motherhood: part-time work; full-time, nightshift work; full-time, day-shift work; and sequencing. Within each of these employment strategies, she discovered "strategies of being" which she explains as any strategy that has the goal of identity construction (1999, p. 23). For example, Garey’s study uncovered women engaging in identity work to form and maintain the part of their identities that corresponds with "being a mother" by engaging in visible motherhood activities, such as helping with homework, volunteering at their children's schools and getting involved in their extra-curricular activities (1999, pp. 39-40). However, Garey focuses on the construction of a single identity, that of "working mother" and the strategies and behaviours she uncovered are all related to "being a mother" and "being a worker." Further, she argues that the women in her study rejected the identity of "career woman" due to its overemphasis on the importance of work over family. Once again, we find a framing of two separate, competing identities rather than a consideration of the continued evolution of a woman's sense of self as she figures out what she wants and who she wishes to be. It is also worth noting that Garey's subjects were not pursuing high-powered, professional/ managerial careers and as a result may have been less inclined to view their work as a central element of their sense of self. 
In addition to Garey's work, past research has served as a precursor to the notion that women's identity work is an important aspect of combining career and family, even though these studies do not make direct references to issues of identity. That is, scholars who laid the foundation for investigating the benefits of engaging in multiple work and family roles to women’s well-being (e.g., Barnett \& Baruch, 1985; Baruch \& Barnett, 1986, 1987) also provided important recognition that combining career and family is linked to issues of the self. For example, Barnett (1998) conceptualized the act of balancing work and family as fit, which she sees as, "a dynamic process of adjustment between work conditions and the characteristics of workers and their strategies to meet their own needs, as well as the needs of the other people or entities in their social system, and their interconnections” (p. 143). In other words, engaging in both work and family in a way that supports well-being (and by extension, "sense of self") requires finding the right "fit" between individual, family, and work demands and resources. Several studies now support this perspective; for example, Gareis and Barnett’s (2002) research on female physicians working full-time and reduced-hours work schedules demonstrated that marital role quality was dependent upon the fit between work schedule and family demands, not the number of hours worked.

Another stream of research addresses the overemphasis on the distinction between work identity and family identity by exploring how professionals see themselves in the context of their lives, and how they conduct identity work as they navigate the complexities of combining career and family. For example, Meiksins and Whalley (2002) conducted a qualitative study of 127 engineers and technical professionals who had chosen to work part-time. Not surprisingly, this sample was mainly comprised of women, 99 in total, of which 58 had children under the age of 5 and another 18 had school-aged children. Using an unstructured interview format, these scholars 
made some important discoveries. Work emerged as an important element of each informant's identity, though each professional's self-understanding included aspects of their work and nonwork lives (Caron, 2002). While the largest segment of the sample of part-time professionals was made up of young women with caring responsibilities for children or an elderly parent, the authors discovered that many of the individuals, both women and men, had chosen to work parttime in order to engage more fully in the non-work aspects of their lives. Of particular interest is the finding that women with children indicated a desire to be "moms" and not "housewives," a distinction that reflects a rejection of the traditional female role and the construction of what the authors refer to as a customized identity. In fact, Meiksins and Whalley (2002) conclude that the mothers in their study were, "creating themselves in a lifelong process of reflection on all the various aspects of social life that they no longer take for granted. They are living out what might be called a new narrative identity” (p.169). This study supports the idea that women engage in identity work as they craft their lives to include career and family.

Another example of research supporting the notion that identity work is a key aspect of combining career and family is found in an autoethnographic study by three women academics, Cohen, Duberley and Musson (2009). In the study, these scholars reflect upon their own experiences of the home and work aspects of their lives in order to, "know more about what the relationship feels like, how it ebbs and flows, what people do to negotiate and manage it, how it is performed and made sense of more reflexively.” Through an analysis of their emails and conversations with each other, they uncover their own strategies for creating and managing boundaries between work and home. In other words, these scholars examined their own identity work in the context of combining career and family. Drawing upon boundary theory (Ashforth, Kreiner, \& Fugate, 2000) and Nippert-Eng’s (1996) “integration-segmentation continuum,” 
Cohen and her colleagues sought to understand how their "mum” and "professional” identities interact and how they manage the boundaries between them. While this theoretical framing perpetuates the distinction between work and home as separate spheres, these scholars do conceptualize identity work in relatively holistic terms. Drawing on Gergen (2000), they describe identity as a "project of the self," and identity work as an "ongoing cycle... an active and critical process of making sense of and for our 'selves'” (2009, p. 232). Through this study, Cohen and her colleagues conclude that identity plays an integral role in how they combine career and family. They provide several examples of active identity work, such as bringing personal and family photos into their academic offices, telling their students stories about their children, and intentionally leaving a work signature on a personal email.

Although Cohen et al. (2009) focus on the boundaries they create and cross between their work and home lives, once again perpetuating the separate, competing domains perspective, they do shed light on the need to move beyond measuring a woman's family identity and work identity at a single point in time. Accordingly, their research provides support for conceptualizing combining career and family as an ongoing period of transitions and decisionmaking in which women engage in active, ongoing identity work. In fact, scholars must move beyond attempts at categorizing professional and managerial women along a career identityfamily identity salience spectrum if we are to increase our understanding of women's choices in the work/family realm.

\section{GAPS IN THE LITERATURE AND RESEARCH QUESTIONS}

Although identity has become an increasingly prevalent theme in work-family research, the extant literature fails to explain how women make sense of who they are and what they hope to become during significant turning points in their lives, or how their sense of self evolves over 
time through and across these transitions. For one, the majority of identity-based studies of work and family are quantitative and cross-sectional. As a result, we lack knowledge about how women conduct identity work at different points in their lives and how their identities evolve as they journey from university students to professionals/managers with children. As demonstrated by the preceding literature review, identity-based investigations of engagement in work and family are generally grounded in the assumption that work and family represent competing identities, especially for women. What is missing from this body of literature is a conceptualization of combining work and family as a complex set of life transitions and ongoing identity work.

The contributions that have been made thus far to the extant literature reveal several gaps in scholarly knowledge that the present study seeks to fill. First, while identity theorists have demonstrated that individuals are most likely to engage in identity work during times of significant change or transition, the primary focus of this research has been sequential occupational role transitions (Ladge et al., 2012), termed “macro role transitions” (Ashforth , 2001). We know little about the identity work that women engage in during the significant transitions that are involved in crafting a life that includes career and family. The one exception is the transition to motherhood, which scholars have shown to be a potentially identity-altering event for women. However, this is only one of many significant transitions women experience as they pursue careers and raise families. The early career transition and the transition to combining career and family are also significant turning points that are common to all professional and managerial women who combine career and family; however, we know little about how these specific transitions, and the identity work used to navigate them, impact the evolution of a woman's sense of self. 
Second, women's identity and career development scholars have demonstrated the temporal shifting of focus on career/challenge, family/relationships, and balance over time; however age/career stage models suggest that women generally experience the same issues at a particular point in their lives, and address them in the same way. In addition, researchers continue to assess women's identity or career/family salience at a single point in time. This has led to the perpetuation of conceptualizing career and family as competing identities for women, and the categorization of women according to an orientation toward one domain or the other. What is lacking is research that examines how a woman's holistic sense of self evolves through the transitions involved in crafting a life that includes a professional/managerial career and family. Given that identity drives behavior, this gap in the literature reveals an opportunity to increase scholarly understanding into why professional/managerial women combine career and family in the variety of ways in which they do by investigating identity shifts over time.

Third, although narrative identity work provides a theoretical framework that allows for the conceptualization of identity as an unfolding life story, this approach has not been applied to researching the link between identity work at specific transitions and the evolution of identity over time. Ibarra and Barbulescu (2010) bridge this issue conceptually in their model of narrative identity work, and call for scholars to paint a more dynamic picture of identity work that reflects, "the accumulated understandings of a whole life's experiences" (p. 149). However, this approach has not been applied to researching how women see themselves in the past and in the present, and how they envision themselves in the future. While the transition to motherhood studies have contributed to our understanding of how women experience identity shifts as they add "mother" to the list of roles in their identity repertoires, there is much more to be learned about how professional/managerial women's sense of self evolves over time. In particular, we 
lack insight into other major transitions, such as the move from university student to young professional, and from childless professional/manager to combining career and family, and how they collectively impact women's identity.

Given these gaps in the literature, the aim of this dissertation is to increase scholarly understanding of how a professional/managerial woman's sense of self evolves over time by examining links between identity work at three specific transitions related to combining career and family, and the arc of identity from early to mid-career. Accordingly, in this dissertation I address the following research questions:

1. What is the variation in the narrative identity work professional/managerial women engage in as they construct stories about three significant life transitions: the early career transition, the transition to motherhood, and the transition to combining career and family?

2. What recurring themes, if any, can be identified in the kinds of identity work women engage in within and across significant transitions?

3. How does a narrative identity work lens help us to better understand the evolution of women's identity over time, and through the significant transitions involved in pursuing a professional/managerial career and raising a family? 


\section{CHAPTER 3: METHODOLOGY}

In this dissertation, I set out to increase scholarly understanding of the evolution of women's identity, from university student to professional/manager, to mother, to combining

career and family, in the current context in which women are becoming more highly educated than their male counterparts and are beginning to comprise the majority in previously maledominated professions. To that end, I examined the stories women tell about significant life transitions, and the patterns that link their narrative identity work over time. In order to address the three research questions posed at the end of Chapter 2, I designed my research to elicit explicit tellings of narratives (Boje, 1991; Pentland, 1999) that could be analyzed for evidence of identity work. Specifically, I was interested in understanding the identity journeys of women who are heavily invested in their education and professional/managerial careers and who are currently raising young children. Through interviews and written reflections, I invited my study participants to tell me their stories about being a university student, starting a professional/managerial career, becoming a mother and combining career and family. As noted by Petriglieri \& Petriglieri, "identity work is an ongoing process; however, it is undertaken most intensely and consciously during specific junctures and transitions” (2010, p.45). Accordingly, the present study was designed to capture narrative identity work (Ibarra \& Barbulescu, 2010) by eliciting stories about three significant life transitions: the early career transition, the transition to motherhood, and the transition to combining career and family. By probing deeply into each woman's narration of, as well as her written reflections upon, her sense of self prior to, during, and following these significant life transitions, I endeavored to uncover different kinds of identity journeys and variations in narrative identity work. Accordingly, the research design 
described herein allowed me to investigate how women's retrospective identity work in early and mid-adulthood relates to present identity work.

Initially, I identified four significant life transitions that I believed would reveal richness and variation in narrative identity work, based on a review of the literature. One of the four transition points that I identified was marriage/partnering, based on McAdams' (1993) claim that marriage is a major life event in which individuals engage in identity work. This viewpoint is supported by careers scholars who claim that marriage is damaging to women's careers, but not to men's, as pregnancy and raising children tend to interrupt, and may even terminate, women's career trajectories (Gutek \& Larwood, 1989). This transition to becoming someone’s wife, destined for childbearing and career interruptions, seemed to be a potential catalyst for engaging in active identity work. However, when I asked my informants about getting married/cohabiting with a chosen life partner, the majority explained that they did not experience this event as having an impact on their sense of self. Further, as this is an exploratory study, I chose to be open to other transitions that might emerge as particularly important for this group of women. Accordingly, I allowed each informant to choose the transitions that stood out to her as most significant/self-defining when writing her written reflection. Very few of my informants included getting engaged, moving in together, and/or getting married as a self-defining experience. Therefore, I chose to focus on the three transition points that were both clearly identified in the literature, and expressed by the majority of my informants, as particularly identity-laden.

Narrative identity theory provides an appropriate theoretical lens for the study of present and retrospective identity work because it conceptualizes identity as a "life story" that constantly evolves as we change how we perceive ourselves in the past, how we shape who we are in the 
present and how we envision ourselves in the future. Accordingly, the present research is a qualitative study that employs a modified grounded theory approach and is rooted in the principles of narrative analysis. Pure grounded theory techniques, as first developed by Glaser and Strauss (1967), call for the researcher to enter the field prior to conducting a literature review and developing a theoretical framework (Charmaz, 2006). In the present study, I allowed for themes and patterns to emerge from the data, as in grounded theory; however, I combined the data with an a priori understanding of identity work and narrative identity based on an extensive review of the literature. To that end, my research design is exploratory yet guided by previous research that has uncovered identity work using qualitative methods in various contexts.

The research design described herein is appropriate to the aims of this study as qualitative methodologies have been demonstrated to be well-suited to uncovering identity work through stories, reflections, and discourse (Ibarra, 1999; Pratt, et al., 2006). Extant investigations of identity work utilize various qualitative methods, from ethnographies to interviews to analysis of written self-reflections and autobiographies (see Down \& Reveley, 2009; Sveningsson \& Alvesson, 2003; Snow \& Anderson, 1987). For example, Snow and Anderson (1987) spent time on the streets with homeless people, listening to what they told the researchers as well as what they told each other. This ethnographic work was supplemented with in-depth, life history interviews that reveal how homeless people conduct identity work to construct identities that provide some sense self-worth and dignity. In their research on managerial identity work, Sveningsson and Alvesson (2003) used both interviewing and on-site observation to uncover the focal manager's narrated self-identity constructions. Kreiner, Hollensbe, and Sheep (2006) conducted two qualitative studies, one using an open-ended survey and the other semi-structured 
interviews, to investigate how identity work is used to "balance" personal and social identities in a sample of male and female Episcopal priests.

In addition to interviews and/or observations, narrative methodologies often elicit written, self-reflective material. For example, in a study of managers’ identity work, Watson (2008) collected and analyzed ethnographic and interview material, as well as an extensive autobiography, written by one of the two focal managers in his study. King \& Raspin (2004) asked divorced women to write narrative descriptions of their best possible future selves before (retrospectively) and then after their divorce. Down \& Reveley (2009) conducted a year-long case study of one first-line supervisor's identity work that included participant observation and interviews as well as a self-reflective essay written by the single research subject.

In the following sections, I provide a detailed explanation of my sample criteria, sample recruitment and selection, data collection, and data analysis.

\section{Sample}

In order to increase our understanding of the evolution of professional/managerial women's identity as they enter demanding professions/managerial positions once dominated by men, become mothers, and combine career and family, I sought to include a sample of women with professional or managerial work experience who have at least one child under the age of 6. In specifying these criteria, I sought to include women who are heavily invested in their education and careers and who are also raising young children. Accordingly, I only included women who met the following criteria:

- University degree or higher

- Minimum 3-5 years full-time (or equivalent) experience employed in a demanding professional context (e.g., accounting, academia (tenure-track only), corporate law, engineering or management consulting) OR 3-5 years as managers responsible for 
subordinates

- At least one child age 6 or under living in the home

I also sought variation in occupation and number of children to increase my exposure to a variety of narratives and narrative identity work. In addition, I wanted to include fairly equal numbers of women in the following employment situations:

a) Working full-time

b) Working voluntarily on a part-time or reduced-load basis

c) On parental leave or taking a temporary break from career to be a stay-at-home mother

By including women in each of these three statuses, my sample is reflective of the reality of women's careers and includes accounts of what the informants are doing at present and why they made these different choices: continuing to pursue their careers full-time, choosing to reduce their work hours, or taking a temporary career break. I set out to interview approximately 8 to 12 women per group in order to compare how identity work maps to each of these distinct approaches to combining career and family at a given point in time. However, I did not terminate data collection in any of the three categories until I began to see that adding additional cases seemed to add little new information. This approach allowed me to achieve theoretical saturation (Strauss \& Corbin, 1998).

I limited my selection criteria to college-educated women with work experience in a professional or managerial role and at least one young child at home for several reasons. First, I am interested in how women who are heavily invested in their education and careers, and who also choose to become spouses/partners and mothers, articulate their retrospective identity work, as well as their present identities in the context of combining career and family, and their visions of themselves in the future. Second, work-family researchers contend that parenting demands are greatest when there is a child at home who has not reached school age (Hayghe \& Bianchi, 
1994; Wharton \& Blair-Loy, 2006; Greenhaus, Peng \& Allen, 2012). Third, I sought to include women in three employment statuses in order to accurately reflect women's careers, which we know do not follow the traditional, masculine path of continuous full-time employment. Rather, women’s careers are likely to include periods of part-time work and/or unemployment (Powell \& Graves, 2003). Accordingly, I sought to ensure that my sample accurately represents the various ways in which women combine career and family, whether through continuing with full-time employment, moving to reduced load/part-time employment, taking a career break, or changing jobs/industries. Fourth, I chose married/partnered women because they are more likely to have options in terms of how they combine career and family due to the presence of another potential earner in the household. Having more freedom to choose how one combines career and family is important, as it eliminates constraints on the identity work women conduct through this transition.

Recruitment. To gain access to my target sample, I relied on multiple sources in order to help reduce selection bias (Patton, 2002). To identify potential informants, I began by contacting my personal and professional contacts in Montreal and Boston, emailing them a brief description of my study (see Appendix A). Those who were interested in participating, and fit the study criteria, contacted me directly to set up an interview. Others forwarded my recruitment materials on to their own contacts, several of whom contacted me to participate. Once my interviewing was underway, I used snowball sampling to increase the size of my sample. This technique involves asking study participants to refer their own contacts in order to increase the number of potential informants who fit the sample criteria (Charmaz, 2006; Patton, 2002). I asked all interviewees to forward my recruitment email to anyone who fit the sample criteria. One of my informants posted a brief description of my study on a Boston website targeted at working mothers. This resulted in thirteen contacts, five of whom 
fit the sample criteria and elected to participate after I explained the process and requirements for inclusion. Additional informants were recruited at a McGill women's alumni brunch, and through the personal and professional contacts of two McGill professors. Of all of the women who contacted me about participating in the study, five chose not to participate even though we determined that they fit the sample criteria. The main concern these women expressed was the time commitment required due to the need for two separate interviews as well as the written reflection.

While I include 35 informants in my final sample, I interviewed a total of 37 women. I rejected one participant because, although my recruitment flyer indicated the requirement to be married or partnered, she had been recently divorced and this traumatic experience dominated our discussion. This informant had become a single mother, making her experience and day-today life quite different from that of the other informants. In an attempt to ensure comparable data across cases, I only included women who were married/partnered at the time of both interviews. A second case was excluded because, although she participated in the first interview and completed the reflection assignment, she continually made excuses for why she could not schedule the second interview. After repeated attempts to induce her to commit to a date/time for Interview II, she sent an email clearly stating that she was unable to dedicate any more time to my research project.

Participants. My sample includes 35 women who hold a minimum of a Bachelor's degree and three to five years of full-time work experience in a professional/managerial position. These women are also married or partnered, and have at least one child six years of age or under. As shown in Table 1, my participants range in age from 31 to 45 with an average age of 37.5. They have between 1 and 4 children, with an average number of 2.1 children. This sample is highly educated, with 30 out of 35 women (85\%) holding a graduate degree, including MBA, 
MPA, M. Eng., MD and PhD. These women are all living in either the Montreal or Boston areas, and have work experience in a wide range of industry sectors including, but not limited to, financial services, high tech, pharmaceuticals, consulting and education. At the time of the first interview, 15 were working full-time, 11 were working part-time, and 9 were taking a career break. By the time of the second interview, one of the women who had been taking a career break had returned to full-time work. Total household income ranged from $\$ 50 \mathrm{~K}$ to $\$ 500 \mathrm{~K}$, with an average of just over $\$ 200 \mathrm{~K}$. The women’s husbands/partners held various professional positions, including teacher, dentist, engineer, attorney, professor, architect, partner, vice president and COO.

\section{INSERT TABLE 1 ABOUT HERE}

\section{Data Collection}

In the present study, I take a narrative approach to data collection, using interviews to capture oral stories, and written reflections to capture autobiographic accounts. I interviewed all of my informants on two separate occasions, leaving approximately two to four months between interviews. Each interview lasted between 60 and 120 minutes, for an average of 3 hours of total interview time per participant. Whenever possible, I conducted the interviews in person. In cases in which it was not feasible to schedule the second interview in person, I conducted the interview via Skype. All of my informants agreed to have both interviews recorded, and the recordings were transcribed verbatim by a third party transcription service in India. In order to ensure the accuracy of these transcriptions, as well as to increase my own familiarity with the data, I reviewed all 70 transcripts by simultaneously reading the transcript and listening to the original recording from start to finish. Through this process, I identified all of the mistakes in the transcriptions and made the necessary corrections. 
For both Interview 1 and Interview 2, I used a semi-structured interview protocol in order to elicit similar information from all interviewees regarding career history, the early career transition, getting married/partnering, the transition to motherhood, making decisions about maternity leave and returning to work/taking a career break, and current approaches to combining career and family (see Appendix B). Before posing more specific questions, I asked open-ended questions to allow each informant to freely tell her story by selecting the events and turning points that were most meaningful/significant to her. For example, the first interview began with, "Tell me about your career history, beginning with when you graduated from university all the way through to where you are today. Please include any major life events, such as getting married or partnering, and the birth of each child.” Asking informants about their career histories is acknowledged as an effective method for eliciting career narratives (Chase, 2005) and allowed each of my informants to craft her own self-narrative about starting her career, becoming a mother and making decisions that led to her present situation. In the second part of the first interview, I asked about the informant's current day-to-day life, her present sense of self, and her vision of where she sees herself in five to ten years.

At the end of the first interview, I asked the informant to complete a one-page demographic survey in which I collected data on her age, work hours, education, number and ages of children, spouses' age and occupation, and household income (see Appendix C). I then scheduled a follow-up interview to take place between two and four months later. Shortly after each interview, I wrote down notes pertaining to the setting as well as my own observations of the interview to "establish a context for interpreting and making sense of the interview later" (Patton, 2002, p.384). In preparation for the second interview, I asked each informant to complete a reflection assignment; that is, to think and write about three to four major transitions 
turning points in her past. I provided written instructions regarding how to complete the assignment, including some example events (e.g., starting a first career job, getting married, having a child, losing a job, the death of a loved one, etc.). However, I encouraged the participant to write about events and turning points that stood out to her as particularly meaningful or self-defining. For each turning point, the participant was asked to respond to two questions: 1) What is it about this event/turning point that makes it stand out to you? and 2) How did this event/turning point affect you/how you see yourself? A copy of the reflection assignment document may be found in Appendix D.

Prior to the second interview, many women emailed their reflection assignments to me which gave me time to read what they had written before our second meeting. Others handed their assignments to me when I arrived to conduct the interview. The majority of the women in this study spent a fair amount of time reflecting upon and writing about their turning points, as the reflections ranged in length from one to four pages of single-spaced typed text. At the beginning of the second interview, I explained to the informant that I would be asking about the events/turning points that she had written about, as well as particular transitions that had been identified in the literature as particularly significant and self-defining for women: 1) leaving university and starting a first career job (i.e., the early career transition), 2) getting married/moving in with a partner, 3) having a first child (i.e., the transition to motherhood), and 4) transitioning to combining career and family. In most cases, one or more of my pre-selected transitions overlapped with the transitions that the informant had described in her written reflection. Table 2 provides a summary of the types of events/turning points my informants wrote about in their reflection assignments. 
Before starting the second interview, the participant and I put the combined list of transitions into chronological order. In general, the end result was a list of 6-7 events/turning points. I began the interview by asking the informant to tell me about the earliest event. I had prepared a set of semi-structured questions for each of the transition points that I had preselected based on the extent literature; however, for the non-overlapping events my first question was, "Tell me about what happened and why this this event stands out to you.” I intentionally kept this open-ended to allow my informant to tell her story in her own words. I then posed my questions, making a concerted effort not to ask questions that had already been answered by the written reflection. We continued in this fashion through all of the turning points. When I had finished collecting stories about the turning points/transitions, I posed several reflection questions. These included questions about gains and losses from pursuing a career and raising a family, maintaining a sense of self in her present day-to-day life, and how she may have been impacted by participating in my study.

INSERT TABLE 2 ABOUT HERE

The approach to data collection described herein has several benefits. First, by conducting two interviews per participant, neither interview became too long or overwhelming for either the informant or the researcher. Second, I had the opportunity to build a positive rapport with each of my informants in the first interview through a discussion of relatively “safe” topics, such as her career history and present day-to-day life. This foundation proved important during the second interview, as many of my informants opened up to me, sharing stories about self-defining events and significant turning points that in many cases were quite personal, and even traumatic. In fact, several of my informants shed tears as they recounted their experiences of becoming a new mother, suffering the loss of a parent, facing a life- 
threatening illness, etc. Third, by scheduling Interview II to take place two to four months after Interview I, each informant had the opportunity to reflect upon and write about the events/ turning points in her life that stood out as particularly significant and self-defining. This time lapse also allowed me to have Interview I transcribed and to begin creating the summary and analytic memo. In addition, through the process of reading the transcript and listening to the audio recording of the first interview, I made note of any follow-up, clarifying questions for the second interview.

\section{Data Analysis}

Once the data collection was underway, I began the preliminary steps of data analysis using a systematic procedure. That is, each time I had completed 5 or 6 interviews, I sent a batch of audio files to a transcription service company in India. This company's turnaround time was approximately 7 to 10 days. As soon as I received the completed transcripts, I spot-checked them for quality. On a few occasions, I rejected the transcripts due to an unacceptable level of inaccuracy. In these instances, the transcription service sent new transcripts. In general, however, I accepted the transcripts after the first pass made by the transcription company and made minor corrections on my own by listening to the audio recording of the interview and editing the text.

Once I had assured that the transcripts accurately represented the recorded interviews, I listened to the audio-recording for a second time, and in some cases up to three times, in order to create a summary of each interview. That is, at each natural stopping point, I paused the recording and wrote about what was going on (Chase, 2003). This process resulted in reducing each 40-50 page transcript to 4 or 5 pages of 1.15-spaced text. In parallel, I began creating an analytic memo for each informant that included demographic information, a detailed career 
history timeline and details regarding her present day-to-day life (e.g., working hours, spouses' working hours, childcare and household responsibilities, etc.). Several sections of the memo, including the results of the written reflection assignment, could only be filled in after Interview II had been transcribed. Once I had received and edited the transcript for the second interview, I listened to each recording for a second or third time in order to summarize the second interview and add it to the summary of the first interview. At the same time, I filled in the blank sections of the analytic memo. Through this process, I identified topics and themes that emerged as potentially important (e.g., career sacrifices, career goals, alone time, best/worst part of the current situation, etc.) and added these to the analytic memo template (see Appendix F). Each time I added a new theme, I returned to the completed memos and updated them. At the end of this process, I had created 35 8-10 page transcript summaries, and 35 analytic memos, one for each informant. Both the summaries and the memos include some key quotes that stood out to me as particularly identity-laden.

Once I had completed this data analysis preparation phase, I investigated published approaches to narrative analysis and discovered a book by Catherine Kohler Reissman entitled Narrative Methods for the Human Sciences, which proved to be quite helpful. In this manual, Reissman reviews and explains four distinct approaches to narrative analysis: thematic analysis, structural analysis, dialogic/performance analysis, and visual analysis. In considering each of these methods, I determined that thematic analysis was the most appropriate to the modified grounded theory nature of my study. According to Riessman (2008), thematic narrative analysis is a method of qualitative data analysis that is most closely related to grounded theory. However, whereas grounded theory seeks to identify component themes across cases, thematic narrative analysis requires keeping the story "intact" and theorizing from the case. By 
analyzing four different studies (interview-based, archival and ethnographic) that utilized a variety of approaches to thematic narrative analysis, Riessman argues that there is wide variation in how investigators define "narrative," ranging from a biography, or "life story," to a bounded segment about a single incident.

Based on her review, Riessman outlines an approach to thematic narrative analysis that is effective for interview-based studies: 1) work with a single interview/case at a time, 2) isolate and order relevant episodes into a chronological biographical account, 3) complete steps $1 \& 2$ for all interviewees, identifying and naming the underlying themes in each account, and 4) select particular cases to illustrate general patterns (range and variation), comparing the underlying assumptions of the different cases. Guided by this procedure, I created a single, chronological biographical account for each of the 35 research participants using excerpts from the transcripts and written reflections. The result was a self-narrative of each woman's retrospective understanding of her journey from university student to married/partnered professional with at least one young child. It is important to note that these self-narratives are distinct from the transcript summaries as they represent each woman's story, in her own spoken and written words. Below I explain in detail how I created these self-narratives as well as the procedure I employed to analyze them. The steps I used are summarized in Table 3.

Working with a single case at a time, I read the interview summary, analytic memo, and written reflection in order to create a chronological outline of key episodes/transitions, beginning with the informant leaving university and ending with her present day-to-day life and vision of the future. In cases in which the informant wrote about a transition/turning point that took place prior to or during her university years, this earliest turning point served as the first episode in the outline. I included all events/turning points from the Reflection Assignment, as well as the three 
transitions that I had selected. With these events identified and placed in chronological order, I fleshed out the outline by adding excerpts from the interview transcripts and the reflection assignment in order to create a detailed auto-biographical account, using solely the spoken and written words of each informant. I repeated this process for all 35 cases. These biographical accounts are the "self-narratives" that form the unit of analysis in this study. They range in length from four to six single-spaced pages.

\section{INSERT TABLE 3 ABOUT HERE}

In the third step of the analysis, I focused on making sense of within-case and withintransition narratives. I read each self-narrative carefully several times, identifying key themes in each of the transitions that had been identified by informants as significant, as well as the specific transitions that I probed in Interview II. To facilitate this step, I created an Excel spreadsheet. After identifying the events in the columns of the spreadsheet, I added key quotes from the self-narratives in which the informant explained the significance of each transition. The range in the number of transitions/significant events per case is four to eight. That is, if there was $100 \%$ overlap in the transitions I asked about in Interview II and the events the participant wrote about in her written reflection, the total number of transition/significant events was four. If there was no overlap in the transitions I asked about in Interview II and the events the participant wrote about in her written reflection, the total number of transition/ significant events was eight. Each of the 35 self-narratives includes the events reported in the written reflection as well as the four transitions that I probed in Interview II. As shown in Table 2, these transitions/events included pre-university self-defining events, events related to the early career transition, significant events prior to marriage/partnering, the event of an engagement, marriage 
or moving in together, the transition to motherhood, post-transition to motherhood significant personal/ family/career events, and events related to combining career and family.

After completing this process for an initial set of 10 cases, I began coding the quotes in the spreadsheet for emerging themes. In so doing, it became clear that the variation in the types of transitions/events and the themes they represented was too great to glean common betweencase insights. Therefore, I decided to focus on the central transitions that were common to all 35 cases: the early career transition, the transition to motherhood, and the transition to combining career and family. I chose to exclude the transition to marriage/partnering, because only 11 out of my 35 participants included this turning point in their written reflections. In addition, the responses to my question, "How do you think getting married/partnering changed who you were or how you thought about yourself?” revealed that many women did not consider marriage/partnering to have had an impact on their personal identity. Therefore, this transition did not appear to be a common occasion of active identity work, contrary to claims by some scholars (e.g., McAdams, 1993). This may be a result of a societal trend toward living together prior to getting married/making a firm commitment to a conjugal relationship; that is, once one has been co-habiting, the event of a formal commitment may be less significant/self-defining.

The decision to focus on the three key transition points proved fruitful, as common themes and patterns began to emerge much more clearly. To facilitate the categorization of these common themes, I created a new worksheet in the Excel workbook in which I captured quotes that were evidence of narrative identity work at each transition and began to code them. This allowed me to identify particular forms of identity work that my participants described in their stories of the three transitions. While the initial coding resulted in a vast array of labels for the different forms of identity work I uncovered in the narrative, I began to see some common 
themes emerge. Some of the initial themes included reinventing (experiencing an identity transformation), revising (modifying career goals and reconfiguring priorities), refining (honing one's sense of self-identity), and searching (experiencing a sense of being in limbo and/or identity loss). In identifying, labeling and distinguishing these forms of narrative identity work from each other, I moved between the data and the literature to inform my interpretations and theoretical formulations. By re-reading the quotes and codes, I was able to collapse across similar categories that captured the different forms of narrative identity work my informants engaged in that were specific to each of the three transitions. For example, quotes regarding the early career transition that had been coded as, "rejecting a former identity," "re-thinking who one wants to become," and "expressing an anti-identity” were all subsumed under the narrative identity work label, "shedding." Quotes pertaining to the transition to motherhood that had been coded as, "resisting an identity change," "maintaining one’s professional identity," and "retaining a focus on career" were re-labeled as "preserving." Quotes pertaining to the transition to combining career and family that had been coded as, "playing with provisional selves," “trying out a stay-at-home mom identity," and “testing a working mother identity” I grouped together and relabeled as a form of narrative identity work called, "experimenting.” Through this process, I reduced all of the codes to ten distinct forms of narrative identity work, four in the early career transition, four in the transition to motherhood, and three in the transition to combining career and family.

In the fourth step, I analyzed the different forms of narrative identity work that I uncovered in each transition, looking for recurrent themes or underlying dimensions across cases and across transitions. The goal was to gain more understanding of the similarities and differences in how women navigated the various turning points. In so doing, it became clear that 
there were recurring over-arching themes in the forms of narrative identity work that I had uncovered in each transition. Through careful examination of patterns of identity work across cases and transitions, three higher-order themes emerged that appeared to capture the essence of all of the forms of narrative identity work identified. I conceptualize these themes as representing underlying identity processes: identity exploration, identity adaptation, and identity expression. Table 7 shows how the ten forms of narrative identity work identified through the within-case analysis map onto these identity processes.

My final analytic task was to use the emergent identity processes to investigate patterns in the evolution of my informants' sense of self over time. Accordingly, I coded all 35 selfnarratives by identifying the dominant identity process(es) that was reflected in each transition based on the principal forms of narrative identity work the informant had engaged in. I then examined the within- and between case patterns of identity processes across the three transitions. In so doing, I identified four dominant patterns of identity processes over time. These identity process patterns are shown in Figure 1. 


\section{CHAPTER 4: FINDINGS}

In order to address my three research questions, the unit of analysis I used in this study is a woman's self-narrative, beginning with her time as a university student and focused on three particular transitions. Specifically, to uncover narrative identity work, I examined the stories my informants told of three significant transitions that are common to all women who pursue professional/managerial careers and raise families: 1) the early career transition, 2) the transition to motherhood, and 3) the transition to combining career and family. The results of this analysis are divided into four sections in this chapter. In Part I, I address my first research question: What is the variation in the narrative identity work professional/ managerial women engage in as they construct stories about three significant life transitions: the early career transition, the transition to motherhood, and the transition to combining career and family? Accordingly, I describe and present examples of the different forms of narrative identity work I uncovered in the stories my informants told about each of these three transitions. In Part II, I address my second research question: What recurring themes, if any, can be identified in the kinds of identity work women engage in within and across significant transitions? To answer this question, I identify and discuss the recurring, higher-order themes I discovered through an analysis of what the different forms of narrative identity work reflect in each transition. Specifically, I argue that the recurring themes represent identity processes that can be viewed as the broader means by which identities are constructed, revised and presented. In Part III, I address my third research question: How does a narrative identity work lens help us to better understand the evolution of women's identity over time, and through the significant transitions involved in pursuing a professional/managerial career and raising a family? To address this question, I identify four dominant within-case patterns of identity processes across the three transitions. I then discuss what these patterns tell us about the evolution of professional/managerial women's identity, as well as what the 
dominant processes in each transition indicate about how women navigate the key, identity-laden turning points involved in pursuing a professional/managerial career and raising a family. In Part IV, I discuss new theoretical insights into women's narrative identity work that emerge from this research.

\section{Part I: Narrative Identity Work at Three Significant Transitions}

\section{The Early Career Transition}

As noted by Josselson (1996), preparing to graduate from college/university is a point in a women's life when there are endless possibilities for who she will become; having yet to commit to a profession or partner, women are in theory free to explore and to become anything that they want to be. Leaving university and starting a career is a significant transition that involves becoming an autonomous adult, choosing a vocation, and finding a way to support oneself; it is also the beginning of crafting a professional identity. For my informants, this transition generally began when they ended their time as university students, and continued through the first two to four years post-graduation. During this time, the women in my study tackled the questions of, "Who am I?” and “Who/what do I want to become?” as they made decisions about taking a first career job and building an independent life.

My data reveals a variety of narrative identity work that women engaged in when telling stories about ending their time as university students and embarking upon their adult lives and professional careers. These stories include the very early part of their careers, beginning with leaving university and starting a first career job, up through and including changing jobs, or returning to school to pursue a graduate degree, within a few years of graduation. However, some of my informants expressed the need to tell stories about pre-university experiences that they believed had a significant impact on who they had become. Therefore, rather than limit the timeframe or age range that represents this significant period in a woman’s life, I take an 
inclusive approach and consider the stories my informants told of their significant pre-university experiences (where applicable), as well as their career experiences in the first few years after graduating from university. In general, the stories my informants told about this transitional period reflect a point in time when they were between the ages of 18 and 24. As shown in Table 4, the results of my analysis indicate that women's narrative identity work at the early career transition may be grouped into four categories: searching, shedding then searching, projecting, and claiming. I describe each form of identity work in detail below.

Searching. The first form of narrative identity work uncovered in my informants' stories of the early career transition speaks to a search for an adult identity. That is, the women who told stories of searching had yet to develop a clear sense of who or what they wanted to be as they prepared to take their place as adults in society. Their narratives reveal how some young women complete their university studies and embark on their careers unsure of who they are or where they are headed. Accordingly, they describe this period of their lives as a time when they ventured out to determine who they wanted to be, and what they wanted to become, primarily in terms of choosing a career path.

INSERT TABLE 4 ABOUT HERE

For example, CA03 explains how she had always wanted an education, "I wanted a Diploma more than anything," but had no idea what kind of a career path she would follow: I just sent my CV everywhere and then the first company called me and I went there. After graduating from university with a degree in chemistry, CA03 applied to countless companies in various industries. When she received her first "real" job offer from a research lab, she quit her part-time, "pill counting" job at a local pharmacy and accepted, even though the pay was low and 
the commute was long. Not long after, one of the many resumes she had sent out was noticed by a multi-national cosmetics company and CA03 was invited to interview:

I was working at the pharmacy and then when I got the job [the research lab], I was like, "Okay, well, I'll go." And I remember from my first day, it was like terrible commuting. It would take me two hours going to [research lab], and I was thinking I could work at the IGA making more money and skipping the commute. But it was great. It was like you were doing, I don't know, graduate work. It was like we were doing research. It was very interesting... After my university I had applied at many jobs, so somebody from [cosmetics company] called me, but I was liking what I was doing [at the research lab]. So, I just went thinking, "Okay, let me practice interviews.” And then I bought a car and I switched to [cosmetics company].

Although accepting the job with the cosmetics company set CA03 on an upwardly mobile career path in quality assurance, she did not strategically plan this career move. Rather, she cast a wide net in her job search as part of searching for who and what she would become.

In another example, CA08 tried out several potential paths during her university years, including nursing, a career she had previously rejected due to her African American heritage: "I had always avoided the idea of doing nursing because it was always like, "oh, that's the thing that black women do." She went on to complete a business degree, but spent a fair amount of time searching for a career direction in the early career transition:

After getting my degree, I did one of those, "travel for a while." When I got back in the middle of summer, it was hard to find a full-time job and I just took the first thing that came my way, which was kind of an internship...And I did it for a couple of months and the organization and myself sort of realized that we weren't a fit, and that's when I talked to a few people and I found [company name]. It was a good entry-level position that would enable me to get my feet wet.

Shedding then Searching. While many of my informants told stories in which searching was evident, the most prevalent way in which the women in my study narrated about themselves as transitioning from students to young professionals was in terms of shedding, then searching. This form of narrative identity work involves letting go of a sense of identity and planned future that was developed in high school and/or during one's university years, and setting out to explore 
other possibilities. In essence, shedding then searching is about rejecting an old identity and opening oneself up to finding a new one. The women who told stories of shedding then searching describe experiencing a realization that a prematurely adopted identity (e.g., lawyer, clinical psychologist, etc.) was not at all who they wanted to be or to become, and being determined to find a new path. In fact, some of my informants told stories of starting out with dreams of pursuing a career in the arts, or were focused on getting married and having children, rather than building a career. For example, a few of the women in my study had planned to become performing artists after spending much of their childhood and adolescence honing a particular talent. However, each one experienced an epiphany in which she realized that she wanted to pursue a different kind of life than the arts would provide. These women were also academically inclined, and turned their attention to higher education and the pursuit of a professional career, without really knowing who or what they would become.

In one example, US04 had trained as a musician throughout her childhood and adolescence and planned to attend a prestigious college of music. However, in her senior year of high school she realized that this was not the life she wanted for herself:

....in my senior of high school I thought I was going to be a music major. And suddenly in October I decide, "Whoa, wait a second. I practice, you know, five or six hours a day, and this is going to be my whole life? I don't want to do that."

Although most of the women who described shedding in their narratives of the early career transition focused on career planning rather than family planning, some women told stories of planning to marry and have children soon after university. These narratives exposed the shedding of a soon-to-be dependent spouse/stay-at-home-mom identity. For example, US15 planned to marry her college boyfriend and start a family soon after graduating from university, so she had not thought much about her career plans: 
So I really thought I would be getting married very soon after graduation, my undergrad. And so I can't say I was very focused career-wise, because I thought that, me and this guy, we are going to get married and have babies at 23 or whatever... I think that in my naïve mind I thought that I was, I'd stay at home or maybe just have like a little simple job.

In her story, US15 explains that the relationship ended and she had to let go of this vision of becoming a stay-at-home mom. Shedding this envisioned identity, US15 describes searching for her independent self in her story of joining an international consulting firm after graduation and then accepting an overseas assignment within her first year on the job:

I was away from all my friends and family and learned to meet new people, try new things - to become more independent and adventurous. I tried new foods, took on new hobbies, did a lot of traveling. It was also the first time since I was 16 that I was not in a romantic relationship...I saw myself as a success. I was proud to be making it on my own and to be so far away from home.

Projecting. The third form of narrative identity work to emerge from stories of the early career transition entails crafting a mental image of the kind of individual one hopes to become in the future, then taking actions to become that envisioned self. The informants who engaged in projecting often described themselves as future professionals and/or financially independent women. In fact, several women carried a "personal mantra" that provided an image of who they would become after graduating from university and starting their careers. In many cases, this mantra was handed down by a key figure in the woman's life, such as a parent or teacher. For example, CA10 was encouraged by her parents to pursue a professional career, and she entered university with this idea in mind. After imagining herself in different professional roles, she decided that becoming a medical doctor would be a good fit for her:

I always wanted to be a professional, and always, like my parents really pushed that like accountant, engineering, teacher, lawyer. I wanted to be financially secure. And [medicine] seemed like a good combination of like human contact and science, but I sort of fleshed out the idea while I was there. 
Claiming. The fourth form of narrative identity work at the early career transition surfaced in stories in which my informants asserted a clear sense of who they believed themselves to be at this particular point in time; that is, they professed a well-defined sense of self during this transition, as opposed to exploring possible selves or projecting a future professional identity. By "sense of self" I refer to a holistic view that a woman has of herself; that is, a summative assessment of the various roles and identities one might list out in response to the question, “Who am I?” In these stories, my informants professed a strong sense of who they believed themselves to be as university students and/or young professionals. For example, CA06 describes having a strong sense of who she was even before she entered university: Instead of me going through that 18 to... I think maybe you don't really know who you are at 18 , but I was like, "Well, I know who I am." CA06 describes herself as being a very social person and a 'go-getter' from very early on, and her story demonstrates how this sense of self played out as she embarked on her career:

So I was super proud when I got the job. Fun, big job, really demanding... I was known to be the party animal. I was marketing, so I was at every social event. And I'm a social person just naturally, so put me in the scenario where someone else is paying and I totally leveraged every opportunity.

In another case, US20 claims the identity of mathematician in her story of being selected to attend an elite REU (research experience for undergraduates):

I mean, it's like the absolute best, best, best people in the country. It like kick-started my career, you know? It really let me... it just put me in a different club, you know what I mean? I mean, I am honestly not as good as the other people in that club, but just being in that club, it just kind of showed me like what is possible. ... Like I know I'm not that level of mathematician, but it certainly like raised me, just to have higher expectations of myself.

US20 carried this identity into graduate school where she pursued a $\mathrm{PhD}$ in mathematics. 
As these examples illustrate, the forms of narrative identity work uncovered in my informants' stories of the early career transition reveal that this is a critical turning point in the lives of women who pursue higher education and set out to craft a professional career. They also expose a great deal of diversity in terms of how young women experience this transition. For some women, it seems to be a time of searching for who one wants to be/become and what one wants to do in terms of occupation, while for others it is about letting go of past expectations and opening oneself up to new possibilities. In several cases, stories about this transition demonstrate how some women develop an image of who/what they feel destined to become and then work towards realizing this future identity. For all of the women in my study, rich narrative identity work was evident in their stories of embarking on their careers and wrestling with the questions, “Who am I?,” “Who do I want to be?,” and "Where am I headed?” However, while some women were tackling these questions for the first time, others had already answered them in adolescence. For the women who arrived at the early career transition with answers to these questions, making this transition involved one of two divergent paths. That is, some of my informants rejected their earlier responses and decided to become something different; others held on to their answers, asserting their chosen or envisioned selves as they embarked on their careers.

\section{Narrative Identity Work at the Transition to Motherhood.}

Frequently conceptualized as an identity transforming event (Lee et al., 2005), the transition to motherhood is a critical turning point in women's lives. This transition stands out as particularly significant, because pregnancy is exclusive to the female experience, and becoming a mother means the addition of a new and powerful identity. As demonstrated by the extant literature, the transition to motherhood may be uniquely challenging for professional/managerial women who have spent many years pursuing higher education, earning undergraduate and often 
graduate degrees, and gaining valuable professional work experience. During this transition, from the liminal period of being pregnant at work through the experience of childbirth and maternity leave, professional/managerial women must make sense of their new mothering identity, and what it means for their professional identity and core sense of self. This turning point in a woman's life stands out from other transitions because rather than transitioning out of one role and into another, she gains an entirely new identity. Specifically, a woman transitions from someone who is a professional/manager to someone who is both a professional/manager and a mother. The average age at which the women in this study experienced this transition was 32.5, but ranged from 26 to 39. The stories my informants told me about their experiences during pregnancy and maternity leave demonstrate that identity work at this transition begins at different stages for different women. For some, becoming pregnant triggered identity work, while for others identity work was triggered by the experience of childbirth. As shown in Table 5, my data reveals four forms of narrative identity work in stories about becoming a mother: modifying, transforming, preserving, and interrogating. In the following section, I describe each of these forms of identity work in detail.

Modifying. The women who engaged in modifying in their stories of becoming mothers described seeing themselves and their careers in a different light following the birth of a first child. For many, this translated into a de-prioritization of career, and a sense of feeling less ambitious about getting ahead professionally. For example, CA11 experienced a distancing from the "career woman" identity she had been so strongly attached to when she realized that her priorities had changed:

Having my son made me realized that as much as I love my job, a job was just a job and that having a family was more important to me for the time being. It concurred that having a close family and children close in age was really important to me even if it would mean that it might impact my career and put it on hold in regards of progression 
and promotion. I always saw me as a "career woman" and sometimes it is hard to accept that your life is taking somewhat another direction from what you planned when you graduated, but at the same time I feel that I've grown emotionally.

In a similar case, US18 experienced a shift in her sense of self from a self-centered focus on career progression to a family-centered view of herself and her life:

I just think before that I was much more concerned about my own resume development. And frankly, after I had her, I didn't care about that. It was important, but I then for the first time saw us as a family, as a dual income. Like it didn't matter if I necessarily got a salary promotion or something because we were going to be okay and what really matters was well, how I was, the time that I had with my daughter and the quality of time that she was having with our family. That stuff really mattered to me. And I felt like it became more about meeting our family's needs as opposed to just climbing or something like that. It just, it was just different priorities.

Transforming. The women who engaged in transforming described a transition to motherhood that was so dramatic that their sense of self was completely altered. This powerful identity shift is generally characterized in my informants’ stories as an overwhelming desire to be a caretaker to one’s child. For example, CA06 explains how the birth of her daughter ignited a completely unexpected sense of maternal identity that seemed a complete contrast to her sense of self as a career woman:

So, when my daughter was born I was just, it was like a new beginning for so much of my life. And I think that is where I changed fundamentally in terms of priorities, not necessarily realizing it yet... basically what I mean by not realizing it yet is like, Okay, so you are a career person. Then you are like $200 \%$ maternal person, but you've worked and you've identified yourself in school as being super go-getter, career.

Similarly, US10 experienced an overwhelming sense of wanting to care for and protect her child after giving birth to her first child that completely overwhelmed her sense of self as a professional:

After 36 hours of labor - I did have my daughter with no drugs or medical intervention. It was an amazing experience. I felt like I could accomplish anything after that experience. After this I did not want to work full-time - I did not know for how long but at least for the first year or so of my daughter's life. Even while pregnant - at the end I really deprioritized work - I did not want to do anything that would put my health in 
jeopardy. It wouldn't have mattered to me if I had to borrow or beg for the money to be able to stay home with my baby at that point - I felt fiercely that that was the right thing to do for her.

\section{INSERT TABLE 5 ABOUT HERE}

Preserving. Many women in my study told stories about the transition to motherhood that expose narrative identity work aimed at protecting a pre-motherhood identity. Although these women describe a sense of joy in becoming mothers, they distance themselves from the traditional mother identity that is centered on the role of caretaker of the home and new baby. These women sought to preserve their sense of self as professionals and individuals with identities that are separate from that of "mother." In most cases, this form of narrative identity work expresses a recognition that one is uncomfortable or unsatisfied with staying home and caring for a newborn, and a simultaneous discovery of the importance of work and career to one's sense of self. For example, CA05 found maternity leave very difficult and considered going back to work early to escape the drudgery of being home with a difficult baby: I do remember calling (my husband) at work and going, "When are you coming home? This is awful." I remember saying to him at one point, "I might go back to work early."

In some stories, preserving identity was conveyed in terms of an "anti-identity" in which the informant describes a discovery that she was not someone who could stay home. For example, US17 explains:

Well, you know, I think that maternity leave was hard for me because I had never been at home. Like, I had never spent any time at home, really, ever, other than maybe being sick in the fourth grade or something. I'd just never been home. It's like you're in college, you're doing stuff. So sort of, just sort of being home was not... I'm sort of, I don't lament that I didn't take a longer maternity leave, because I am not one of those people that is sort of good at being home.

Not all stories of preserving identity involved rushing to return to work, however. Some women told stories in which a sense of self remained unaltered after the birth of a first child even in the 
context of taking a career break. For example, CA02 engaged in her mother role but continued to live her life and preserve her sense of personal identity:

I wasn't the type of mother that would take their child to the park and play in the sand with them. Those were not things that interested me. I would do things with [my son] but... I mean I'd go for a lot of walks with him, and yeah, I would take him to the park. But I wouldn't sit in the dirt with him. I would read to him, but we would go out and do things. He was there with me doing things. So, you know, if I took him to the gym... like we had a gym in the condo. You know, I'd bring the stroller down. He'd take a nap down there with me, or just sit there and crawl around. Absolutely, I didn't change; I didn't stop because I had him.

Interrogating. Some of the women told stories about the transition to motherhood in which they question who they are and what they are becoming, as well as those parts of themselves that they feel are being lost. In these stories, the narrative identity work that emerges is a struggle to come to terms with identity loss and difficulty crafting a new or revised sense of self. For example, CA12 tells a story of discovering that she was pregnant and reacting with a realization that a part of herself was gone forever:

I'm not a girl anymore. I can't just sit on the side of the street, and read a book, or go out and have a beer or go travelling or... I'm really, really happy but... I'm going to be the one throwing up. I'm the one who is going to worry for the rest of my life.

In another case, US13 recounted her story of being in-between jobs and moving during her first (and thus far, only) pregnancy. Evidence of interrogating is found in her story of struggling to rationalize her need to do more with her life than just care for her baby:

...by the time I got back to Boston I was like visibly pregnant. I didn’t quite know what I wanted to do...I took four months off, starting a week or two before I had him through, when he was probably about three and a half months old. Financially [staying at home] is not really feasible; I think mentally it's not really feasible. I think part-time is the most I can... I don't think I could have... Four months of stay at home, was like enough... Yeah, I think it's very important in order to be a good parent to have something that's outside of your kids, so that you are not putting all of your energy into your kids, because then they become your project... There are some people who can do it, but if what you are doing is trying to make your kid your career, I don't think it goes well. 
As noted in previous studies, the transition to motherhood is a significant identity marker for women. This is a time when women engage in identity work to change or preserve their sense of self, and to seek answers to the question, "Who have I become?" The various forms of narrative identity work uncovered in my informants’ stories of being pregnant and becoming first-time mothers reveal that professional/managerial women experience this transition in very different ways. For some women, the addition of a mother identity appears to challenge their sense of self as professionals, or is simply not experienced as a profound change; accordingly, their identity work is focused on preserving their pre-motherhood identities. For others, pregnancy and/or first-time motherhood presents a welcomed opportunity to change how they see themselves (Bailey, 1999), and thus their identity work is focused on modifying their sense of self. For some women, the experience of becoming a mother is so dramatic that this transition triggers an unexpected metamorphosis; accordingly, their identity work is centered on transforming from who they were as non-mothers to something completely new and different as women who are both professionals/managers and mothers. Finally, some women experience the transition to motherhood as creating a sense of loss and/or uncertainty; the new mother identity completely overwhelms the pre-motherhood identity such that a woman no longer knows who she is. In this case, identity work is centered on interrogating; that is, trying to understand who she is/wants to be now that she is both a professional/manager and a mother.

\section{Narrative Identity Work In Combining Career \& Family}

The third transitional period I examine in this study is labeled, "the transition to combining career and family.” The nature of this transition is distinct from both the early career transition and the transition to motherhood for several reasons. For one, combining career and family represents a transitional period that involves figuring out how to bring two highly significant identities, that of professional and mother, together. In contrast, the early career 
transition represents the beginning of their independent adult lives, when they embark on their careers and begin to craft a professional identity. The transition to motherhood, on the other hand, represents the addition of a new identity, that of "mother," that a woman must adjust to. Further, this transition is distinct from the other two because, while the starting point is clear, the endpoint is elusive. That is, for the informants in the present study, this transition begins at the end of their first maternity leave; however, the transitional period extends over an indefinite period of time, as her approach to engaging in work and family may be altered by changing circumstances. For example, decisions about employment status and childcare are likely to be revisited following subsequent births, and/or as one's youngest child reaches school age.

\section{INSERT TABLE 6 ABOUT HERE}

Accordingly, similar to my approach in determining the timeframe that constitutes the early career transition, I take an inclusive stance in delineating this third transition rather than setting an artificial cut-off point. That is, I examined the stories my informants told of every experience they had with being pregnant and transitioning from a maternity leave back to work or to taking a career break. This approach is important, as the transition to combining career and family raises a wider range of identity issues. That is, in the early career transition one begins to form a professional identity, and in the transition to motherhood, one adds a new mother identity. The transition to combining career and family, on the other hand, involves finding a way for these two identities to co-exist. Specifically, in making decisions about childcare arrangements, prioritization of careers in the couple relationship, taking advantage of flexibility options at work, or even staying home for an undetermined period of time, women are making choices about how they are going to be professionals and mothers. While these choices are likely to be constrained to some degree by their spouses' careers, family finances, workplace flexibility, etc., 
identity issues regarding who/what one wants to be at home and at work are also at hand.

Further, these choices and issues resurface with the birth of each child; hence, my decision to take a broad stance in defining this third transition by collecting and analyzing data from my informants' stories of every maternity leave and returning to work/taking a career break experience.

At the time of the second interview, when I asked about these experiences, some of the women had only one child who was still quite young, and therefore the practical reality of combining career and family was fairly new. However, the majority of my informants had been mothers for several years. For the women in my study who have only one child, this period may encompass just one or two years; for the women who have multiple children, this period encompasses upwards of 11 years. In fact, the age range of the oldest child is 12 months to 11 years, and the average age of the eldest child is 4.9 years old. For the women with more than one child, this period of their lives involves a series of transitions related to combining career and family. That is, after the birth of each child, the informant faced decisions about how to accommodate the addition of a new member of the family. In addition, some women revisited their approach to combining career and family when their children reached school age.

While the details of each woman's narrative differed significantly, common forms of narrative identity work emerged from the stories they told about each maternity leave and the subsequent questions they faced about what to do next; for example, returning to full-time work, going part-time, taking a career break, changing employers or professions, or some combination of two or three of these options over time. As shown in Table 6, in analyzing these stories I discovered evidence of three forms of narrative identity work: enacting an identity, experimenting with possible identities, and grappling with a sense of identity loss, conflicting 
identities, and/or uncertainty about how to answer the question, "Who am I?" in the context of being both a professional/manager and a mother.

Enacting. Several informants told stories about being both a professional and a mother in which a core sense of self guides decisions about how to combine career and family. That is, this form of narrative identity work is focused on performing the roles of professional and mother in accord with who she wants/believes herself to be. For example, US01, mother of three and partner in a consulting firm, returned to full-time work after each maternity leave. She describes herself as a "provider" and enacts this identity in her work and family decisions. In fact, US01 conceptualizes maintaining a high-powered career while raising three young children as performing her provider identity:

Though my career has continued to be an important vehicle of self-fulfillment, it is more important to me that my career can be managed in a way that allows me to be there for my daughter and sons while still providing financially for their needs... I even view the fact that I gain satisfaction through my work as important because it helps me be a better mom for my kids. I see myself as a provider for my kids. I feel obligated to provide for the significant financial burdens of having children and ensuring they have the financial means to be healthy, happy and successful.

In another example, US07, a member of the senior management team of a high-tech startup, explains that she has never worked less than full-time, and insists that she will never work less than full-time, even though it pains her to drop her daughter off at daycare each morning. This seeming contradiction is resolved in her personal identity as an exceptionally reliable individual. She describes herself as the "the little engine that could;" in other words, regardless of the obstacles she faces, US07 always fulfills her obligations and keeps her promises. In combining career and family, she enacts this identity in both her high-powered career and in mothering her only child. She depicts herself in terms that paint the picture of a "heroine;" that one person both her clients and her daughter can rely on to be there when needed: 
I was always like "the little engine that could" at work. Like, we'd all be traveling to the same location, and I might be the only that made it. You know, like... So I'm always pretty determined to do what I say I'm going to do. And I just can't even imagine, like if (my daughter) needs something or... I feel like maybe (my husband) says I'm a good mom because I'm so good at being there for what she needs. Because that's, if there's a task at hand, I'm good at executing that task. But if I know she needs me, I will get there. Planes, trains, automobiles, I'm pretty good at showing up.

Enacting reveals how some women express a particular self-concept in both their professional and family lives. As shown in the examples above, the "provider" is both a competent professional and a caring parent; the "heroine" is both a reliable employee and a dedicated mother. For others, enacting is focused on expressing changes in one's sense of self as a result of having become a mother in addition to an educated, professional woman. For example, C11 describes being single-mindedly focused on building her career during university and up until she got married and had her first baby. In describing her decision to "coast" in her career for the time being, rather than vying for promotion, she explains:

I think by growing up, I've learned that you can work on different things at different times. Like it doesn't have to be so extreme, in one part or the other, you know? You can try to have a more balanced life between your career and your family. I'm definitely less of a career woman than I was.

Experimenting. The second form of narrative identity work in combining career and family to emerge from my data is experimenting. I uncovered experimenting in stories in which my informants describe imagining and trying out different ways of combining career and family until they found an approach that felt "right.” Some informants experimented with being a highpowered working mother, while others tried out the "stay-at-home mom" identity; some cut back to part-time work, others changed employers or careers altogether, and many tried two or more of these approaches. Regardless of the type of experimentation, this form of narrative identity work expresses what Ibarra (1999) terms “provisional selves.” However, unlike Ibarra’s subjects who often modeled the behavior of individuals who occupied the role they had just assumed, 
many of my informants were without role models. Instead, they tried out different identities, rejecting those that seemed to be a mismatch with who/what they wanted to be, and retaining those that fit with their sense of self.

One example of experimenting surfaces in CA02's story. CA02 explains how she stopped taking on contract work after the birth of her second child, then experienced a surprise third pregnancy just as she was in the process of moving the family to another city where her husband has been offered a transfer. She reflects upon her failed attempt at adopting the stay-athome mom identity in her new home town:

I attempted to do my best and assimilate with the other lululemon-outfitted women who abandoned their seemingly wonderful corporate careers and those who only ever aspired to be stay-at-home moms. I joined play groups and enrolled the children in various social activities for stimulation....I did not identify with women who chose to stay at home and raise families as I felt our interactions could only ever revolve around the children, whereas with working mothers, we could discuss other subject matter. I stayed home with the children for a few years, but clearly I was not very successful, because I returned to work when [my daughter] was 9 months old and I haven’t looked back since.

While CA02 experimented with the stay-at-home mother identity and found it was not one she could sustain, other women experimented with the career-focused, working mother identity. For example, CA06 tells a story of taking two one-year maternity leaves back-to-back during which time she returned to school and finished her MBA before re-entering the workforce. A newly minted business school graduate, she describes trying out the high-powered career woman identity: Coming out of the MBA with two young kids, I can say I did not know who I was as a career woman or a mother... I just was doing the MBA thing. I was supposed to have a big job. After two years of heavy travel demands, a brutal schedule, two disability leaves, and being laid-off, CA06 decided to try out being a working mom in a more family-friendly environment: 
Totally lost and confused, I ended up going right back into a job search which was bruised-ego driven and fully motivated by hatred I had for [XYZ company]. Faced with an option in a similar industry with another 6-figure income but including travel or a banking job which appeared more mommy friendly, I had the self-restraint to go for the latter offer. Thankfully so. I ended up in a company whose culture was very "human" and who truly believes in work life balance.

Grappling. Finally, there was a group of informants who told narratives about combining career and family that reveal grappling over lost/conflicting identities and having some difficulty answering the question, "Who am I?” in the context of being both a professional and a mother. I use the term grappling to capture the narrative identity work my informants engaged in as they struggled with trying to figure out who and what they wanted to be, and how they wanted to craft their lives. Whether taking a career break, negotiating a flexible or reduced load arrangement, or continuing on in a full-time position, these women felt unsettled about how they saw themselves as mothers and as professionals. For example, before becoming a mother US15 quit her high-powered consulting job in order to relocate back to her home town where her parents and fiancé were settled. Intent on starting a family right away, she got married and decided to take a career break; however, after two years of being home, she is grappling with who/what she wants to be, and how she might be both a mom and a professional:

Like two years and two months ago, I mean I was worn out, I was tired of my project, I was tired of the crap and the politics and the... but at the same time, I just, every time I got that pay check I felt a sense of value and I felt smart and I felt influential and I felt like I was contributing...It's such a mixed emotion. I mean like, I'm living my dream. This is what I have always... what I wanted. I have a boy, I have a girl, I am a stay at home mom and like I think about my kids and my husband and I'm just overjoyed with the blessings. And then on the flip side I think I have never worked more tirelessly, more... like I'm exhausted. ...So one thing we do entertain now is maybe working for my dad in a part-time fashion... we kind of throw around talking to my dad seeing if there's, and my brother is buying out my dad, but talking to my dad and my brother, seeing if there's a place for me.

In another case, US14 stayed home with her first child for one year before returning to work out of financial necessity. She, too, had earned an MBA and tried combining a fast-track 
career with raising a family. However, her story exposes grappling due to prioritizing career over family and the resulting level of intolerable stress:

And I was praying, and I got the message that my priorities are not straight, okay? Yeah, my husband is not happy, because I'm like only working, working. So my family, my faith, are all behind. And my career is number one. So that was sort of an awakening and then also I was putting so much pressure on myself. So I was like, "God, take this away from me!”

CA12, on the other hand, returned to work on a reduced-load basis after her first

maternity leave, having negotiated a four-day per week schedule at the professional services firm where she works. At the time of the second interview, she was preparing to return to her reduced-load schedule at the end of a one-year maternity leave with her second child. Her story reveals grappling with the disappointment she experienced from the reality of how hard it is to maintain a professional career with two young children at home:

I'm frustrated and I'm tired and I'm stressed. I'm disappointed. Like frankly, my cousin has two kids the same age as mine, and we were talking the other day about how it's really hard to talk about how disappointing it is. Like you look at a picture of a woman getting married and you think like..., "Oh, she is so happy. She has no idea there is a truck coming down the road to murder her. Like she has no clue, she is just the princess."

CA12 dreamed of becoming a mother for so long and believed that she could "have it all;" however, she now feels disillusioned by what she terms, "feminist rhetoric." Once a young woman who prided herself on overcoming any impediment to her ambitions, she now feels like a different person, one who has lost her strength and drive: ...Like with my honors thing, I wanted to do that and I did it. And I can't do that stuff anymore.

As all of these examples illustrate, women engage in a variety of forms of narrative identity work as they transition from childless professionals/managers, to professionals/managers who are also mothers, both initially as well as over time and through the addition of more children. For the women who engage in enacting, transitioning to combining career and family 
entailed performing an asserted sense of self in crafting a life that included motherhood; that is, making decisions about returning to work (or not) and in what capacity, staying in the same profession or changing careers/employers, making childcare arrangements, and carving out personal time in a way that is consonant with one's self-concept. In contrast, those who engage in experimenting were not quite sure of who they wanted to be as managers/ professionals and mothers; accordingly, these women tell stories of actively trying out various ways of being or “possible selves.” This form of narrative identity work reveals how some women approach this transition as an opportunity for self-renewal; that is, allowing themselves to imagine and try out different ways of being both a professional/manager and a mother and to choose the one that feels "right;” that is, to craft their lives in ways that reflect how they see themselves and how they wish to be viewed by others. Finally, some women engage in grappling with an altered sense of self; that is, this transition sparks a sense of confusion and feeling unable to reconcile their two identities of professional/manager and mother. These women find themselves uncertain about who they are and who they want to be as both professionals/managers and mothers. Rather than playing out an asserted identity, or freely experimenting with new identities, these women describe struggling with an inability to find answers to the questions: “Who am I?” "What do I really want?”

\section{Part II: The Identity Processes: Exploration, Adaptation, and Expression}

As demonstrated by the preceding section, I addressed my first research question by uncovering a variety of forms of narrative identity work that emerged from the stories my informants told of the early career transition, the transition to motherhood, and the transition to combining career and family. In this section, I address my second research question: What recurring themes, if any, can be identified in the kinds of identity work women engage in within 
and across significant transitions? Accordingly, I analyzed the different forms of narrative identity work that I uncovered in each transition, looking for recurrent themes or underlying dimensions that could help articulate similarities and differences in how women navigated the various turning points. In so doing, it became clear that three over-arching themes capture the essence of the different forms of narrative identity work: identity exploration, identity adaptation, and identity expression. Accordingly, in this part of the Findings chapter I discuss how I came to conceptualize these themes as higher-order identity processes and demonstrate how particular forms of narrative identity work reflect each process. I also explain how the identity processes help us to understand how a professional/managerial woman's sense of self is formed, revised and/or preserved, and presented in the early career transition, the transition to motherhood, and in combining career and family.

By examining the similarities and differences in the narrative identity work engaged in by my informants, I discovered that in all three transitions there was evidence of questioning and exploring one's sense of self, actively altering and/or sensing a change in one's sense of self, and asserting and expressing one's sense of self. While these themes manifested differently in each transition through different forms of narrative identity work, they were very clearly recurring. For example, in the early career transition, the transition to motherhood, and the transition to combining career and family, there is evidence of women pondering the questions, "Who am I?" and "Who/what do I want to be?” in the context of the changing circumstances in their lives. That is, whether transitioning to becoming an independent adult/young professional, making sense of one's new mother identity, or finding a way for one's mother identity to co-exist with one's professional identity, various forms of narrative identity work reflect a common theme of seeking to understand who one is and who/what one wishes to become. Accordingly, I label this 
theme, identity exploration. Similarly, the notion of altering/changing one's identity was present in all three transitions. For example, in the early career transition, the transition to motherhood, and the transition to combining career and family, there is evidence of women acknowledging and accepting that something has changed in their sense of self. While this change may be gradual vs. sudden, or subtle vs. acute, a woman sees herself in a different light as a result of it. Accordingly, I label this theme identity adaptation. Lastly, the theme of asserting one's identity was evident in all three transitions. Specifically, women were engaged in proclaiming who they are in the present and/or who they will become in the future in their stories about the early career transition, the transition to motherhood, and the transition to combining career and family. Accordingly, I label this process identity expression.

\section{INSERT TABLE 7 ABOUT HERE}

In conceptualizing these themes as fundamental identity processes, I propose that identity exploration, identity adaptation, and identity expression recur across individuals and transitions. Accordingly, they can be conceptualized as the broader means by which a professional/ managerial woman's sense of self is constructed, revised and/or preserved, and presented over time. I conceive of narrative identity work, on the other hand, as the retrospective and/or storied version of the tactics my informants used to form, maintain, repair, or revise their sense of self (Sveningsson \& Alvesson, 2003) during particular significant transitions. As such, I posit that each form of narrative identity work reflects a higher-order identity process. Further, the various forms of narrative identity work uncovered in each transition help us to understand that the three identity processes manifest somewhat differently depending upon the type of turning point. In addition, I found that identity exploration was a dominant process in the early career transition while identity adaptation was a dominant process in the transition to motherhood; however, all 
three processes were fairly equally prevalent in the transition to combining career and family. In general, though, these processes appear to capture the essence of how individuals form, revise and present their identities as they navigate through significant transitions.

As shown in Table 7, searching, interrogating and grappling reflect the process of identity exploration; shedding, modifying, and transforming, indicate the process of identity adaptation; and claiming, projecting, preserving, and enacting manifest the process I refer to as identity expression. While each of these individual forms of narrative identity work reflect one particular identity process, I found that experimenting, which was uncovered in the transition to combining career and family, is about both identity exploration and identity adaptation.

Across each of the transitions, three forms of narrative identity work provide evidence of an identity process that may be conceptualized as identity exploration. That is, searching at the early career transition, interrogating at the transition to motherhood, and grappling at the transition to combining career and family. Identity exploration is also an element of experimenting in the early career transition. This identity process involves responding to major turning points and transitional periods by reflecting on one's path in life with a broad openness to a variety of responses to the questions, "Who am I?" and "Who/what do I want to become?” As evidenced by the narrative identity work that exposes this identity process, identity exploration is primarily intrapsychic and reflective rather than active.

In the case of identity adaptation, there are three forms of narrative identity work that reflect this process: shedding at the early career transition, modifying or transforming at the transition to motherhood, and experimenting at the transition to combining career and family. All of these forms of narrative identity work are about the individual acknowledging that something about their sense of self has changed, and/or making conscious changes in how they think about 
themselves and who they are. Identity adaptation as a higher level process is about embracing the changing circumstances in one’s life and making the necessary identity alterations to accommodate them. For example, in the case of shedding and transforming, a woman suddenly realizes that something fundamental about her sense of self has been altered and, rather than resisting, she accepts this change and crafts her identity around it. In the case of modifying and experimenting, identity adaptation involves recognizing the need for change. Accordingly, a woman revises her priorities and/or considers new ways of being, trying them out until she finds one that matches her present circumstances and altered sense of self. Therefore, identity adaptation is both reflective and action-oriented. That is, recognizing a change in one's sense of self and considering different ways of being are both intrapsychic, whereas taking steps to do something about those thoughts by letting go of a previous identity, shifting one's priorities, and/or trying on alternative identities, on the other hand, are all external and active.

Finally, the narrative identity work that reflects the process of identity expression -claiming, projecting, preserving, and enacting -- reveals how a woman's sense of self is asserted, articulated and proclaimed in the context of work, family and personal life. That is, each significant turning point is an opportunity to profess and protect, rather than question or alter, who a woman believes herself to be. This process involves 'putting a stake in the ground' regarding who one is in the present, as well as who/what one plans to be in the future. Having defined and committed to a particular self-conception, a woman takes action to demonstrate to herself and others who she is, and/or will be, as a person, a professional and a mother.

In the following section, I demonstrate how the specific forms of narrative identity work uncovered at each transition reflect the three higher-order identity processes of identity exploration, identity adaptation, and identity expression. I explain each of these identity 
processes in detail, using quotes from both the interviews and written reflections to demonstrate how the various forms of narrative identity work help us to understand each of the three identity processes. I also explain how these processes manifest differently in each transition, and discuss the dominant processes discovered in each transition.

Identity Exploration. Three forms of narrative identity work provide evidence of an identity process that may be conceptualized as identity exploration. That is, searching at the early career transition, interrogating at the transition to motherhood, and grappling during the transitional period of combining career and family reveal a questioning of one’s identity. Accordingly, the questions, “Who am I?” and “Who/what do I want to be?” are not exclusive to the early career transition; rather, the process of identity exploration reveals how these questions are re-visited during the transition to motherhood and the transition to combining career and family. For many women, these turning points are destabilizing and raise new questions about who they are and where they are headed. Consequently, they engage in what may be conceptualized as "intrapsychic exploration" by freely envisioning different ways of being. What is particularly distinct about the process of identity exploration is how it reflects an internal journey. That is, rather than a more agentic or goal-driven process, identity exploration entails imagining and being open to a number of different possibilities. It also involves consideration of other people and external circumstances when contemplating different paths.

Beginning with the early career transition, the form of narrative identity work I label searching reveals a woman engaging in the process of identity exploration by contemplating and setting out to discover who she might become as an independent adult, and a working professional. For example, CA05 completed an economics degree, spending her final year as an exchange student in the UK and then staying on to do her MBA because there were few jobs 
available when she graduated with her bachelor's degree. Her story reveals searching as she narrates her decision to return to the UK to be with her boyfriend, even though she had no idea where her career was headed nor where they would live long-term:

I was kind of always looking to get back to the UK, primarily because my current husband and I were still having this sort of long distant relationship. And so it was kind of, "Will we go somewhere in Europe together? Or will we come to Canada or whatever?" So in any case the easiest thing at the time then, because London was a bit more booming in terms of jobs, was for me to go to the UK, to go back. So I went. I ended up at [financial services firm] in London.

In another case, US06 engaged in identity exploration by searching during the early career transition. Although she envisioned herself as a future $\mathrm{PhD}$, she describes the start of her career as an exploration of who/what she might become with this degree:

At the time I was kind of like, I kind of felt like I was going to get my PhD. I didn't know in what exactly, but there was something alluring about that... I couldn't see myself teaching, per se. I come from a family of teachers, they're public school teachers. That's the one world I was a familiar with, not necessarily college-level, but... And so I said, "I don't want to be a teacher." ...There was something about getting a PhD, like going off to do graduate work, that I really wanted to do. And I wasn't sure how that would manifest itself, but that was kind of where I was thinking - get some work experience and then go back and get a PhD.

During the transition to motherhood, identity exploration is manifested in interrogating.

This form of narrative identity work reveals how, for some women, becoming a mother triggers a questioning of who she has become, and who she is going to be, as a professional/manager who is also a mother. Similar to searching at the early career transition, women who engage in interrogating when they become mothers are wrestling with trying to figure out who they have become, and who they really want to be. In so doing, the process of identity exploration is evident in how these women question their decisions, and imagine various ways of both mothering and working. For example, anxious to start a family, US15 married a man she had only been dating for a short time, got pregnant, then quit her demanding, highly-compensated consulting position in order to move closer to family. However, she soon questioned her 
decision to take on the traditional male breadwinner/female homemaker model of family life; in fact, she soon realized that she had become a caretaker and housewife, rather than a partner, to her new husband:

...I think we just were trying to be that all-American family...I think we just kind of envisioned, you know, husband goes to work, mom stays home and has babies... you know, live the dream... I didn't picture it to be as 1950s as it is. I really thought there would be more sharing of household responsibilities and that we would partner together a lot more in the everyday rigors of life of running the house.

In contemplating her choice to stay home with her baby for an undetermined length of time, US15's narrative reveals the process of identity exploration as she compares her pre-motherhood identity as a self-assured professional woman, to her identity as a dependent housewife/stay-athome mom:

...I think of [former job] and I think high heels, although I never wore them. I think high heels. I see... I just kind of see that powerful, self-assured, self-sustaining... I didn't need [husband] at all. He was a joy to have, but I didn't need him. Now I think of myself... I don't see that same woman in high heels. It's for me, I depend on [my husband] for everything financially. So it's ... I feel a lot more dependent.

Finally, in combining career and family, identity exploration is evident in the form of narrative identity work I label grappling. That is, in thinking through the question of, "Who/what do I want to be?” in the context of putting one’s professional self and one's mothering self together, some women engage in exploration by imagining different ways of being, but struggle to find a satisfying solution. For example, US06 returned to her demanding job as a marketing manager in a prestigious pharmaceutical company, then moved to a job share in order to spend more time at home. However, she grappled with feeling that she had given up a part of herself by scaling back her work hours and career progression in combining career and family:

Gosh, yeah, I mean it felt... It was a mixture of like honoring what I wanted and what I had driven myself to find, but then also of like giving up on some part of me that strived for excellence, that had always done that, always, in everything, in my education, and 
things I had pursued. And so that was hard. It is hard to put it into words because it was both at the same time and yeah.

To assist her in resolving this struggle, US06 describes seeking the guidance of a life coach to help her work through the process of identity exploration:

I'm working with a life coach and I have a little homework assignments from that...starting to think about what that next move is and what I want to do.

CA12 also engaged in grappling at the transition to combining career and family as she wrestled with a desire to be a full-time, stay-at-home mom, and an inability to tolerate being thought of as "just a mum.” Through her description of this struggle, there is evidence that she is engaging in identity exploration as she imagines alternative ways of maintaining her professional identity as a writer in her fantasies about staying home:

...I dreamt about [staying home], but also realized that I needed to do something with my brain. I would if I could do other stuff, kind of at the same time. Like if I could, if I could take a class, or if I could keep working with [translation association] or with the literary mag or like the other stuff I do. I would have to... I could be a stay at home mom. I would love to be able to do that, if I could have my other interests... As long as my kids and I knew that I was not just a mum, then it would be okay with me.

In another example, US19 engaged in grappling with a competing desire to be home with her son, and at the same time wanting to find a way to hold on to her professional identity:

I never envisioned not wanting to work; my career was my whole identity. But right now, I'd love to quit my job and spend one day a week writing, and the rest of my time playing with my son.... It makes me feel so crazy out of control. I want to quit my job at the same time I want to excel.

Her struggle reveals a process of identity exploration as she imagines two opposing approaches to combining career and family: taking a career break or focusing on getting ahead.

As these examples illustrate, three different forms of narrative identity work, searching, interrogating and grappling, all expose a higher-order identity process in which one's identity is called into question during times of significant transition. In addition, experimenting involves both imagining possible selves, which reflects identity exploration, and actively trying out 
provisional selves, which reflects identity adaptation. All of these forms of narrative identity work demonstrate the intrapsychic and reflective nature of identity exploration that involves the pursuit of satisfying answers to the questions, "Who am I?” and "Who/what do I want to be?”

Identity Adaptation. Several forms of narrative identity work across the transitions provide evidence of a second higher-order identity process that may be conceptualized as identity adaptation. That is, at each transition, different forms of identity work emerged that reveal how a woman's sense of self is revised as life's circumstances change. Specifically, identity adaptation involves an internal acknowledgement of a change in one's sense of self and a revising of one's self-concept to incorporate it. In the early career transition, shedding reveals identity adaptation in the letting go of a formerly held identity in order to become someone/something different. In the transition to motherhood, both modifying and transforming represent identity adaptation, with the latter being more radical than the former. Modifying reveals identity adaptation as a response to feeling that one's career has become less central to one's sense of self than it previously had been, while transforming is a reaction to the discovery of an unexpectedly powerful desire to care for and protect one's child. In combining career and family, experimenting reflects both the process of identity exploration and the process of identity adaptation. That is, exploration is reflected in how a woman contemplates who/what she wishes to be as a professional and a mother, while identity adaptation is manifested in how a woman works through changing how she sees herself by trying out different ways of being both a professional/ manager and a mother. At a high level, what all of these forms of narrative identity work have in common is making changes to one’s responses to, "Who am I?" and/or "Who/what do I want to become?” Accordingly, the process of identity adaptation involves renewing one’s self-concept during times of significant transition. 
Beginning with the early career transition, shedding reveals identity adaptation in the letting go of an adolescent vision of who a young woman thought she would become in order to free herself up to be and become something different. While the "trigger" for each woman is different, some form of an epiphany is experienced that causes her to recognize a need to change directions. For example, US14 studied actuarial science in university and landed a prestigious job as an actuary after graduation; however, her ultimate plan was to marry her wealthy boyfriend and become a stay-at-home mom. When the relationship ended, she shed this envisioned housewife identity and began to refocus on building her career and becoming financially independent:

He had been a big influence in my teenage life since I dated him from when I was 15-22. He was very traditional and I thought I'd get married and raise children and be a traditional housewife. He was also very wealthy so I never worried about having to make money. After breaking up, I realized I now have to take control of my future, including financial responsibility.

In another example, US17 describes experiencing an epiphany that allowed her to free herself of the path she was on to become a clinical psychologist. Identity adaptation is revealed in her acting upon the realization that she was on the wrong path by shedding this future professional identity and deciding to change directions:

I was studying abroad my Junior year in France and at a museum in the South of France, here was a Picasso painting, with an accompanying description referencing joie de vivre. This was the first time that I thought about moving away from something. All prior to this it was moving towards something... I had almost a 4.0. Going to grad school, especially for clinical psych, would have meant moving somewhere post-college not so great and then 8 to 9 years of academic drudgery for a somewhat uncertain future...It was really the first time that I went off of the plan, since all prior to that it seemed like a path was so clearly mapped out.

The process of identity adaptation is also represented in two forms of narrative identity work that emerged in the stories of the transition to motherhood: modifying and transforming. 
For example, US01 engaged in modifying as she transitioned to motherhood; that is, she adapted her pre-motherhood identity to make room for who she had become as a mother:

The experience of becoming a mother is one in which I felt that I lost myself to a great degree, especially initially. It's as though the old me was torn down and a new me was built up with some parts of the old and the new "mommy" parts of me that I was inventing as I went along.

US06, on the hand, describes the form of narrative identity work I label transforming as she experienced such a shockingly powerful desire to care for and protect her first child that she nearly instantaneously found herself engaged in a process of identity adaptation; that is, she immediately began to revise her pre-motherhood vision of being a full-time working mother:

I had always known I wanted to have children and wanted to be a mother, but was absolutely convinced I could have it all, be a mom and have a career and be satisfied from all of it. From the moment she arrived, this vision was shattered. All I wanted to do was care for this small, helpless being. Amazing to know we had made her from nothing but instantly felt, on a primal level, the need to care for her and protect her above ANYTHING else in my life. The thought of dropping her off at daycare at 6 months old to return to work was now so shocking and so against my desire and my plan you could truly apply the term insanity.

During the transition to combining career and family, the form of narrative identity work I label experimenting reveals the process of identity adaptation as a woman engages in trial and error with different ways of being both a mother and professional/manager. For example, US14 decided to take on the role of stay-at-home mom, an identity she had envisioned since adolescence, but soon altered the image of who she would be as a professional and mother when this first approach turned out to be disappointing:

Finally, goal achieved. I'm a mother. This is not as thrilling as I thought it would be. Also, we need more money to buy a house and we can't live on [my husband's] income alone. I look for a job and find a full-time job as a Product Specialist at [company name]. I don't think I'll enjoy being a stay-at-home mom. This was my dream, but it's way too boring for me. I now need to learn to manage work/life balance as a working mother. 
In another case, CA06's experimenting at the transition to motherhood reflects identity

adaptation in how she recognized that her high-powered job and "career woman" identity did not align with who she wanted to be as a working mother:

So I put my kids in daycare and I'm like looking for a mommy job, OK? Really all I wanted was a mommy job to, well I call it mommy job, to balance out the responsibility on my husband and keep my career alive. This is what I was looking for, or at least what I should have been looking for. And what I ended up getting was this high-profile, crazy career job that paid really well, in the six figures, and would have been a dream for a young, single 30 year old, probably male, who like didn't care about sleeping.

....and relinquished her vision of reaching the upper echelons of an organization while her children are still young:

...I think I'm in a learning phase. I'm willing to admit that I'm probably not going to be the next CEO, not in the next 10 years.

As these examples illustrate, four different forms of narrative identity work, shedding, modifying, transforming, and experimenting, all expose a higher-order identity process in which a woman lets go of constraints on who she is and who she will become and envisions new possibilities. Further, she acts upon these visions by letting go of past identities and/or trying on new ones. Accordingly, identity adaptation represents how women make changes to their selfconcept, revising how they see themselves as they work through significant transitional periods.

Identity Expression. Three forms of narrative identity work across the transitions provide evidence of a third higher-order identity process that may be conceptualized as identity expression. This identity process involves acting upon and seeking to convey a chosen identity and/or a core sense of self in making choices about one's professional and personal life. In the early career transition, both claiming and projecting reflect identity expression in the way in which a woman clearly articulates for herself who she is and/or is going to become and then chooses a career path that allows her to convey this present or future identity. At the transition to motherhood, preserving reveals identity expression in a woman's efforts to demonstrate to 
herself and others that no change in her personal and/or professional identity has taken place. In other words, she expresses an unaltered sense of self in how she crafts her day-to-day life during her maternity leave, and in the plans she makes for how she will engage in work and family. In combining career and family, enacting speaks to the process of identity expression by exposing how a woman proclaims who she is through her work/family choices. That is, whether continuing to pursue her high-powered career, changing jobs or employers, moving to part-time or reduced load, taking a career break, and even attempting to carve out personal time, a woman engages in identity expression by asserting, "This is who I am" in how she crafts her career and family life.

Beginning with the early career transition, the form of narrative identity work I label claiming speaks to identity expression as a young woman declares who she believes herself to be and carries this identity into the start of her independent adulthood and the beginning of her career. For example, US12 describes the start of her career as overcoming the challenges of working in the most demanding group of an extremely challenging industry and claims her identity as a "well-respected analyst:"

I kind of fell into investment banking; like it was probably the most rigorous thing that you can possibly do... So, I mean I liked it a lot, I mean I did well. So, I got placed in one of the most demanding groups, which is mergers and acquisitions. And then investment banking is real good, but tough, and I made a lot of mistakes at the beginning. But eventually I kind of made my way, and figured out how to work all the systems, and get all the data, and get all the models right. Because at the end I was a pretty good, wellrespected analyst.

In so doing, US12 is expressing her identity as a competent, intelligent woman capable of succeeding in an occupation that is known for being extremely competitive and male-dominated.

The form of identity work I label projecting reflects identity expression at the early career transition in how a young woman creates an image of who she plans to become in the future and embarks on her career with this goal in mind, taking the proper steps to achieve the identity she 
sees as "meant to be." Projecting also reflects identity expression in how a woman embarks on her career with a vision of becoming professionally accomplished. For example, US03, an immigrant to the U.S., describes securing her first professional job with a prestigious consulting firm and envisioning a successful future career:

...now, I was professional and in charge of decisions, rather than being a student living in the well-protected environment of campus life and focused on classes and social life. Having this first job initially gave me confidence, energy and desire to achieve great heights career-wise.

In reflecting upon her decision to remain in the U.S. and to build her career in this foreign country, the process of identity expression is evident in how US03 asserts her identity as an independent woman who saw herself as a success for overcoming her lack of experience and understanding of the Western world and making it on her own:

I guess any other person who comes from a more traditional background, who was born in US, it may appear as a slow career trajectory. I could have maybe been a manager by this time, but for me it was a big achievement, I felt, because I was sort of closing up a huge gap that I had in terms of understanding what is around me and how this new world functions. And the other thing is I didn't have any guides in this world. I was alone, yes, and I did not have a support network to explain this world.

At the transition to motherhood, the form of narrative identity work I label preserving

reveals how a woman continues to express her pre-motherhood sense of self even as she takes on the role of mother. For example, CA01found it very difficult to be home during her maternity leave; that is, she engaged in preserving her professional identity in the story she tells of wanting to get out of the house on her own, and of longing to be at work rather than home with a baby:

I was happy to have the child and there's sort of all sorts of pictures of me smiling. But, my God, it was tough. It was really, really tough. And I remember waiting for him to come home, you know, "Here!” type thing. And I had some very temporary help. I had someone come in two days a week for couple of hours just so I could go and get a sandwich or something. But, it was tough...It's not my preferred time with my kids. I found it hard. They are little, they are crying all night. And so I would rather have a nanny around me, get on the train in the morning with my cup of coffee, and come back at the end of the day. 
The image CA01 creates of going off to work on the train with her coffee is an expression of her independence and the centrality to her identity of having a life outside of the home. In another example, CA02 engages in preserving her pre-motherhood sense of self by describing her new baby as an accessory that had no impact on her day-to-day life. In so doing, she engages in identity expression by minimizing motherhood and emphasizing the continuity of her work, personal life and independence:

I would take him to the park but I would also go, take him to lunch meetings. I would go to the gym or I would go meet with friends and he was like an accessory. He wasn't the focus of anything. And it was really interesting that my life hadn't really changed. It hadn't really changed. I was still doing everything I normally would have done. I just had more things to carry.

In the transition to combining career and family, identity expression is evident in enacting; that is, an asserted self-concept is expressed in how a woman's decisions regarding how to combine career and family are driven by a desire to craft a life that aligns with her professional and/or mothering identity. For example, US09 expresses the centrality of her work identity by linking her decision to continue working full-time as a professional to a visceral sense that not working is simply not an option:

I mean, just for me it's very important to work...I mean, like mental sanity. But also just as a base level, there is no other option. But, I mean having the family is the best, and having work is nice. So, I mean I wouldn't chose work over family, family comes first, but I love working. And I love spending quality time with the kids.

In another example, CA09's enacting at the transition to combining career and family reflects the process of identity expression as crafting a life that reflects the independent career women she always believed she would become; that is, by continuing to work full-time and to progress in her career while raising a family expresses the identity of someone who, "has it all:"

...I knew I always wanted a career that was sort of my independence and being selfsufficient. And I've been successful on that and I'm very proud of that. And then I've always wanted children, so I feel very fortunate. I feel very successful on those fronts and I think I'm a good mom. 
While these examples are reflective of women asserting their professional identities, other women engage in the process of identity expression by reducing their commitment to work, by going part-time or by taking a career break. That is, some women express a caregiver or mothering identity in the choices they make to reduce a focus on work and prioritize the needs of their families. For example, US18 returned to work in a four-day-per-week arrangement at the end of her maternity leave. However, she quickly realized that between her husband's demanding job as a corporate attorney and her job in business development, their family life was not reflective of her values nor of who she wanted to be as a person who prioritizes the people in her life. Her written reflection articulates how her decision to take a career break was an expression of her sense of self as an independent person who is unafraid to do what she believes is right for herself and her family:

For this final and most recent transition, I can easily see how my previous experiences have shaped my decision: Building a sense of independence, learning to appreciate that we only have one life and it would be sad to waste it doing something unsatisfying or unfulfilling, prioritizing the people in my life, gaining confidence in myself and who I am as well as confidence to follow my heart when logic and practicality might differ - this understanding of myself provided a great foundation for me to make this choice. My choice to leave my job above made me feel as though I was being authentic to who I am.

As all of these examples demonstrate, recurring themes within and across the three transitions reveal how the narrative identity work I uncovered in my informants' stories of the early career transition, the transition to motherhood, and the transition to combining career and family reflects three higher-order identity processes. As revealed by the variation in the forms of narrative identity work that characterize each process, identity exploration, identity adaptation, and identity expression represent the fundamental means by which a woman's sense of self is constructed, revised and/or preserved, and presented in particular ways during times of significant transition. 
Beginning with identity exploration, this process is manifested differently in each transition, but is consistent in its nature; that is, regardless of the turning point, identity exploration entails openly questioning one's self-concept. In the early career transition, identity exploration involves trying to figure out who one is going to be as an independent adult and a budding young professional. This transition stands out as the first time a woman is stepping out onto her own path and looking for her own identity. In the transition to motherhood, on the other hand, identity exploration involves questioning who one has become now that "mother" has been added as a new identity. Having worked for a number of years, and possibly having earned an advanced degree, a woman has developed a sense of professional identity. In experiencing pregnancy and childbirth, she transitions from a childless woman to a "mom.” Accordingly, identity exploration means revisiting the questions, "Who am I?" and "What do I really want?," but the inquiry is now more complex than it was at the early career transition, involving the addition of new, foreign identity. Lastly, in the transition to combining career and family, identity exploration represents a struggle to come to terms with who one is/wants to be as she makes some significant life decisions. At this point in time, a woman is trying to figure who she is going to be moving forward, in the context of what is essentially the start of a new life.

As is the case with identity exploration, the process of identity adaptation is manifested differently in each transition, yet the nature of this process remains consistent; that is, regardless of the type of turning point, identity adaptation involves actively altering one's sense of self. In the early career transition, this identity process involves letting go of a previously adopted identity, whether this identity was imposed by one's parents or developed via some other influence, and imagining becoming someone/something different. In this case, identity adaptation is the process of a) acknowledging a disconnect between one's sense of self and the 
path one is on, and b) ridding oneself of a projected identity. At the transition to motherhood, identity adaptation involves embracing the new identity of mother and allowing it to alter one's sense of self. For some women, identity adaptation at this stage involves a shifting of priorities, primarily in terms of allowing one's mother identity to move into equal or greater focus than one's professional identity. For others, it involves a complete metamorphosis as one's mother identity completely overwhelms one's professional identity, and a woman must alter her sense of self to accommodate this profound change. At the transition to combining career and family, identity adaptation entails playing with provisional selves; that is, actively trying out different identities, such as “working mother” "stay-at-home-mom” or "part-time professional," adapting to these different identities in order to choose the one that feels right.

Finally, the process of identity expression is manifested differently in each transition, but the nature of this process is consistent in terms of asserting one's sense of self; that is, declaring to herself and those around her that, “This is who I am,” or, “This is who/what I am determined to become.” In the early career transition, this process is reflected in how a woman asserts her sense of self by claiming who she is in the present, or by declaring who/what she plans to be in the future. Having yet to live and function as an independent, self-supporting, young professional, identity expression at this point in a woman's life is focused on presenting herself to the world in a way that legitimates her present and/or intended future identity. At the transition to motherhood, identity expression involves asserting that becoming a mother has not altered one's sense of self by resisting both the open questioning involved in identity exploration, and the revising involved in identity adaptation. That is, rather than wondering about who one is as a mother, or embracing motherhood as a new and powerful identity, identity expression involves a woman asserting that she has not changed as a person. In combining career and 
family, identity expression entails a woman affirming her sense of self in the choices she makes about how to engage in work and family. For example, some women proclaim that they could never be stay-at-home moms and assert this by returning to their professions and continuing to dedicate oneself to advancement. Other women engage in identity expression at the transition to combining career and family by declaring that work had become less central to their sense of self and affirm this by going part-time/reduced load, or perhaps even taking a career break.

Although the three identity processes are reflected in different forms of narrative identity work in the various transitions, the nature of each process is the same across individuals and in all three transitions. That is, regardless of the transition, there is evidence of seeking answers to the questions, “Who am I?” and “Who/what do I want to be?” (i.e., identity exploration), actively changing /accepting a sense of change in one's identity (identity adaptation), and asserting one's sense of self (i.e., identity expression) in response to the changing circumstances in one's life. Accordingly, I posit that these three identity processes are the fundamental means by which a professional/managerial woman's sense of self evolves over time. As previously noted, this is not to suggest that every woman engages in all three processes in every transition, nor do my findings reveal that these processes form a neat, recurring cycle of exploration in the early career transition, adaptation in the transition to motherhood, and expression in combining career and family. Rather, while I did find evidence of all three processes in all three transitions, identity exploration did appear to be the dominant identity process in the early career transition, while identity adaptation seemed to be the dominant identity process in the transition to motherhood. That is, both searching and shedding then searching were uncovered as the most prevalent forms of narrative identity work in the early career transition, and both reflect the process of identity exploration. This is not an unexpected result, of course, as the adult development and careers 
literatures have long indicated that individuals engage in seeking and developing their adult identities as they end their time as dependent children and venture out to choose an occupation and become independent citizens. In the transition to motherhood, however, the dominant identity process appears to be identity adaptation as revealed by two forms of narrative identity work that were discovered in stories of this significant turning point: modifying and transforming. Taken together, these represent the most prevalent form of narrative identity work at this transition. Once again, this is not an unexpected finding as the extant literature has demonstrated that becoming a mother is often experienced as an identity-altering event.

While I uncovered a dominant identity process in both the early career transition and the transition to motherhood, all three identity processes appear to be equally prevalent in the transition to combining career and family. That is, given the diversity with which women navigate this particular transition period, I find evidence of identity exploration and identity adaptation, both operating as distinct processes and together as complementary processes, as well as strong evidence of identity expression in women's stories of figuring out how to be both professionals and mothers. Further, given that the transition to combining career and family is an extended transitional period in a woman's life, it seems plausible to expect a series of identity processes to occur. As women have additional children, and/or their job, financial, marital, etc. circumstances change, some who were expressing their sense of self may find this has become a major challenge, while those who were stuck in the process of identity exploration may figure out who/what they want to. For those who narrated both identity exploration and identity adaptation in transitioning to combining career and family, their experimenting may finally result in a solution that provides for identity expression. 
The discovery of the three identity processes in all three transitions suggests that, with each new transition, a woman's self-concept continues to form and evolve. Furthermore, we may presume that at the start of each transition a woman's sense of self is in a different state. Specifically, at the early career transition, the possibilities for who one may become are essentially endless; the transition to motherhood, on the other hand, is much more constrained because a new and distinct identity is added and must be confronted; at the transition to combining career and family, many professional women with children have a number of choices regarding how they reconcile their professional identity and mother identity, and making these choices is challenging, with significant implications for a woman’s career and identity. Therefore, in order to glean insights regarding how individual women's identities evolve over time and through these three transitions, I identified and examined the identity processes that are evident in each of my informant's self-narratives, in all three transitions. In the following section, I introduce and explain the four most prevalent patterns of identity processes across transitions that I discovered. In so doing, I attempt to provide insight into the various ways in which professional/managerial women engage in exploration, adaptation, and expression over time. Ultimately, I lay the foundation for building theory regarding how these identity processes help us understand how women’s identities evolve over time and across the significant transitions that are involved in pursuing a professional/ managerial career and raising a family.

\section{Part III: Identity Process Patterns Across the Three Transitions}

As demonstrated by the previous section, the variation in narrative identity work that is evident in professional/managerial women's stories of three significant transitions can be understood to represent three essential identity processes: exploration, adaptation and expression. According to the between-case themes, it is clear that each of these identity

processes is going on for some women in the early career transition, the transition to 
motherhood, and the transition to combining career and family. The data analysis within and across these transitions suggests that these processes constitute the higher-order means by which identities are constructed, revised and presented through major turning points. They illuminate how and why women are similar and different in how they narrate their navigation of important career and life transitions. In this section of the Findings chapter, I address my third research question: How does a narrative identity work lens help us to better understand the evolution of women's identity over time, and through the significant transitions involved in pursuing a professional/managerial career and raising a family? In so doing, I focus on patterns of identity processes across transitions within each self-narrative. That is, I concentrate on illuminating what can be learned from the identity processes that are reflected in individual women's narrative identity work, beginning with the early career transition, through the transition to motherhood, and into the transition to combining career and family. In taking this approach, I find that while individuals may be engaged in more than one of the identity processes at any given transition, their narratives suggest that one process, or a combination of two complementary processes, was typically dominant in each transition. I also find that, in some cases, the same dominant identity process was evident in all three transitions; in other cases, the dominant identity process varied by transition.

As shown in Figure 1, addressing my third research question resulted in the discovery of four within-case, dominant patterns of identity processes across the three transitions. In this figure each identity process is represented by a particular symbol. For example, identity expression is drawn as an arrow to illustrate how women assert and proclaim who they are as they navigate a significant transition; identity exploration, on the hand, is depicted by a curve that slopes upward and then ends in a series of dashes to illustrate unresolved searching for 
answers to the questions, “Who am I?” and "What do I really want?” during a major turning point. Finally, identity adaptation is drawn as the Greek symbol, delta, to represent change; that is, how women recognize, accept, and act upon a change in their sense of self in the context of a significant transition. These three symbols, arrow, curved/dashed line, and delta, are shown in four different configurations in Figure 1 to illustrate the four patterns of identity processes that I uncovered through my within-case, across transition analysis. However, this is not to say that each of my 35 cases may be assigned to one of these four patterns, but rather that I observed four patterns that were common to at least 5-6 self-narratives. Two of these patterns, Unwavering Expression and Enduring Exploration, demonstrate how women narrate the three transitions in terms of a single, dominant identity process. The other two patterns, Iterative Alteration and Punctuated Expression, demonstrate how other women narrate the three transitions in terms of multiple identity processes within and across the three transitions that were investigated in this study. In the following section, I describe and present one example case for each of the four patterns. I then discuss what these patterns reveal about the meaning and identity implications of each transition.

INSERT FIGURE 1 ABOUT HERE

\section{Pattern 1: Unwavering Expression}

One pattern to emerge from seven of the self-narratives reveals how some women tell stories that reflect identity expression in the early career transition, the transition to motherhood, and in the transition to combining career and family. Of the cases that constitute this pattern, six informants were working full-time at the time of the second interview, and one was working part-time. In this pattern, the process of identity expression is found across all three transitions; that is, in a woman declaring who she is and asserting her sense of self as she embarks on her 
career and crafts a professional identity, in taking on a motherhood identity, and in combining the two. In these Unwavering Expression narratives, women tell stories of entering early adulthood with a keen understanding of who they were, and/or a vision of who/what they felt destined to become in the future. In narrating the transition to motherhood, these women describe themselves as relatively unchanged, and continue to profess, "I know who I am” even though "I" is now both a professional and a mother. In their stories of transitioning to combining career and family, they continue to profess their identities in how they approach engaging in work and family. In essence, through their self-narratives, these women assert that who they are today is essentially a more fully developed version of who they were/felt destined to become when they left university. In Figure 1, this pattern is visually depicted by a series of arrows that conveys a straight path in which there is very little change. That is, women who engage primarily in identity expression across all three transitions assert who they are/who they will become in the early career transition, and then charge ahead, declaring, "This is who I am!” through subsequent transitions.

An example of the "Unwavering Expression” pattern is found in the case of US08, mother of three children and full-time Director in the pharmaceutical industry. Her self-narrative reveals a pattern of projecting in the early career transition, preserving in the transition to motherhood, and enacting at the transition to combining career and family. All of these forms of narrative identity work reflect the higher-order process of identity expression. She begins her story by describing how, at a very young age, her mother encouraged her to become a financially independent woman:

And my mom started lecturing me every single day about being financially independent, so I wouldn't get screwed like she did. She told me this, like every day. She told my friends. Not like men are bad, but just, "You should be financially independent." 
US08 projected this sense of self in the early career transition. She launched her career as an actuary, leading the kind of financially independent life she expected herself to be leading:

Had a full-time "real" job, married, lived in a great city far from family. Worth noting that the details were all surprising, but this isn't far off from what I'd "expected" to be doing when in college or even earlier.

She continues to express her identity as a career woman in her story of following her husband to a new city, and spending a few months as an unemployed spouse, “...it was like the most traumatizing thing in the world. Because I just could see they viewed me as like, 'the wife without a job.' I couldn't deal with it." Through the transition to motherhood, US08 describes identity expression in the form of preserving her professional identity:

I think I just changed how I worked, because I was much more like, just about getting the job done, and that kind of thing... not letting people down. Because I didn't want to not do a good job, but also because you don't want people to think like, "Oh, you know, she had a baby and now she doesn't do her work.”

In combining career and family, she enacts her professional identity by returning to full-time work after the three-month maternity leave provided by her employer. Interestingly, US08 admits that she does not actually enjoying working: “...every time in my life I've been in that situation, where I am not working but I have a job, best ever! Yeah. Because I don't like working very much.” Rather, her career is important because it validates her core sense of self:

I only emotionally considered not going back to work, I never really considered it. Like I mean I would have... like, I didn't want to go back to work. But I knew I was going to go back to work. Because I just wasn’t going to be a stay-at-home mother.

As demonstrated by this example case, some of the women in my study narrated all three transitions in terms that reflect identity expression as the dominant process. Through their stories, these women assert that they have answered the questions, "Who am I?" and "Who/what do I want to become?” at the very dawn of, or even before they started, their careers; and that they have maintained their responses to these questions through the transition to motherhood and 
in combining career and family. In general, the cases in which the dominant process across all three transitions is identity expression reflect the importance that some women place on having a career; however, this is not to say that these women describe their family lives as less important, but rather that being independent and having a professional career is an important, and unwavering, element of their sense of self.

\section{Pattern 2: Enduring Exploration}

A second pattern to emerge from my data was revealed by five self-narratives in which my informants were primarily engaging in the process of identity exploration in all three transitions. In this pattern, three of the women were taking a career break at the time of the second interview, and two were working part-time. The women who narrate this pattern tell stories in which they embarked upon their careers without a clear sense of direction or a known destination; rather, they entered early adulthood with many more questions than answers about who they were and who they hoped to become. Through the transition to motherhood, and in the transition to combining career and family, their stories reveal how some women revisit the questions, “Who am I?” and “What do I really want?” each time they face a major turning point involved in crafting a professional career and raising a family. Accordingly, in Figure 1, this pattern is depicted as a series of curves that end in dashes. As the image conveys, this pattern suggests that some women openly question who they are and who/what they want to be as they embark on their careers, become mothers, and figure out an approach to combining their professional and motherhood selves. It is important to note that these questions frequently remain unanswered. That is, while a woman's self-narrative may include stories about advancing in her career, changing employers and/or occupations, or even taking a career break, 
there is no evidence of acknowledging and accepting a change in her sense of self, nor of declaring, "This is who I am.”

For example, the narrative recounted by US02 is a compelling example of the Enduring Exploration pattern. US02 spent several years working as an engineer, completing her master’s degree while working full-time, before getting pregnant and deciding to stay home with her baby. She describes identity exploration through searching for her professional self at the early career transition:

I grew up where it was the first generation where women could be whatever they wanted to be, and I wanted to make the most of it. I think I wanted to see how far I could I go, honestly. I knew I would be successful, because I'm smart. That was just engrained in me growing up. Beyond that, where it would lead me, I wasn’t quite sure.

As her story continues, she reveals that she quit her job as senior product development manager one month before her first child was born. In her story of the transition to motherhood, she again describes identity exploration as she interrogated the reasons she had had multiple miscarriages, questioned whether or not to take maternity leave and return to her employer, and considered taking a career break, after realizing that she had finally achieved a pregnancy that was likely to be successful:

...[having a miscarriage] kind of takes over your whole mentality, though. You kind of put other things to the side. Okay, what happened? Why did this happen? Is it something in my job that created this situation? Is it something, just because I'm a little bit older and it happens? So it started whole investigations of those things because I'm an engineer. I want to know why... [After announcing my pregnancy] I let things play out [at work] just to see where they would go, and I didn't like the direction that [the employer and management team] were going.

In combining career and family, US02 explains how she was preparing to re-enter the workforce when she discovered that she was pregnant with her second child. Her story continues to reflect identity exploration as she describes grappling over letting go of her plan to return to work and returning to being home taking care of a baby: 
I was considering calling up [former employer] to see if they had anything in the marketing area that they needed some extra help with, on a part-time basis. By the time I was ready to make the call, I found out I was pregnant.... [I was] grateful for the chance to have that second child, but I kind of had to switch gears pretty quick. So that was where the mixed emotions came in... We were already out of diapers; we were just kind of moving on to the next step.

The process of identity exploration continues in US02's story as she anticipates where her life and career might be headed, with very little direction:

So now I'm wrestling with, "What do I do next?” Because now that she's two, I better start planning ahead a couple of years ahead and see where I might want to be. Or, if I need to get certified for something different or...I'm thinking part-time, definitely... Sitting in the house is not something that I care to do...I'm not sure yet. I don't think I'll ever be sure. Just because I like, I don't like to be bored, I don't like to be static. I don't ... so you never know what's going to come around the corner.

As this case demonstrates, the pattern of Enduring Exploration reveals how some women engage predominantly in the process of identity exploration in all three transitions. That is, their stories reveal how the questions of, "Who am I?" and "Who/what do I want to be?” are reflected upon at each significant transition. In general, these narratives expose a hope that satisfying answers to these questions will be found, and/or that the ongoing search will be interesting and enjoyable, as women continue to contemplate where their careers are headed and how they want to engage in both work and family.

\section{Pattern 3: Iterative Alteration}

A third pattern to emerge from my data was revealed by seven self-narratives in which my informants engage in identity adaptation followed by identity exploration in the early career transition, identity adaptation in the transition to motherhood, and identity exploration followed by adaptation in the transition to combining career and family. Of these cases that reveal this pattern, three were working part-time, two were working full-time, and two were taking a career break at the time of the second interview. I label this pattern, Iterative Alteration, to represent the step-by-step identity changes that take place in these stories. In other words, the change that 
takes place over time is an iterative process of experiencing an altered sense of self and reflecting upon this before making further revisions. This pattern is depicted in Figure 1 as a series of deltas and curves. Specifically, the pattern begins with a delta followed by a curve to illustrate shedding then searching at the early career transition. That is, the women who narrate this pattern first engage in identity adaptation when they experience a revelation that the identity they had chosen was no longer who they wanted to be/become. In most cases, this involves rejecting a particular, planned-upon professional identity. However, identity adaptation is incomplete in shedding, in that although an identity change has been acknowledged, there is no immediate switch from a rejected identity to a newly accepted one. Accordingly, identity exploration serves as a follow-on process to adaptation as these women search for who/what they really want to be. At the transition to motherhood, identity adaptation is illustrated by the delta in Figure 1 to indicate modifying or transforming, in which a woman senses that her priorities have changed, or that something fundamental about her sense of self has changed, and then accepts that change. In the last transition, the process of identity exploration recurs and is followed by identity adaptation to reflect experimenting in the transition to combining career and family; accordingly, the pattern terminates in a curve that leads into a delta. Specifically, by imagining possible selves in terms of how one may be both a professional and mother, a women engages in exploration; by trying out provisional selves she engages in identity adaptation by actively making changes, accepting some and rejecting others. In sum, this pattern demonstrates how professional/ managerial women's identities evolve through an ongoing learning cycle in which change is the only constant. However, whereas the Enduring Exploration pattern reflects an ongoing search for who and what one wants to be, the Iterative Alteration pattern speaks to constant revision and renewal. 
A case illustrating Iterative Alteration is CA15, who at the early career transition planned to marry her college boyfriend, a writer from a wealthy family. Despite her own love of literature and writing, she assumed that she would be content to "live in the shadow of greatness.” When the engagement broke off, CA15 shed her planned "dependent spouse” identity and went on to explore different options for crafting her own independent life and career:

I was planning to get married, quit my job, and move to [UK] where I would attempt to find work while my spouse got his $\mathrm{PhD}$. Thereafter the plans were rather vague but it was assumed that I would be the "trailing spouse." Once the relationship ended, I realized that that was not at all the future that I wanted - I wanted to be financially independent with a proper career of my own.

CA15's exploration took her to several countries in Europe and multiple jobs until a serious illness caused her to return home to Canada. She eventually pursued an MBA, got married, and gave birth to her only child. In transitioning to motherhood, CA15 describes identity adaptation in her written reflection about her experience of becoming a mother:

Hard to summarize how much I feel like motherhood has changed me... mostly for the better. For sure, I am far less driven to advance my career by any means possible and that has had some repercussions. And I feel fulfilled in a manner that I could never have imagined.

CA15 explains that she had hoped to be able to stay home with her daughter and pursue other life interests beyond her marketing career:

I thought I might eventually go back to school. I thought this would be like, foolishly, I thought this would be really a time for me for like self-exploration. I don't know what I was thinking, but it seemed I thought I would have kids on the side and then really be able to invest in myself.

Unfortunately, in the transition to combining career and family CA15 found that her husband's salary could not support the family's lifestyle, and she had no choice but to return to the job she held before going out on maternity leave. In so doing, however, she engaged in both 
processes of identity exploration and identity adaptation as she tried to rekindle her career

ambition while longing to be spending more time with her daughter:

...when I dropped her off at day care, I had like pictures of her on my desk and I would just stare at her all day long. And a couple of months in, I was like, "This is not working." So I put away the pictures and I kind of compartmentalized. I was like, "I am just going to pretend to be like a man here. I am going to drop my kid of at day care. I am going to focus on work.” ... it was very helpful in terms of compartmentalizing, really; I think it sometimes helps in terms of focus. I tried to find a little bit of the pride that I used to have in my professional performance... it was there, but it was just kind of hidden under some blankets...Yeah I dug it out. I kind of dusted it off.

CA15's self-narrative also provides a foreshadowing that, for some women, this pattern of adapt/explore-adapt-adapt/explore may ultimately be a search for identity expression:

...it's been very difficult for me and I have done a lot of work on trying to marry more closely the idea of who I want to be and who I actually am, because the friction of not being who I want to be was wearing me down, was making me really anxious and depressed.

Whether or not CA15 will find a way to express both her ambitious career-woman self and her motherhood identity in how she combines career and family is a chapter in her self-narrative that has yet to be written. However, the desire for identity expression is quite evident in her narrative, as well as in several other narratives that follow this identity process pattern.

\section{Pattern 4: Punctuated Expression.}

A fourth pattern to emerge from my informants' stories is: identity expression, followed by identity exploration and/or identity adaptation, followed by a resurgence of identity expression. Of the six cases that reveal this pattern, three were working full-time, and three were working part-time, at the time of the second interview. This pattern reveals how some women narrate the process of identity expression in the early career transition by asserting who they believed themselves to be and/or who they would become, but then reveal identity adaptation in their stories of the transition to motherhood. These altered identities are then expressed in stories of the transition to combining career and family. Accordingly, this pattern is 
depicted in Figure 1 as a straight arrow that points to the bottom left corner of a delta, followed by a second straight arrow that begins at the same level as the peak of the delta. This image conveys how some women engage in identity expression in the early career transition and again in combining career and family by asserting, “This is who I am” in both transitions. However, the delta in the middle represents identity adaptation at the transition to motherhood.

Accordingly, the identity being expressed in combining career and family is different and therefore represented as an arrow on a different plane. It is important to note that in some of these self-narratives, identity adaptation at the transition to motherhood began with identity exploration; in others, identity adaptation was narrated as an immediate reaction to motherhood. In both cases, the transition to motherhood is recounted as an identity-altering experience that is preceded and followed by identity expression.

A good example of the Punctuated Expression pattern is found in CA13's narrative in which we find the unfolding of a story that comes full circle; that is, from identity expression in the early career transition, to identity exploration and adaptation in the transition to motherhood, and a return to identity expression in the transition to combining career and family. CA13 describes leaving Europe and moving to Canada after graduating from university to take on a managerial job. Evidence of identity expression is found in the story she tells of becoming the projected image of an independent woman responsible for her own success that was crafted in her childhood:

There are not that many people who immigrate at such a young age and get a job, and it was good job, it was well-paid. And I was like, “Wow, I'm doing good.” Because it's not something that was reinforced when we were brought up, "You're going to do great." It was more, "You do whatever you have to do to make it happen.” So I felt like I did everything good to make it happen.

In the transition to motherhood, evidence of identity exploration is found in how CA13 recounts interrogating the very essence of her identity upon the birth of her first and only child. 
The struggle was so intense that she was unable to refer to herself as a mother for the first six months of her son's life:

The first few months I would say was, it was tough. It was tough more on my side because I felt like I wasn't myself anymore. I was just a mother, but I wasn’t myself. And the, I was still hurting quite a bit from the delivery, because it lasted a couple of months and I didn't feel like comfortable in my own skin. And it was not about the weight or anything. It's just like I wasn't into that role yet so it was both physical and mental also. ...It took me a long time to call myself a mom. Probably six months. I would address [my son] and say, “Come see me.” I wouldn’t say, “Come see mommy.” I was like, "Come see me."

As CA13 continues her story, she provides evidence of engaging in the process of identity adaptation as she began to embrace her new mother identity and to enjoy spending time with her son. In fact, she took an extended maternity leave that became a career break as she quit her job and remained out of the workforce for two years. She explains how, after resisting motherhood for so many months after childbirth, she finally embraced it and began doing more things with her son in the second year:

My first year I was so exhausted that I have very few memories of that year. I have a few, I have some pictures when you get new baby it's like... But the memory thing I think it really started for me the second year making events, making outings, making, going to the doll store and getting a little thing that you could play with. Something simple but that for me had some value, and I wasn't able to do it the first year.

In combining career and family, CA13's story reveals a resurgence of her identity as an independent career woman, indicating that she one again engaged in the process of identity expression as she transitioned from her two-year maternity and returned to work:

...when I started working I was like, "Oh my God! He’s going to be fulltime in the daycare.” It's not that I felt bad about it, because I knew that I needed to go back to work. I was never going to be that person that was going to stay at home. It was not me.

CA13's narrative demonstrates the power of the transition to motherhood to dramatically transform a professional/managerial woman's sense of self. However, it also shows the potency of some women's desire for identity expression, especially in combining career and family. 
Overall, CA13 tells a story that reflects both the process of identity expression, and the process of identity adaptation; that is, she professes a keen sense of self as an independent, successful woman, yet also explains incorporating a completely unexpected sense of herself as "mother." Specifically, her sense of self as an independent working woman is asserted in her story of the early career transition and again in the transition to combining career and family; however, she also describes herself as transformed by motherhood. In fact, she comments in her written reflection: ... who I am has changed so much. I define myself more now as a mom than even a woman. Accordingly, although she returned to full-time work at the director level in the industry in which she had developed her expertise, she explains that her primary criteria in her job search were proximity to home and flexibility. Herein we observe a case in which a woman re-engages in the process of identity expression in the transition to combining career and family, but the identity she is asserting is different from that which she proclaimed prior to becoming a mother.

In sum, my analysis of the within-case, across transition patterns of dominant identity processes revealed four distinct patterns, two of which included a single, dominant identity process, and two of which included some combination of identity processes. Specifically, Pattern 1, Unwavering Expression, reveals how a woman tells her story of journeying from a university student to a professional/ manager with children through the forms of narrative identity work that reflect identity expression in all three transitions. That is, throughout her selfnarrative, she asserts that she knows who she is and proclaims this unwavering sense of self from beginning to end. In Pattern 2, Enduring Exploration, identity exploration is the dominant process in all three transitions; accordingly, this pattern reveals how some women tell stories in which the questions, "Who am I?” and "Who/what do I want to be?” are revisited with each major turning point, and yet are never really resolved (or are resolved in between transitions and 
then re-engaged in during the transitional period). Patterns 3 and 4, Iterative Alteration and Punctuated Expression, on the other hand, demonstrate how some women's self-narratives expose multiple identity processes within and across the three transitions investigated in this study. In Pattern 3, Iterative Alteration, identity adaptation and identity exploration are narrated together in the first and third transitions, revealing how these processes complement each other to provide for continuous learning and self-renewal. Finally, in cases that reveal Pattern 4, Punctuated Expression, identity expression is the dominant process in the early career transition and in the transition to combining career and family, but is disrupted by identity adaptation in the transition to motherhood. Accordingly, this pattern reveals how a woman embarks on her career declaring that she knows who she is/is going to become, but then experiences a change in her sense of self when she becomes a mother. Acknowledging and embracing this change through the process of identity adaptation, she returns to identity expression in combining career and family by re-asserting, “I know who I am”, even though the proclaimed identity is now different.

The discovery of the four dominant patterns, Unwavering Expression, Enduring Exploration, Iterative Alteration, and Punctuated Expression provides important insights into how women's identities evolve over time and through significant transitions. However, these patterns also provide insight into the identity implications of the three significant transitions that were examined in this study. That is, rather than examining Figure 1 by looking across the rows that denote the four patterns, we may examine this figure by considering the identity processes that are present in each of the columns that represent specific transitions. While we find evidence of all three identity processes in each transition, we also observe that particular identity processes stand out over others at each turning point. Beginning with the early career transition, the two dominant processes are expression and exploration. While the discovery of exploration 
at this particular transition is expected, the discovery of expression is novel. That is, the adult development and careers literatures conceptualize this period as a time when individuals explore who they are going to be as adults by choosing an occupation and confronting the questions, "Who am I?” and "Who/what do I want to become?” However, the discovery of identity expression in this transition demonstrates that some women refrain from posing these fundamental identity questions and simply assert, “This is who I am” or “This is who I am going to become.” In the context of the stories provided by the professional/managerial informants in this study, these declarations essentially indicate that there is no question in the minds of these women that they are and/or will be independent, contributing members of society.

In the transition to motherhood, we observe that identity adaptation is the dominant process. In and of itself, this finding is not particularly surprising, as many scholars conceptualize this transition as having the potential to be an identity-transforming event for women. However, the observation that identity adaptation disrupts identity expression in Pattern 4 speaks to the powerful impact that becoming a mother may have on professional/managerial women. That is, a woman who confidently declared, "I know who I am” discovers that she is no longer who she believed herself to be. In addition, the presence of identity exploration in this transition in Pattern 2, and as a complement to identity adaptation in some cases of Pattern 4, demonstrates that this particular transition causes many women to question who they are when they take on a motherhood identity.

Finally, in the transition to combining career and family, we observe identity expression and exploration as the dominant processes. The discovery of identity expression in this transition challenges the idea that women are either career-oriented or family-oriented, or as simply in search of "balance" at this stage of their careers. By engaging in identity expression, 
women are proclaiming who they are in what they say about themselves and in how they combine career and family. For example, as seen in the case of CA13, a woman who works fulltime in a high-level position while her son attends daycare declares that she sees herself first and foremost as a "mom," but also as someone who could never be the "stay-at-home mom." Accordingly, she does not view herself as family-oriented, nor career-oriented; rather, she sees herself more globally as an independent woman who enjoys her career, but who is also a dedicated and engaged mother. The discovery of exploration in this transition demonstrates that combining career and family is, for some women, an opportunity for wiping the slate clean of past decisions and starting over as they pose open-ended questions about who/what they want to be as both a professional and a mother. As a standalone process, these questions go unanswered and therefore the possibilities are endless. However, as a predecessor to identity adaptation in Pattern 3, identity exploration provides for imagining different ways of being both a professional and a mother, such as stay-at-home or high-powered working mother. Adaptation then allows for taking on these provisional selves until she finds one that "fits." Accordingly, combining career and family is, for some women, a period of trial and error and thereby learning and renewal.

Investigating how the three identity processes manifest and interact in the four patterns provides important insights into the distinct nature of each process, and furthers our understanding of how women construct, revise and/or preserve, and present their sense of self through and across significant transitions. In addition, examining the four patterns illuminates how women's identities evolve over time, and provides important insights into how women navigate the significant, identity-laden transitions involved in pursuing a career and raising a 
family. In the following section, I discuss the theoretical insights that may be gleaned from the findings presented herein.

\section{Part IV: New Theoretical Insights on Women's Narrative Identity Work Across Transitions}

The various forms of narrative identity work uncovered in this study reveal three higherorder identity processes: exploration, adaptation and expression. These processes may be conceptualized as the means by which women construct, revise, and present their identities within and across three significant transitions involved in pursuing a professional/ managerial career and raising a family. Further, by examining the within-case configurations of identity processes and discovering four dominant patterns across the 35 cases, my study offers new insights into the meaning of women's narrations of their journeys from entering the world of professional/managerial work, to becoming mothers, to navigating the complex landscape of combining career and family. Specifically, I draw theoretical insights from the observations that, a) all four patterns begin and end with the same identity process, b) the process of identity adaptation is most prevalent in the transition to motherhood, and c) two of the patterns reflect the concept of "narrative closure" while the other two are lacking in this feature.

Coming Full Circle. The first observation that offers new theoretical insights about women's narrative identity work across transitions is evident from the patterns depicted in Figure 1; that is, all four patterns begin and end with the same identity process. This finding suggests that as women craft self-narratives and engage in narrative identity work in their stories of significant transitions, they make a connection between where they ended up and where they started. In other words, how they see themselves in the present appears to influence how they narrate about themselves in the past. This finding suggests that as women craft self-narratives and engage in narrative identity work in their stories of significant transitions, they seek to craft a 
coherent story in which the ending is somehow logically connected to the beginning. McAdams (1996) defines coherence as, “...the extent to which a story makes sense on its own terms” (p.315). As noted by Ibarra and Barbulescu (2010), “...a good story hangs together coherently from one episode to the next so that the turns of events are plausibly accounted for and the protagonist acts consistently from beginning to end.” These scholars posit that individuals use narrative identity work to revise and reconstruct their identities during macro work role transitions by crafting stories regarding the reason for the transition that others will find legitimate. In the context of the present study, however, the "story" incorporates multiple significant transitions rather than a single, macro role transition.

The self-narratives elicited and analyzed herein represent three major turning points and extend from the beginning of a woman's career to her present situation in which she is combining career and family. In essence, as conceptualized by narrative identity scholars, this self-narrative, or “story,” represents a woman’s identity. Accordingly, we may posit that women engage in narrative identity work, and in particular the identity processes that it reflects, as they craft self-narratives to represent who they believe themselves to be, and to make sense of how they got there. That is, by beginning and ending with the same identity process, the narrative reflects a coherent identity. Further, the results of the present study provide particularly strong support for the idea that individuals strive for coherence in their self-narratives, as the stories solicited involve significant transitions and changing life circumstances. In fact, even the patterns in which a major change takes place in the middle transition, Iterative Adaptation and Punctuated Expression, begin and end with the same identity process. Accordingly, my findings suggest that as women narrate across major transitions, how they see themselves in the present 
influences the way they view themselves in the past as they seek coherence in their own personalized story of the self.

Beginning with Pattern 1, Unwavering Expression, we observe that the women who narrate this pattern tell stories in which there is a connection between who they believe themselves to be in the context of combining career and family, and who they were/felt destined to become at the early career transition. Proclaiming, "I know who I am/who I am going to be," as they embark on their careers, they preserve/pursue this identity through the major turning points of becoming a mother and combining career and family. Accordingly, we may infer that these women make sense of who they have become by crafting a self-narrative in which they fulfill an identity quest. That is, the sense of self they express at the beginning of the story is essentially the same one that they express at the end. Similarly, in Pattern 4, women narrate the first and third transitions in terms of identity expression; however, this pattern differs from Pattern 1 in that there is a major disruption in the transition to motherhood as identity adaptation interrupts identity expression. Specifically, the self-concept that is expressed in the transition to combining career and family has been altered by the transition to motherhood. However, a woman who narrates this pattern declares, “I know who I am” even after experiencing a major change in her sense of self. Accordingly, we may infer that seeing herself as someone who has always been able to assert her identity allows her to express her new sense of self as a woman who is both a professional and a mother.

In contrast, those who narrate Pattern 2, Enduring Exploration, narrate the transition to combining career and family in terms of pondering the fundamental identity questions, "Who am I?” and “Who/what do I want be?” as they reflect upon what it means to be both a professional and a mother. However, they also narrate the early career transition in terms of having no set 
career plan nor a clearly articulated response to, “Who am I?,” or of rejecting a previous response to this question without a clear alternative. Accordingly, we may infer that these women view their continuous searching and openness to new possibilities as part of who they are, and who they have always been. That is, rather than seeing themselves as "lost” or lacking a sense of self, they may see themselves as free and unlimited.

Finally, those who narrate Pattern 3 begin and end with identity adaptation. In this pattern, women narrate combining career and family in terms of exploration and adaptation as they experiment with different ways of engaging in career and family, making changes and adjustments along the way as life's circumstances change, or when a particular approach no longer feels "right." Similarly, these women narrate the beginning of the early career transition in terms of exploring and adapting, only the order of these processes is reversed. That is, they begin with identity adaptation by letting go of a prematurely-adopted identity and, lacking an alternative identity, they engage in exploration as they ponder who/what they wish to be. Accordingly, we may infer that women who narrate Pattern 3 see themselves, or desire to see themselves, as flexible and adaptive; able to adjust to whatever life confronts them with.

The Power of the Transition to Motherhood. The second key theoretical insight to emerge from this study is the power of the transition to motherhood to alter, or call into question, a woman's sense of self. While previous studies have indicated that this transition has the potential to be identity-transforming for some women, the study presented herein reveals that this particular transition seems to have the most widespread impact on a professional/managerial woman’s sense of self. The observation that identity adaptation emerges as the dominant identity process in two of the four patterns, and that identity exploration emerges as the dominant process in another, demonstrates the power of this transition to change how a woman sees 
herself, and/or to cause her to question who she is. There are several ways to make sense of this phenomenon. For one, the transition to motherhood involves the addition of a completely new identity, versus the transition from child to adult/student to professional or the transition to trying to find a satisfactory way of engaging in different identities. Further, as evidenced by the stories analyzed herein, many women experience a completely unexpected reaction to motherhood that disrupts their projected plans for combining career and family. That is, some women narrate this transition as experiencing an unforeseen, overwhelming sense of not only wanting, but of needing, to protect and care for one's baby. Others describe an intense sense of loss or confusion with regards to what it means to be someone's mother. These findings indicate that how a professional/managerial woman's identity evolves is strongly influenced by how she reacts to becoming a mother.

Closure. The third theoretical insight that may be inferred from the four patterns is that, while some women indicate a need for closure in their self-narratives, others appear to be comfortable living with unanswered identity questions. Carroll (2007) conceives of the concept of closure as, “...the sense of finality with which a piece of music, a poem, or a story concludes" and contends that, "Closure is a matter of concluding rather than merely stopping or ceasing or coming to a halt or crashing. When an artist effects closure, then we feel that there is nothing remaining for her to do. There is nothing left to be done that hasn't already been discharged. Closure yields a feeling of completeness” (p. 2). In theorizing specifically about narrative closure, Carroll argues that narratives achieve closure, “...when all the questions saliently posed by the narrative are answered.” In the context of the present study, the salient questions in the self-narratives refer to, "Who am I?” and "Who/what do I want to be/become?” 
Interestingly, in Patterns 1 and 4, Unwavering Expression and Punctuated Expression, we observe a sense of closure in the third transition. In the self-narratives that expose Pattern 1, the recurrence of identity expression in all three transitions suggests that the questions of, "Who am I?” and "Who/what do I want to become?” are answered prior to the early career transition and then do not resurface. That is, rather than raising and subsequently responding to questions about who one is and/or will become, this pattern illustrates a resistance to probing the assertion, “This is who I am.” This observation allows us to posit that, as a recurring process, identity expression is a means of proclaiming and sustaining an identity by resisting questioning and change. Pattern 4, Punctuated Expression, on the other hand, exposes a desire for closure in the move from identity adaptation at the transition to motherhood to identity expression in the transition to combining career and family. In this pattern, we observe how claimed identities may be revised and then re-proclaimed. Specifically, although a woman declares, "This is who I am" or "This is who/what I am going to become" in the early career transition, the transition to motherhood sparks a change in her sense of self that she either questions and then accepts, or acknowledges and embraces without question. However, the re-surfacing of identity expression in the transition to combining career and family demonstrates how this process provides for emerging from questioning and/or revising one’s sense of self and re-staking a claim that, “This is who I am.” At the end of the narrative, there is a sense that the salient questions have been answered and there is nothing left for the narrator to do.

In contrast, we observe a lack of closure in Patterns 2 and 3. In Pattern 2, Enduring Exploration, identity exploration dominates all three transitions. By recurring, this process resurfaces open-ended questioning and searching with each subsequent transition. Accordingly, we may infer that the process of identity exploration provides for the opportunity to wipe the 
slate clean and renew one's identity with each major turning point. That is, rather than providing a path to closure, recurring identity exploration allows for continuously starting over, putting aside previous decisions made and paths taken, and re-posing fundamental identity questions about who one is and/or will become. Moreover, the nature of this ongoing process indicates that there is no urgency, nor even a requirement, to answer these questions by staking a claim that, "I know who I am," or to make any changes. Specifically, this pattern reveals that some women may not feel the need to achieve closure and therefore end their self-narratives without answering the salient questions that have been raised. In Pattern 3, Iterative Adaptation, on the other hand, the narrative ends with exploration followed by adaptation. However, as previously discussed, we observe exploration and adaptation over time in this pattern. In fact, in the cases that reflect this pattern, the stories of combining career and family indicate that the complementary processes of exploration and adaptation are ongoing; that is, many women reengage in these processes when they have additional children or when one other of life's circumstances changes. Accordingly, this narrative pattern lacks closure, as even though the salient questions have been answered for the moment, there is an expectation that the responses will change in the future. Again, we find that some women do not seem to need or want closure regarding who they are and who/what they will become.

The four identity process patterns uncovered in this study provide key insights into how professional/managerial women's identities evolve over time and through the significant transitions involved in crafting a professional career and starting and raising a family. Further, they demonstrate that most women who pursue careers and become mothers cannot be labeled as career-oriented or family-oriented, as this categorization glosses over the critical role that identity processes play in how women navigate the start of their careers in the transition to 
becoming a mother, and in figuring out how to engage in both work and family. Specifically, women narrate these key transitions in terms of fulfilling an identity quest, re-claiming the ability to assert one's identity, remaining open to all of life's possibilities, and being flexible and able to adjust to all of life's challenges. These self-narrations indicate that women do not see themselves in terms of prioritizing career or family, or even of seeking balance. In addition, the patterns reveal that not all professional women experience the same issues at particular career stages/ages, nor do they navigate key transitions in the same way.

In addition, this study not only confirms but strengthens the argument that the transition to motherhood is a particularly powerful turning point that leads many professional/managerial women to revise or question their sense of self as they take on the new identity of "mother." Some women emerge from this transition able to proclaim, "This is who I am" as they transition to combining career and family whether they feel the same or different. However, many women continue to question who they are or to engage in an ongoing process of questioning and revising their identities as they combine career and family. In these cases, pursuing both a career and a family life is an ongoing learning cycle that involves working through many changes in one's identity. And finally, the lack of closure in two of the four patterns helps us to understand that not all women have the need to stake a claim on a particular identity but prefer to remain open to possibilities or to ongoing learning and renewal. Accordingly, attempts at 'measuring' women's identity and assigning them to a category would ignore and even violate their very sense of self. 


\section{CHAPTER 5: DISCUSSION \& CONCLUSION}

Although identity has become an increasingly prevalent theme in work-family

research, the extant literature fails to explain how a woman's sense of self evolves over time as they work through the significant transitions involved in pursuing a professional/managerial career and raising a family. In fact, while scholars claim, “...integrating work and family life is intimately tied to constructions of identities” (Emslie \& Hunt, 2009), none provides a satisfactory explanation of how. The extant literature is rife with explanatory factors and theories regarding the impact of such constraints as inflexible employers, inaccessible/unfeasible HR policies, lack of spousal and/or supervisor support, etc. on how women approach combining career and family. However, identity-based insights into women's choices in the work/family realm are limited at best. In fact, the majority of work/family studies that apply an identity lens are quantitative and cross-sectional, measuring women's identity at a single point in time on a career vs. family identity salience spectrum. Such studies tend to categorize women as "careeroriented" or "family-oriented," as though women are inherently inclined to prioritize one domain over the other. Scholars who take a career stage/age-based approach suggest that women mainly seek "balance" over objective measures of career success (e.g., title, salary, etc.) once they have children, or posit that women generally face the same issues and progress in similar ways based on age/career stage. None of these perspectives is grounded in women's own life stories of journeying from university students to young professionals, to mothers, to women who are faced with combining career and family. Accordingly, we lack a holistic perspective regarding how women come to understand who they are, and how issues of identity are linked to women's pursuit of professional/managerial careers and motherhood. 
In the present study, I take a narrative identity work approach in order to gain a more nuanced view of how women develop a sense of who they are on the path to professional and mother. In so doing, I answer scholars' call to paint a more dynamic picture of identity work that reflects, "the accumulated understandings of a whole life’s experiences" (Ibarra \& Barbulescu, 2010, p.149). By applying a narrative identity lens, my research is grounded in the perspective that crafting a professional/managerial career and raising a family is dynamic; that is, it entails working through multiple transitions and ongoing decision-making. Specifically, I investigate narrative identity work in 35 professional/managerial women's stories of three specific transitions: the early career transition, the transition to motherhood, and the transition to combining career and family. In so doing, I address three research questions: 1) What is the variation in the narrative identity work professional/managerial women engage in as they construct stories about three significant life transitions: the early career transition, the transition to motherhood, and the transition to combining career and family? 2) What recurring themes, if any, can be identified in the kinds of identity work women engage in within and across significant transitions? and 3) How does a narrative identity work lens help us to better understand the evolution of women's identity over time, and through the significant transitions involved in pursuing a professional/managerial career and raising a family?

By addressing these research questions, my study provides important insights into how managerial/professional women's identities evolve over time in the context of journeying from university students to young professionals/managers, to mothers, to being faced with figuring out how to combine career and family. In particular, the results of my research indicate that there are three identity processes, exploration, adaptation and expression, through which women tackle the questions, "Who am I?” and "Who/what do I want to be/become?” during three major 
transitions. Further, my findings expose four dominant patterns of identity processes across transitions that provide a fresh perspective on women's choices regarding how they combine career and family. For example, rather than presume that women who take a career break are "family oriented" and those that continue working full-time after becoming mothers are "career oriented," or assuming that all women seek "balance” at the early/mid-career point, my research indicates that there is much more to the story. That is, rather than taking a career versus family focus, the three identity processes uncovered in this study, and in particular the four patterns of identity processes over time, suggest that women continue to question who they are/want to be, alter their self-perceptions, and/or declare, “This is who I am” throughout the transitional period of combining career and family. Accordingly, my research demonstrates that attempting to associate employment status or career stage with a woman's identity undermines the variation and dynamism with which professional/managerial women develop a sense of self in the context of their combined career and family lives.

My findings also suggest that women seek coherence in their self-narratives (consciously or unconsciously) even when they are narrating about major transition points and complex changes, and they achieve this coherence by linking the past and present through the same identity process. For example, a woman who narrates the early career transition as a time when she asserted, "I know who I am/who I am going to become” also narrates combining career and family in terms of identity expression. In other words, a woman makes sense of who she has become by demonstrating to herself and others that she is acting consistently in the beginning and at the end of her story, even if this consistency is disrupted in the middle (e.g., Punctuated Expression). In addition, my results strengthen the claim that becoming a mother is a potentially identity-altering event for professional/managerial women by demonstrating how the majority of 
my informants narrate this transition in terms of identity adaptation or exploration. I also provide theoretical insights into the distinction between "sense of self" and "identity" by examining how women experience a shift in their holistic view of themselves as a result of adding the new identity of mother. Finally, my study demonstrates that while many women seek closure in their self-narratives, many others craft self-narratives in which stories about the third transition are open-ended. This lack of closure suggests that some women see themselves as perpetually open to new possibilities regarding who/what they might become.

By uncovering three identity processes and four dominant identity process patterns across the three transitions, this thesis contributes to the identity work, women's careers, and workfamily literatures by providing an identity-based perspective on how women pursue professional careers and raise families. That is, by focusing on women's narrative identity work, the present study offers insights into how women see themselves, and how this view changes or remains the same, as they navigate three key transitions that provoke the questions, "Who am I?" and “Who/what do I want to be/become?” In the following sections, I discuss implications of these insights for theory and practice, as well as the limitations of the study, and directions for future research.

\section{Theoretical Implications}

The results of the present study make several theoretical contributions to the extant literature. First, by rooting my investigation in women's own life stories and examining how women develop a sense of self through the key transitions involved in combining career and family, I move beyond the orientation and career stage perspectives that currently dominate the literature. In so doing, I illuminate the potential for making inaccurate assumptions about the link between employment status and/or career stage, and women's identity. In so doing, I make 
a second theoretical contribution; that is, rather than attempting to categorize women based on a career versus family-identity salience continuum, or according to a generalized age/stage-based model, my approach exposes three identity processes through which women develop a sense of who they are. Further, by uncovering four dominant patterns of identity processes across the three transitions, I provide a fresh perspective on how women develop a sense of self over time, and through significant transitions. Third, by discovering the centrality of coherence in women's self-narratives, the power of the transition to motherhood to alter a woman's core sense of self and professional identity, and the variation in women's need for closure in their self-narratives, my study advances theory on women's narrative identity work. Fourth, and finally, by taking a holistic approach in this study rather than a career and/or family focus, my findings reveal a need to re-examine two dominant scholarly perspectives on the relationship between work and family; namely, work-family conflict and boundary work. In the following sections, I discuss each of these theoretical contributions in detail.

\section{Beyond Orientation and Career Stage}

At present, the literature is dominated by two perspectives that offer differing explanations for how and why women combine career and family in the ways that they do. The first perspective posits that women are inherently inclined toward career or family; in other words, women may be categorized as career-oriented or family-oriented, and their work/family decisions attributed to these orientations. Some scholars provide for a third category of women whose orientation is a form of "balance" or compromise, such as "adaptive lifestyle preferences,” assuming that the majority of today’s working women prefer to spend as much time with their families as they do with their work (Hakim, 2002). This perspective associates employment status with inherent preferences, and does not necessarily resonate with women's 
own self-perceptions. The second perspective attempts to link women's choices in the work/family realm to particular career stages. Several models have been presented in the literature and all generally conclude that, in early career, women explore who they want to become, and seek challenge and career progression, in early to mid-career, women seek a balance between work and family, and in mid to late-career, women re-focus on contributing to their organizations and communities, and/or on figuring out what they really want to do with their lives (Mainiero \& Sullivan, 2006; O’Neil and Bilimoria, 2005; Pringle and McCulloch Dixon, 2003). While this perspective acknowledges that women’s priorities and life focus evolve over time and is therefore more dynamic than the orientation perspective, it makes a sweeping assumption that most women face the same challenges, and manage them in essentially the same way, according to age/career stage.

The results of the present study demonstrate that women do not see themselves as “career-oriented” “family-oriented” or "balance-seeking,” nor do they face the same issues at particular age/career stages. Rather, my results suggest that women's career and life choices are driven by identity issues and different life transitions that are not necessarily related to age or career stage. These findings are important, as they suggest a dissonance between scholars’ tendency to place women into theoretical categories, and women's inclination to adapt, explore, and express who they are, in their own way, and on their own timeline. A number of sociologists have investigated women's career and family choices and concluded that women who continue to work full-time while raising their children are essentially “career-oriented,” while women who reduce their work hours or stop engaging in paid work altogether are "family-oriented.” For example, Arlie Hochschild (1989) argued that dual-earner couples enact three types of marital ideology that reflect a woman's identification with either work or home; in the "traditional" 
ideology, the woman is primarily identified with home activities, in the "transitional" ideology the woman wants to identify with her role at work and her role at home, and in "egalitarian" ideology Hochschild found men and women who jointly prioritized either their careers or the home, or some balance between work and family. Kathleen Gerson (1985) concluded that the women she studied fell into one of three categories: work-committed, domestically-oriented, or reluctant mothers. Mary Blair-Loy (2003) categorized women according to a family-devotion schema or a work-devotion schema, assigning them to one group or the other based upon whether or not they continued in their demanding careers following the transition to motherhood. Catherine Hakim (2006) classified the women in her study into three categories: "workcentered," "home-centered" and "adaptive lifestyle preferences." The "work-centered" women were more likely to return to work after the birth of a child whereas the "home-centered" women were less likely to return to work after the birth of a child. However, Hakim found that the majority of the women in her study fell into the "adaptive" category in which they were more likely to work part-time in order to "balance" their work and family roles.

There are a number of shortcomings with this “orientation approach” to explaining how and why women combine career and family in the way that they do. For one, the categories place work and family roles at odds, perpetuating the "work-family conflict" perspective that neglects the mutually beneficial outcomes of pursuing a professional/managerial career and raising a family (Barnett \& Hyde, 2001). The orientation perspective also assumes that women are inherently inclined to prioritize either career or family. In so doing, it fails to reflect how many women continuously revise their approach to combining career and family as their sense of self, as well as their own needs and desires, and those of their family members, evolve with changing life circumstances. Further, while some women do assert that they know who they are 
and seem to resist making changes to their sense of self, the terms they use denote a holistic view of themselves in the context of their combined work and family lives (e.g., "provider," "the little engine that could"), rather than in terms of a single domain. Finally, some women see themselves as unsure of who/what they want to be, but the very state of being uncertain and open to endless possibilities appears to be a core element of their identities.

In addition to challenging the orientation perspective, the present study demonstrates that attempting to map women's identity development to an age/career stage model denies the diversity in how women construct, revise and present their identities over time. While a variety of developmental models have been proposed, they all assume that women generally experience the same identity issues and navigate the same transitions in essentially the same way based on age or career stage. In so doing, the age/career stage perspective glosses over the great diversity we observe in how women navigate the beginning of their careers, experience the transition to motherhood and combine career and family. For example, Levinson (1978) in his stage-based model of adult development, supplemented by his later study of women (Levinson \& Levinson, 1996), suggests that women begin the process of identity formation during the Early Adult Transition that occurs between the ages of 17 and 22. In the present study, the early career transition was validated as an identity-laden period in which women engaged in various forms of active identity work; however, from this point on, there was wide variation in terms of when and how the informants wrestled with who they wanted to be and how they wanted to structure their lives. Further, Levinson argued that the Age 30 Transition, which he posits occurs between the ages of 28 and 33, is experienced by women who pursue careers as a reassessment of occupational aspirations and the relative value placed on work, family and other aspects of life. However, in my sample of 35 women, there was wide variation in the age at which women 
transition to motherhood and begin to wrestle with the questions of who they want to be as professionals and mothers and where their priorities lie. Moreover, for many women, these questions were continually revisited and, for some, the answers were revised over time.

In another example of the age/career-stage perspective, Mainiero and Sullivan (2006) propose the Kaleidoscope Career Model. These scholars contend that women follow a career pattern in which challenge is the focus of early career, balance is the focus of early/mid-career and authenticity the focus of mid/late career. They refer to authenticity as addressing the question, “Can I be myself in the midst of all this and still be authentic?” Further, they claim that it is not until a woman reaches her late 40s/early 50s that she begins to ask, "What about me?” and/or, “What about what I want to be?” In stark contrast, my findings show that professional/ managerial women are inclined to consider these questions at the very beginning of their careers, and to be true to their sense of self in the midst of changing life circumstances. In addition, the high level of adaptation that is present in the Iterative Alteration and Punctuated Expression patterns demonstrates that women test and revise their self-conceptions at different points in time, and at various turning points. Further, many of my informants described experimenting with full-time, part-time and career break status at different points in time, as they face the challenges and decision-making involved in combining career and family.

Overall, the identity process perspective presented herein offers a fresh alternative to the career-orientation and age/career stage perspectives by providing insight into the diversity and variation in how women make sense of who they are as they navigate three key turning points on the path to professional and mother. Beginning with the early career transition, through the transition to motherhood, and into the extended transitional period of combining career and family, my results show that professional/ managerial women are continually shaping who they 
are in the present and hope to be in the future. These findings are important as they suggest that the differences in women's choices may be partially explained by issues of identity, especially considering that the four patterns cross employment status boundaries. Accordingly, my study highlights the potential for drawing inaccurate conclusions about women’s work/family decisions by mapping them to employment status. In other words, the identity process patterns suggest that we have been attributing inaccurate meanings to women's actions; for example, taking a career break does not mean a woman places a low priority on her career, nor does continuous full-time employment equate to placing a priority of career over family. Rather, many women are actively engaged in trying to figure out who/what they want to be, or in asserting who they believe themselves to be across a variety of employment statuses. In sum, the identity perspective provided by the present study disentangles presumed meanings behind women's career choices, as many women appear to engage in different identity processes over time.

\section{A New Perspective on Women's Identity Development}

By providing a fresh perspective on women's choices in the work/family realm, the present study offers important new insights regarding how professional/managerial women develop a sense of self in the current context in which women have more options for approaching career and family than ever before. That is, by moving beyond a focus on career versus family orientation, and age/career stage models of women’s development, my research exposes exploration, adaptation, and expression as the means by which women's identities evolve within and across three key transitions. More importantly, the four dominant patterns of identity processes indicate that these processes do not function in one particular, lock-step order; rather, they are fluid and result in a variety of configurations of how women determine who they are and/or wish to become. 
One compelling approach to illuminating the contributions to women's identity development research made by the present study is to compare the four identity process patterns to the results of Josselson’s longitudinal study. Using Marcia’s identity status survey instrument, Josselon (1996) classified her informants when they were seniors in college according to the dimensions of exploration and commitment. However, while she recognizes identity as a process that involves ongoing change, Josselson maintained her original categorization over the course of her study, which spans two decades. While the results of the present study are consonant with some aspects of Josselson's findings, there are noteworthy distinctions that provide for theoretical advancements. For example, Josselson’s category, Guardians, resonates with the identity process pattern I label, Unwavering Expression. That is, Josselson's Guardians made identity commitments based on plans crafted by their parents. As such, they, “...knew where they were going without having considered alternatives” (p. 37). Similarly, the Unwavering Expression pattern reveals how some women project or claim an adolescent identity, often handed to her by her parents, and assert it through the transition to motherhood and into combining career and family.

Although there is a great deal of similarity between the Guardians and the Unwavering Expression pattern, my findings around the other three patterns are quite divergent from Josselson's.. For example, Josselson explains that her Pathmakers engaged in a period of exploration before making identity commitments, linking this finding to Erikson's theory that identity progresses from exploration to commitment. This category is closest to my Iterative Alteration pattern in which exploration and adaptation are ongoing identity processes over time. The key difference is that the Iterative Alteration pattern demonstrates how women make and break "identity commitments" over time as they navigate major turning points and reconsider 
who/what they want to be and do. Josselson's Searchers, on the other hand, are described as being in a state of identity crisis at the end of college, having engaged in active exploration without committing to any of the identities they tried out. This group is similar to my Enduring Exploration pattern in which exploration and wrestling with the questions, "Who am I?" and "Who/what do I want to become?" is evident in the early career transition as well as in the subsequent transitions. However, my findings reveal how women revisit these questions in the context of navigating the significant transitional periods of their lives. This does not imply that women are not making identity commitments in between transitions, but rather that they see themselves as continually open to considering new possibilities.

It is also worth noting that none of the patterns uncovered in my study resonate with Josselson's "Drifters" which she described as, "leaves blown by the wind” (p. 38). She explains that the women she studied who fit this category neither explore nor make identity commitments; rather, they live day-by-day, avoiding thinking about or planning for the future. It is therefore not surprising that none of my patterns aligns with this category as my sample is comprised of women who have invested heavily in their education and careers. Finally, the pattern I label, Punctuated Expression, does not resonate with any of Josselson's categories. In this pattern, the middle transition is dominated by a different identity process from the one that dominates the first and last transition. This discovery was possible because I focused on the dominant identity processes in each transition and on recurring patterns across transitions, rather than attempting to categorize all 35 of my informants into a static classification system. Accordingly, my research provides new insights into the dynamic manner in which women's identities evolve over time.

In sum, both Josselson's "gateways to identity" and the identity process patterns uncovered in the present study demonstrate that age and stage-based models of identity 
development do not accurately reflect the tremendous variation in when and how women wrestle with the question, "Who am I?" and how often the answers to this question are reconsidered, and/or revised. However, one of the key differences between the research presented herein and Josselson's study is the power of the identity process patterns to reflect the important changes that take place through and across the significant transitions in professional/managerial women's lives. That is, whereas Josselson used Marcia's instrument to categorize her subjects as young adults and maintained those groupings over the course of her study, I elicited candid stories that expose how women see themselves develop, changing and/or remaining the same as they navigate identity-laden turning points in their lives. Based on the various forms of narrative identity work I uncovered in my informants' self-narratives, I discovered three identity processes that help us to understand how women make sense of who they are over time. Specifically, rather than exploration and commitment, I argue that professional/managerial women are engaging in the identity processes of exploration, adaptation, and expression as they journey from university students to professionals/managers faced with decisions about how to combine career and family.

It is important to note that while the notions of exploration and adaptation have previously been employed by adult development, identity and careers scholars, the results of the present study broaden our understanding of the nature of these processes and how they relate to women’s identity development. For example, Erikson, Levinson and Marcia viewed exploration largely in terms of choosing an occupation, as their subjects were exclusively male at a time in American history when career paths were typically chosen and maintained over the life span. Contemporary careers, on the other hand, are known to involve occupational and/or career changes which are likely to involve iterative periods of exploration (e.g. Hall, 2002; Super \& 
Hall, 1978). My findings illuminate identity exploration in a broader context that goes beyond exploration as a career process. Specifically, I conceive of exploration as the opening up of oneself to endless possibilities, questioning who one once was or may have been, and imagining possible selves (Yost, Strube \& Bailey, 1992). Further, my results show that this process is not specific to late adolescence/early adulthood, nor is it necessarily expected to be resolved once and for all at any point in time.

In addition to providing a new approach to understanding how exploration relates to women's identity development, my conceptualization allows for distinguishing between identity exploration and identity adaptation. For example, whereas Marcia (1966) conceived of exploration as questioning the views, values and career plans laid out by one's parents as well as trying out different identities or ways of being, I distinguish between the reflective nature of exploration and the active nature of adaption. That is, in my view, adaptation involves engaging in an actual change by letting go of one identity and/or taking on a new one, or by simply acknowledging that something fundamental about one's sense of self has been altered. In the literature, the notion of identity adaptation is primarily found in studies of role transitions, which are typically conceptualized as a process of identity change in which an individual separates from a former role/identity and takes on a new one (Ladge, et al., 2012). The identity transition literature is dominated by studies of work-role transitions; however, Ladge and her colleagues extend this line of research into the domain of the liminal period of pregnancy in which women begin to contend with conflicts and enrichments between their established professional identities and visions of their maternal identities. In my study, I elicit and analyze stories about pregnancy and/or childbirth in which women see themselves as fundamentally altered as the result of becoming a mother. Further, I find evidence of identity adaptation in early career when women 
shed their former visions of who/what they are going to become, as well as in the transition to combining career and family as women adapt to different ways of being/identities as part of finding an approach that "works.” For example, making friends with other stay-at-home moms in the neighborhood and attending “mommy classes” or telling oneself to, “pretend you’re a man” in order to survive working full-time.

Another important distinction between the results of the present study and findings from previous research is the movement beyond associating exploration and adaptation with specific transitions. For example, careers scholars generally agree that the very beginning of an individual's career is a time of exploration in which multiple options are considered, and possibly even tested, before one chooses a path (Super \& Hall, 1978). Adaptation, on the other hand, is recognized as a potential response to the transition to motherhood, as well as an element of moving from junior to more senior roles in organizations (Ibarra, 1999). In the present study, exploration and adaptation are uncovered as dominant processes in all three transitions. Further, my research exposes identity expression as an important identity process that has been overlooked in the literature. That is, while scholars recognize that self-narratives are expressive of identity (Ibarra \& Barbulescu, 2010; McAdams, 1996), they conceived of expression in terms of the story being a reflection of an individual's identity. In my study, I discover that identity expression involves staking a claim, and very clearly asserting, “This is who I am” that requires little to no interpretation on the part of the listener/reader.

Beyond uncovering identity expression in all three transitions, I found that this process dominates two out of four patterns uncovered in my study: Unwavering Expression and Punctuated Expression. Accordingly, my study shows how professional/managerial women take ownership of their identities by declaring, "I know who I am” as far back as the early career 
transition, and through subsequent transitions. The Punctuated Expression pattern is particularly interesting as women who narrate this pattern return to proclaiming that they know who they are even after acknowledging a major shift in their sense of self as a result of becoming mothers. This finding suggests that many women seek to articulate a clear sense of self and manage to do so even whilst incorporating change. In other words, when a woman's claims about who she is no longer resonate with her core sense of self, she re-writes her self-proclamation and asserts it in all that she does.

\section{Advancing Theory on Women's Narrative Identity Work}

Beyond providing a new perspective on women's identity development, my study offers new insights that advance theory on women's narrative identity work. That is, by extending the concept of narrative identity work to the study of multiple macro-level transitions in the workfamily domain, my research contributes to our understanding of how women develop and articulate a sense of self over time. In particular, whereas the majority of identity work studies focus on a single macro occupational role transition, the present study investigates narrative identity work over time; that is, across three significant transitions that provoke the questions, “Who am I?” and “What do I really want?” In so doing, I demonstrate that narrative identity work may be conceived of as the retrospective, and/or storied version of the tactics individuals use to form, maintain, repair, or revise their sense of self (Sveningsson \& Alvesson, 2003). Specifically, I build on Ibarra and Barbulescu's (2010) theorizing about how individuals make macro role transitions and successfully adopt a new identity. These scholars posit that individuals successfully complete transitions to new role identities by crafting self-narratives that others accept and validate as compelling explanations for the change from one role to another (e.g., from corporate employee to entrepreneur). My findings substantiate this theory, but 
broaden it to include multiple self-defining transitions that influence how a woman develops her sense of self. Specifically, my informants were drawn to achieving coherence in their selfnarratives, as evidenced by the observation that all four patterns begin and end with the same identity process. That is, in crafting their self-narratives, women make sense of who/what they are today by creating links between the present and the past; between where they have ended up and where they started.

This insight goes beyond the claim that coherence is a key element of effective selfnarratives that validate macro occupational role transitions and thereby assist individuals in revising their identities (Ibarra \& Barbulescu, 2010). Rather, the present study demonstrates that even when narrating about multiple transitions and periods of significant change, individuals are drawn to craft coherent self-narratives. Further, my findings illuminate that women achieve this coherence by making a link between who they are in the present with who they were in the past; not in terms of identity content, but rather in terms of engaging in the same identity process in combining career and family as they did at the early career transition. By linking the beginning and the end, coherence may be achieved even when a major change occurs in the middle; for example, when identity adaptation disrupts identity expression in the transition to motherhood.

My research also furthers our understanding of the transition to motherhood as a powerful turning point that wields significant influence on the evolution of professional/ managerial women's identity. The prevalence of adaptation, in addition to exploration, in women's stories of becoming mothers indicates that this particular transition has more widespread impact on a professional/managerial woman's understanding of herself than the early career transition or the transition to combining career and family. Although scholars have previously conceptualized becoming a mother as an “identity-altering” event (Lee et al. 2005; 
Millward, 2006), my study provides a very personal view of what this transition means to professional/managerial women. In particular, this transition stands out as particularly important, because it adds a new identity that a woman is unable to "try out" before taking it on. In fact, many woman have such a completely unexpected reaction to becoming pregnant for the first time and/or giving birth, that we may conclude that there is essentially no way to predict how a woman is going to react to, nor navigate, this particular transition. In addition, the discovery that several of my informants continued to engage in identity expression during this transition indicates that becoming a mother is not an identity-altering event for all women. Finally, this transition is specific to women and helps to explain why we see more variation in women's careers than we do men's. However, it is important to note that the "transition to fatherhood" warrants more scholarly attention as men who become fathers today are more likely to be significantly involved in childcare and family life; thus, men are likely to be encountering fatherhood identity issues that did not exist in the past.

Beyond increasing our awareness of the nature of the transition to motherhood and its impact on women, we may draw new theoretical insights from this study's results regarding the relationship between a woman's sense of self, her professional identity, and her motherhood identity. As noted by Ibarra (1999), “...most scholars agree that people have multiple identities that they invoke in different social circumstances and that identities change and adjust in response to challenges from the social environment (Gecas, 1982).” However, there is less agreement over the existence of an immutable "self" (Ibarra, 1999). The results of the present study suggest that we may distinguish between a woman's core "sense of self," and her multiple identities, such as "professional” and "mother." Based on my informants' stories of the transition to motherhood in which many describe a fundamental change in their understanding of 
who they are, what they want, and where their priorities lie, I conceptualize a woman's "sense of self" as her summative, holistic view of herself in terms of all of the roles that she plays, her hopes, dreams and values, her world view, etc. In other words, my view of "sense of self" is akin to what some scholars refer to as the self-concept (e.g., Gecas, 1982), the unifying construct that represents the whole of who a person believes him/herself to be.

Based on the results of the research presented herein, we may posit that adding the new identity of, "mother," has the power to alter a woman’s core sense of self, as well as her professional identity. That is, many women engaged in adaptation or exploration at the transition to mother, thus altering or questioning their sense of self in becoming mothers. In addition, many experienced a shifting of priorities in terms of work and career goals seeming less important. Accordingly, my findings suggest that, for many women, the addition of a motherhood identity impacts her sense of self, as well as her professional identity.

Finally, the present study provides theoretical insight into women's differing need for closure in their self-narratives and what this tells us about the nature of identity. That is, two of the four identity process patterns, Unwavering Expression and Punctuated Expression, provide a sense that, “...that there is nothing remaining for her to do" (Carroll, 2007, p. 2). In these patterns, the narrator engages in identity expression in the third transition, combining career and family, declaring, "I know who I am!” Accordingly, the salient questions in the narrative, "Who am I?” and “Who/what do I want to become?” have been answered, and therefore closure has been achieved. However, as noted by Carroll, not all narratives have closure; for example, narrative histories are published while many of the events are ongoing and unresolved, and soap operas go off the air before most of the plot lines are "tidied up” (2007, p.2). This lack of closure is evident in the other two patterns uncovered in my study, Enduring Exploration and 
Iterative Alteration. These identity process patterns demonstrate that many women craft selfnarratives that end without the salient questions being resolved. In the case of Enduring Exploration, the narratives that reflect this pattern end with no indication that closure will ever be attained, nor is it desired. In fact, the very essence of this pattern, which is ongoing, open-ended questioning, stands in direct opposition to the concept of closure. In the case of Iterative Alteration, on the other hand, the self-narratives suggest that the cycle of exploration and adaptation will continue, such that whatever answers have been provided are likely temporary.

The discovery that some women desire closure while others either, a) continually re-open the identity questions they pose, or b) repeatedly change their responses, provides an important insight into women's identity. Identity theorists such as Erikson, and those who accept his conjectures, contend that achieving identity "closure" is an essential developmental task. In fact, Erikson $(1950 ; 1963)$ argued that intimacy and relationship may only be achieved if one resolves the adolescent “identity crisis.” Feminist scholars, on the other hand, argue that women’s identity is rooted in attachments and relationship. Following the logic of these two perspectives, we might conclude that women desire achieving identity closure in the early career transition in order move on to attaining intimacy in the form of marriage/partnership and having children. However, my findings reveal that some women go on to marry/partner, become mothers, and enjoy close relationships with their spouses and children and yet see themselves as "explorers" who may choose not to come to closure once and for all on exactly who they are or what they want to be.

\section{Re-examining The Relationship Between Work and Family}

In addition to advancing our understanding of women's identity development and narrative identity work through and across significant transitions, my study sheds new light on 
two of the dominant perspectives in work/family research: the work-family conflict perspective, and boundary work. The work-family conflict perspective asserts that role pressures from the work and family domains are mutually incompatible in some respect (Greenhaus \& Beutell, 1985). While this perspective dominated the literature throughout the 1980s and 1990s, new theories emerged in the 2000s in which engaging in work and family was viewed as mutually beneficial (see Frone, 2003). That is, experiences in one role improve the quality of life in another role (Greenhaus \& Powell, 2006). However, the popular press continues to present career and family as incompatible domains (see Belkin, 2003), and many women continue to convey difficulty in pursuing high-powered careers and meeting the needs of their families (Slaughter, 2012). This difficulty is assumed to reside primarily in limited resources, such as time and energy rather than issues of identity.

The second leading perspective in work-family research is rooted in boundary theory (Ashforth et al., 2000) and the belief that individuals have preferences for managing their combined work and family lives along a "segmentation-integration" continuum (Nippert-Eng, 1996). In other words, some women prefer to keep their work and family lives as separate as possible, while others view these domains as two aspects of a single life. While these two extremes represent "ideal typical” approaches, most people do not conduct their lives from one end of the continuum or the other, but rather tend toward segmentation or integration in how they structure their combined career and family lives. Some scholars conceptualize boundary work as identity work (Cohen et al., 2009; Nippert-Eng, 1996), but primarily in the context of making daily role transitions according to the similarity and differences between work and family roles (see Ashforth et al., 2000). 
By conceptualizing combining career and family as a complex set of life transitions that provoke the questions, “Who am I?” and “Who/what do I want to be?” rather than competing identities or domains around which women create boundaries, my research provides a more holistic view. In particular, the results of the present study suggest that a re-examination of scholarly understanding of conflict and boundaries between work and family is warranted. For one, an overlooked element of the "conflict” that a woman experiences in pursuing a professional/managerial career and raising a family may be the constraints placed on her ability to engage in exploration, adaptation, and expression on her own terms, and in her own way. For another, how a woman conducts boundary work and displays a preference along what scholars conceptualize as an “integration-segmentation continuum” (Nippert-Eng,1996) may involve more than managing boundaries between work and home, or their professional and mother identities (Cohen et. al, 2009). That is, by actively working through how one’s professional and motherhood identities might co-exist, women may be attempting to develop a coherent sense of self, and assert who they wish to be.

In conclusion, the present study makes several theoretical contributions, including: providing a more nuanced and flexible alternative to the orientation and age/career stage perspectives on women’s identity development, illuminating the centrality of coherence in womens' self-narratives, demonstrating the power of the transition to motherhood to alter a woman's sense of self, teasing out the distinction between professional identity, mother identity and sense of self, and using the concept of closure to help us understand the variation in how women's identities evolve over time. In addition, my research also makes an important overarching contribution by moving our thinking about women's choices, preferences, priorities, and identities away from a dichotomized framing of work versus family, and towards a 
perspective that may help us to understand work-family conflict and boundary work in a new way. Accordingly, my research sheds new light on how women find and present a holistic sense of self regardless of their employment status, or the boundaries they may create between their work and personal/family lives.

\section{Practical implications}

For Individual Women. In addition to making theoretical contributions, the present research has several practical implications, both for individual women and for organizations. Perhaps the most important practical implication of this study for women is that the findings reinforce the idea that there is no one right way to pursue a professional/managerial career and raise a family. The variation in identity work and identity processes within and across transitions in my study suggests there are many different ways in which women figure out who they are, what they want, and how to craft a combined career and family life. Further, how a woman approaches combining work and family is not a one-time decision that determines her fate. Rather, much change and fluidity is evident in women's self-narratives. If women can move away from seeking specific solutions and being influenced by how they might be seen or trying to avoid the stigmas associated with them and rather pay attention to their own identity processes, they might be able to make choices based on their current sense of self. As demonstrated by my findings, women are engaging in all kinds of identity work, and different identity processes, as they try to figure out who they are and who/what they want to be. Some are actively experimenting with different ways of being both professionals and mothers, revising their identities as they go along while others assert who they are and avoid making revisions. Still others remain open to life's possibilities and seem to resist staking a claim on one way of 
being. Accordingly, my study indicates that there is no magic recipe for combined career and family "success." In fact, one of my informants articulated this very conclusion:

I actually met with Professor [name] for her answer, and I asked everyone in the universe for their answer, and I wanted to meet with you for your answer. And what I find interesting is that finally going through this process, I just needed my answer.

The insight provided by the quote above also indicates a second practical implication of my study. That is, telling her story to others may help a woman make sense of how she sees herself as a professional and a mother, to get better clarity on an approach to combining career and family that feels "right.” Further, if the importance of identity processes is accepted, women could be freed from the imperative of seeking the "best" approach or balance and embrace the fluid nature of identity and identity processes. At present, women face being discounted or judged for specific choices. In fact, some of my informants were concerned about being perceived as less committed by their supervisors and co-workers after becoming mothers. In general, women who reduce their work hours by going part-time/reduced-load, or take a career break, are perceived as "family-oriented" or less dedicated to their careers. On the other hand, those who have a stay-at-home husband/partner, or who hire nannies to care for their children while they maintain high-powered positions are often viewed as absent mothers. As an alternative, my research shows that these various approaches to combining career and family may be viewed in a different light; that is, as temporary or dynamic; a single chapter in a lengthy novel. Applying an identity lens places less onus on women to find the one "right way" of doings things and suggest that reflecting on what feels right/wrong is critical. Further, allowing themselves to re-evaluate the situation and to make adjustments and changes along the way may be key to overall well-being for individual women and their families. 
For Organizations. The results of the present study also have several practical implications for organizations. For one, by demonstrating the various ways in which women journey from university students to professionals and managers wrestling with how to combine career and family, the results suggest that "one-size-fits-all” organizational policies and practices are likely to be ineffective; rather, organizations need to consider a more flexible approach that allows for individual tailoring.

In addition, the transition to motherhood is a time in many women's lives when previous decisions, future plans, and day-to-day life are re-evaluated, yet most organizations fail to help their employees to prepare for and manage this transition. The results of this study suggest that there is an excellent opportunity for organizations to increase the likelihood of retaining talented female employees who go out on maternity leave. That is, by recognizing the power of the transition to motherhood to unexpectedly alter a woman's sense of self and her feeling about work indicates that many women would benefit from being offered guidance and support as they are making decisions about how to combine career and family. Specifically organizations might provide career counseling, or even personal counseling, as they prepare for maternity leave and as their leaves are coming to an end. It would also be important to offer flexible return-to-work options, and to create an open dialog between the organization and the employee in order to find a solution that works best for everyone involved. As companies seek to retain their valuable and talented women employees, providing resources, maintaining contact, and offering more tailored flexibility options to employees who are out on maternity leave should increase the likelihood of a successful transition back to work.

Finally, several of the women in my study were taking a career break at the time of the first and/or second interview, and many of these women were exploring who/what they wanted 
to be and do. Many of these women expressed a desire to find a way to re-engage in their professional lives, but in a flexible way that would not completely undermine the family lifestyle they had established by being at home. Other studies, for example as described in Pamela Stone’s Opting-Out: Why Women Quit Careers and Head Home (2008) also demonstrate that a significant percentage of educated, experienced women are not presently in the workforce. This creates a pool of untapped talent that creative organizations could reach out to.

\section{Limitations}

As is the case with all research projects, there are inherent limitations in the present study that are important to highlight. For one, the research design is retrospective rather than longitudinal, and therefore the various forms of identity work that were uncovered were recollected and subject to greater interpretation. That is, rather than observing subjects' actual identity work, or interviewing informants exclusively about the present or recent past, this study asked participants to recall events that took place between 10 and 25 years in the past. However, it is important to note that my approach to data analysis and interpretation kept this limitation in mind; that is, I actively kept in mind the fact that early identity processes were viewed through the lens of the present.

As this was a qualitative in-depth study of a small, and very specific sample: managerial and professional women with at least one child under the age of six, there was never any intent to generalize the findings to a broader population. The goal was theoretical generalization, that is, to generate theory or theoretical ideas that could be applicable more broadly. While it is fair to assume that all women engage in identity work as they transition from students to workers, to mothers, to women faced with combining paid work and family, the present research represents the identity journeys of women who have invested heavily in their education, constructed a professional identity, and have had the financial flexibility and/or spousal/family support to 
consider multiple options. Further, the transitions studied are likely to be experienced differently by non-professional working mothers and therefore different forms of narrative identity work might emerge. However, it is reasonable to assume that the identity processes of exploration, adaptation, and expression, as conceptualized in this research, would be more widely applicable to working mothers who do not necessarily have highly-demanding professional/managerial careers. In particular, we might expect to uncover identity exploration in the early career transition and adaptation at the transition to motherhood. Working mothers who see themselves as providing for their families might also be likely to engage in identity expression in all three transitions. However, exploration at the transition to motherhood and in combining career and family might be less likely for women who do not have the option to consider cutting back to part-time work or taking a break. In other words, women who have no choice but to work fulltime, or even multiple jobs, to put food on the table, might not allow themselves the luxury of reflecting upon, “Who am I?” and “What do I really want?” The women in the present study were nearly all in dual-earner relationships and most indicated that finances had not been the primary determinant of their present employment status. While I specifically targeted this group of women in the hope of capturing unrestrained identity work, I also recognize that many working mothers face constraints on considering, and pursuing, who/what they would ideally like to be.

In addition, the present study is limited by its context. For one, all of the women in the present study had been educated and pursued careers in North America. While some of the women were born in other countries, they all experienced the three transitions in a single culture. It is possible that in a different cultural context in which societal expectations for women in terms of career and family are not the same as in N. America, I would have observed different 
forms of identity work and, as such, different identity processes. Further, while the cultural context is narrow, the industry/occupational context from which the sample was drawn is rather broad. My informants had previous experience, and are presently working, in a wide range of industry sectors and occupations. Due to the variation in work environments, it was not possible for me to examine how the organizational discourses and ideologies might have influenced my informants’ identity work (Sveningsson \& Alvesson, 2003).

Another limitation pertains to the single perspective I garnered; that is, my data includes each individual woman's stories and reflections about three specific transitions, but excludes the perspective of the spouse/ partner. While this focus resulted in novel insights into women's narrative identity work and identity journeys, it is limited in its ability to draw inferences about the key role played by the spouse/partner in how women structure and live their lives. In particular, while I did ask my informants about their husband's/partner's occupation, title, how much they contributed to the household income, etc., I did not probe deeply into how the marital/ partner relationship impacts how a woman sees herself, nor how it affects the kinds of identity work and identity processes she engages in over time.

Finally, the importance of relationships in women's development did not emerge as a key element of women's identity work in this study. While feminist scholars contend that relationship and connection are fundamental elements of women's identity (Chodorow, 1978; Josselson, 1996), others argue that women's career theorists have placed too much emphasis on the role of relationships in women's lives and careers (Pringle \& McCulloch Dixon, 2003). Unfortunately, my study is unable to contribute to this debate as I did not probe directly on the importance of relationship to the women in my study. Josselson (1996) explains that feminists believe girls grow up feeling much more connected to their mothers than boys do; she herself 
concludes that the relationship to one's mother is a central axis of women's identity. In the present study, I elicited stories about specific transitions that took place when my informants were young adults, beginning somewhere between ages 18 and 22. At this point in time, most of the women in my study were not living with their mothers, and most did not include talk of their relationships with their mothers in their stories of the early career transition. Had I asked about their relationships with their mothers, and/or selected an earlier transition in their lives when they were still living in their family of origin, I may have uncovered more links between identity and relationship. The one striking connection between the narrative identity work uncovered in this study and the mother-daughter relationship was in projecting. That is, many women who engaged in identity expression in the early career transition described projecting an image of their future selves as financially independent professionals and attributed this vision to their mothers' wishes for their future. This is a particularly interesting finding as it indicates that some mothers are encouraging their daughters to pursue education and careers; that is, to lead financially independent lives rather than relying on a man for financial support as in years past.

\section{Directions for Future Research}

The limitations of this study indicate fruitful opportunities for future research. In particular, longitudinal studies that examine identity work in the present, and track how women alter their views of their past, present and future selves, would allow for the creation of new and more accurate models of identity development. In particular, observing how women actually engage in identity work when leaving university and starting a first career job, while pregnant at work, immediately after having a first baby, at the end of maternity leave, and then at several points during the first few years of combining career and family, would provide tremendous insights into how women actually navigate these turning points and how they see themselves in 
each transition. After collecting this data, at a later point in time the same sample of women could be asked to narrate about those transitions from the perspective of her current situation; that is, in retrospect. Comparing the findings of the present, real-time identity work to the narrative identity work in their later stories about these transitions, would provide additional insights into the nature of narrative identity. New theoretical insights could be gleaned from examining the identity processes women engage as they work through each transition in the present, and comparing these findings to those reflected in their retrospective self-narratives. In addition, such a study would help us to see the kinds of changes that take place over time in terms of how a woman sees herself in the past and future based on where she is in the present. Another fruitful area for future research would be to examine women's narrative identity work in the context of the significant transitions that take place later in a woman's life. The present study examined the three most widely-accepted significant transitions in the lives of women who combine career and family; however, subsequent turning points have been understudied by researchers, such as the transition from having very young children at home to having all school-aged children and facing the demands of managing homework, activities, play dates, etc. in this age of "over-parenting." The transition to parenting adolescents has also been understudied, yet the Atlantic Monthly article, “Why Women Still Can’t Have It All” (Slaughter, 2012), calls our attention to the particular challenges women may face at this point in their lives. We might also include the transition to becoming an empty-nester as women transition back to being without day-to-day parenting responsibilities and may consider, "What next?” In so doing, we would learn more about where the patterns lead. For example, do the women who narrate the Enduring Exploration and Iterative Alterative eventually reach closure on who/what they want to be?; and, if so, how? 
Further, while I intentionally sampled women in different employment status categories in order to ensure that my participants represent the reality of women’s careers in which employment status is likely to be discontinuous, the size of my sample within each employment status category is quite small. In order to provide theoretical validation for my findings, I suggest that future research explore the variation in identity work within larger samples of women who hold the same employment status, and compare results across employment status categories. For example, the same research design that was employed in the present study could be applied to a larger sample of 90-105 informants, with 30-35 in each of the three employment status categories: full-time, part-time and career break. Studying the narrative identity work and identity processes within and across each employment status group would demonstrate the theoretical validity of my findings if in fact the same identity processes emerged and crossed employment status boundaries. This line of research could shed light on the relationship between women’s identity processes and their decisions to continue to work full-time versus going reduced load or taking a career break and their identity development. That is, we might find that women who go part-time or take a career break are more likely to narrate the Enduring Exploration pattern, whereas the women who narrate the Unwavering Expression pattern might be more likely to continue on the same career path, and maintain full-time employment, after the transition to motherhood.

The line of inquiry explored in this dissertation could also be extended in future studies to other segments of the workforce. In particular, we are sorely lacking studies that explore men's identity work and new modes of fatherhood. The approach taken in the present study could be replicated with a sample of professional/managerial men to investigate the nature and meaning of men's identity work as they transition from students to professionals, to fathers, to combining 
career and family. Such a study would surely help us to understand the changes taking place in how men navigate the transition to fatherhood, and in particular the power of this transition to alter a man’s identity in the current social context in which the gendered distinct between parental roles is blurring as men’s and women's career paths continue to converge.

In sum, the present study lays the groundwork for multiple streams of future research that have the potential to advance scholarly understanding of the nature of narrative identity work and the evolution of identity through understudied transitional periods. Further, the methodology employed herein provides for the investigation of men's identity work in the context of combining career and family, and in particular the transition to fatherhood. By increasing our understanding of how both women and men develop a sense of who they are as they pursue careers and raise families, we may aid individuals and organizations alike in providing more flexible and tailored solutions that help individuals to craft healthier and more satisfying lives. 


\section{REFERENCES}

Anderson, D., Vinnicombe, S., \& Singh, V. 2010. Women Partners Leaving the Firm: Choice, What Choice? Gender in Management: An International Journal, 25(3): 170-183.

Aryee, S., \& Luk, V. 1996. Balancing Two Major Parts of Adult Life Experience: Work and Family Identity Among Dual-Earner Couples. Human Relations, 49(4): 465-487.

Ashforth, B. E. 2001. Role Transitions in Organizational Life: An Identity-Based Perspective. Mahwah, NJ: Lawrence Erlbaum Associates, Inc.

Ashforth, B. E., Harrison, S. H., \& Corley, K. G. 2008. Identification in Organizations: An Examination of Four Fundamental Questions. Journal of Management, 34(3): 325-374.

Ashforth, B. E., Kreiner, G. E., \& Fugate, M. 2000. All in a Day's Work: Boundaries and Micro Role Transitions. Academy of Management Review, 25(3), 472-491.

Ashforth, B. E., \& Mael, F. 1989. Social Identity Theory and the Organization. Academy of Management Review, 14(1): 20-39.

Bailey, L. 1999. Refracted Selves? A Study of Changes in Self-Identity in the Transition to Motherhood. Sociology, 33(2): 335-352.

Bailyn, L. 2006. Breaking the Mold: Redesigning Work for Productive and Satisfying Lives. Ithaca, NY: Cornell University Press.

Bardwick, J. 1980. The Seasons of A Woman's Life. In D. McGuigan (Ed.), Women's Lives: New Theory, Research and Policy, 35-55. Ann Arbor, MI: University of Michigan Center for Continuing Education of Women.

Barnett, R. 1998. Toward a review and reconceptualization of the work/family literature. Genetic, Social, and General Psychology Monographs, 124, 125-182.

Barnett, R. C., \& Baruch, G. K. 1985. Women's involvement in multiple roles and psychological distress. Journal of Personality and Social Psychology, 49(1), 135-145.

Barnett, R. C., \& Hyde, J. S. 2001. Women, Men, Work, and Family. American Psychologist, 56(10): 781-796.

Baruch, G. K., \& Barnett, R. C. 1986. Role quality, multiple role involvement, and psychological well-being in midlife women. Journal of Personality and Social Psychology, 51(3), 578585.

Baruch, G. K., \& Barnett, R. C. 1987. Role quality and psychological well-being. In G. K. Baruch, R.C. Barnett, \& F. J. Crosby (Eds.), Spouse, parent, worker: On gender and multiple roles, 63-73. New Haven, CT: Yale University Press.

Belkin, L. 2003. The Opt-Out Revolution. The New York Times, October, 26, 2003. 
Bielby, W. T., \& Bielby, D. D. 1989. Family Ties - Balancing Commitments to Work and Family in Dual Earner Households. American Sociological Review, 54(5): 776-789.

Blair-Loy, M. 2003. Competing Devotions: Career and Family Among Executive Women. Cambridge, MA: Harvard University Press.

Boje, D. M. 1991. The Storytelling Organization: A Study of Story Performance in An OfficeSupply Firm. Administrative Science Quarterly, 36(1): 106-126.

Burke, R. J., \& McKeen, C. A. 1993. Career Priority Patterns Among Managerial and Professional Women. Applied Psychology, 42(4): 341-352.

Buzzanell, P., \& Lucas, K. 2006. Gendered Stories of Career: Unfolding Discourses of Time, Space, and Identity. In J. T. W. Bonnie \& J. Dow (Eds.), The Sage Handbook on Gender and Communication,161-178. Thousand Oaks, CA: Sage Publications, Inc.

Buzzanell, P. M., \& Liu, M. 2005. Struggling with maternity leave policies and practices: a postculturalist feminist analysis of gendered organizing. Journal of Applied Communication Research, 33(1): 1-25.

Callero, P. L. 1985. Role-Identity Salience. Social Psychology Quarterly, 48(3): 203-215.

Caron, C. 2002. Communicating Research Findings to Workers: A Dialog with Authors Meiksins \& Whalley. Sloan Work and Family Research Network: Reflections from the Sloan Foundation, 4(2): 12-14.

Carroll, N. 2007. Narrative Closure. Philosophical Studies, 135(1): 1-15.

Charmaz, K. 2006. Constructing Grounded Theory: A Practical Guide Through Qualitative Analysis. Thousand Oaks: Sage Publications Ltd.

Chase, S. E. 2005. Narrative Inquiry: Multiple Lenses, Approaches, Voices. In N.K. Denzin \& Y.S. Lincoln (Eds.), The Sage Handbook of Qualitative Research, 651-679. Thousand Oaks, CA: Sage Publications.

Chase, S. E. 2003. Taking Narrative Seriously: Consequences for Method and Theory in Interview Studies. In Y.S. Lincoln \& N.K. Denzin (Eds.), Turning Points in Qualitative Research: Tying Knots in a Handkerchief, 273-296. Walnut Creek, CA: Alta Mira Press.

Chodorow, N. 1978. The Reproduction of Mothering. Berkeley, CA: University of California Press.

Clark, S. C. 2000. Work/Family Border Theory: A New Theory of Work/Family Balance. Human Relations, 53(6): 747-770. 
Cohen, L., Duberley, J., \& Musson, G. 2009. Work - Life Balance?: An Autoethnographic Exploration of Everyday Home - Work Dynamics. Journal of Management Inquiry, 18(3): 229-241.

Cote, J. E., \& Levine, C. G. 2002. Identity Formation, Agency, and Culture: A Social Psychological Synthesis. Mahwah, New Jersey: Lawrence Erlbaum Associates, Publishers.

Cytrynbaum, S., \& Crites, J. O. 1989. Adult Development Theory and Career Adjustment. Cambridge: Cambridge University Press.

Davidson, M. J., \& Burke, R. J. 2011. Women in Management Worldwide: Progress and Prospects-An Overview. Surrey, England: Gower Publishing Limited.

Dellinger, K. 2000. Weaving Work and Motherhood (a review). Social Forces, 78(3): 11651166.

DeRue, S. \& Ashford, S. 2010. Who will Lead and Who will Follow? a Social Process of Leadership Identity Construction in Organizations. Academy of Management Review,35 (4): 627-647.

Down, S., \& Reveley, J. 2009. Between Narration and Interaction: Situating First-Line Supervisor Identity Work. Human Relations, 62(3): 379-401.

Emslie, C. \& Hunt, K. 2009. Live to Work or Work to Live? A Qualitative Study of Gender and Work-life Balance Among Men and Women in Mid-life. Gender, Work \& Organization 16(1): 151-172.

Erikson, E. H. 1968. Identity: Youth and Crisis. New York, NY: WW Norton \& Company.

Erikson, E. 1950, 1963. Childhood and Society. New York, NY: WW Norton \& Company.

Erikson, E. H. 1958. Young Man Luther. New York, NY: WW Norton \& Company.

Erikson, E. H., \& Rapaport, D. 1959. Identity and the Life Cycle: Selected Papers (Vol. 182). New York, NY: International Universities Press.

Frenkel, M. 2008. Reprogramming Femininity? The Construction of Gender Identities in the Israeli Hi-tech Industry between Global and Local Gender Orders. Gender, Work \& Organization, 15(4): 352-374.

Frone, M. R. 2003. Work-Family Balance. In J.C. Quick \& L.E. Tetrick (Eds.), Handbook of Occupational Health Psychology, 143-162. Washington D.C.: American Psychological Association.

Galinsky, E., Bond, J. T., Sakai, K., Kim, S. S., \& Giuntoli, N. 2008. 2008 National Study of Employers. New York, NY: Families and Work Institute. 
Gallos, J. 1989. Exploring Women's Development: Implications for Career Theory, Practice, and Research. M. B. Arthur, D.T. Hall, \& B.S. Lawrence (Eds.), Handbook of Career Theory, 110-132. Cambridge, UK: Cambridge University Press.

Gareis, K. C., \& Barnett, R. C. 2002. Under what conditions do long work hours affect psychological distress? A study of full-time and reduced-hours female doctors. Work and Occupations, 29(4), 483-497.

Garey, A. I. 1999. Weaving Work and Motherhood. Philadelphia, PA: Temple University Press.

Gecas, V. 1982. The Self-Concept. Annual Review of Sociology, 8: 1-33.

Gerson, K. 2010. The Unfinished Revolution: How a Generation Is Reshaping Family, Work, and Gender in America. Oxford, UK: Oxford University Press.

Gerson, K. 1985. Hard Choices: How Women Decide about Work, Career, and Motherhood. Los Angeles, CA: University California Press.

Gibbs, N. 2009. The Growing Backlash Against Overparenting. Time.com Retrieved from: http://content.time.com/time/magazine/article/0,9171,1940697,00.html

Giddens, A. 1991. Modernity and Self-Identity: Self and Society in the Late Modern Age. Stanford, CA: Stanford University Press.

Giele, J. 1980. Crossovers: New Themes in Adult Roles and the Lifecycle. Ann Arbor, MI: University of Michigan Center for Continuing Education of Women.

Gilligan, C. 1982, 1993. In a Different Voice. Cambridge, MA: Harvard University Press.

Gilligan, C. 1980. Restoring the Missing Text of Women's Development to Life Cycle Theories. Ann Arbor: University of Michigan Center for Continuing Education of Women.

Gergen, K. 2000. The Saturated Self: Dilemmas of Identity in Contemporary Lfe. New York: Basic Books.

Gergen, K. 1994. Realities and Relationships: Soundings in Social Construction. Cambridge, MA: Harvard Business Press

Glaser, B., \& Strauss, A. 1967. The Discovery of Grounded Theory. London: Weidenfield \& Nicolson.

Gould, R. L. 1978. Transformations: Growth and Change in Adult Life. Oxford, England: Simon \& Schuster.

Grady, G., \& McCarthy, A. M. 2008. Work-Life Integration: Experiences of Mid-Career Professional Working Mothers. Journal of Managerial Psychology, 23(5): 599-622. 
Greenhaus, J. H., Peng, A. C., \& Allen, T. D. 2012. Relations of Work Identity, Family Identity, Situational Demands, and Sex with Employee Work Hours. Journal of Vocational Behavior, 80(1): 27-37.

Greenhaus, J., \& Powell, G. 2006. When Work and Family are Allies: A Theory of Work-Family Enrichment. Academy of Management Review, 31(1): 72-92.

Greenhaus, J., \& Beutell, N. 1985. Sources of Conflict Between Work and Family Roles. The Academy of Management Review, 10 (1): 76-88.

Grote, G. \& Raeder, S. 2009. Careers and Identity in Flexibility Working: Do Flexible Identities Fare Better? Human Relations, 62(2): 219-244.

Gutek, B.A. and Larwood, L. 1989. Women's Career Development. Newbury Park, CA: Sage Publications.

Hakim, C. 2006. Women, Careers, and Work-Life Preferences. British Journal of Guidance and Counselling, 34(3): 279-294.

Hall, D. T. 2002. Careers In and Out of Organizations. Thousand Oaks, CA: Sage Publications.

Hall, D. T. 1996. The Career is Dead-Long Live the Career: A Relational Approach to Careers. San Francisco, CA: Jossey-Bass Publishers.

Harrington, B., \& Hall, D. T. 2007. Career Management \& Work-Life Integration: Using SelfAssessment to Navigate Contemporary Careers. Thousand Oaks, CA: Sage Publications.

Hay, A. and Hodgkinson, M. 2006. Exploring MBA Career Success. Career Development International, 11(2): 108-124.

Hayghe, H. V., \& Bianchi, S. M. 1994. Married Mothers' Work Patterns: The Job-Family Compromise. Monthly Labor Review, 24-30.

Hecht, T. D., \& Allen, N. J. 2009. A Longitudinal Examination of the Work-Nonwork Boundary Strength Construct. Journal of Organizational Behavior, 30(7): 839-862.

Hewlett, S. A. 2002. Executive Women and the Myth of Having it All. Harvard Business Review, April, 66-73.

Hochschild, A., \& Machung, A. 1989. The Second Shift: Working Parents and the Revolution at Home. New York, NY: The Penguin Group.

Honeycutt, T. L., \& Rosen, B. 1997. Family Friendly Human Resource Policies, Salary Levels, and Salient Identity as Predictors of Organizational Attraction. Journal of Vocational Behavior, 50(2): 271-290. 
Ibarra, H. 1999. Provisional Selves: Experimenting with Image and Identity in Professional Adaptation. Administrative Science Quarterly, 44(4): 764-791.

Ibarra, H., \& Barbulescu, R. 2010. Identity as Narrative: Prevalence, Effectiveness, and Consequences of Narrative Identity Work in Macro Work Role Transitions. Academy of Management Review, 35(1): 135-154.

Ibarra, H., \& Petriglieri, J. L. 2010. Identity Work and Play. Journal of Organizational Change Management, 23(1): 10-25.

Inkson, K. 2007. Understanding Careers: The Metaphors of Working Lives. Thousand Oaks, CA: Sage Publications.

Josselson, R. 1996. Revising Herself: The Story of Women's Identity from College to Midlife. New York, NY: Oxford University Press.

King, L. A., \& Raspin, C. 2004. Lost and Found Possible Selves, Subjective Well-Being, and Ego Development in Divorced Women. Journal of Personality, 72(3): 603-632.

Kohlberg, L. 1976. Moral Stages and Moralization: The Cognitive-Developmental Approach. In T. Lickona (Ed.), Moral Development and Behavior: Theory, Research, and Social Issues, 31-53. New York: Holt, Rinehart and Winston.

Kofodimos, J. 1993. Balancing Act. San Francisco, CA: Jossey-Bass Publishers.

Kreiner, G. E., Hollensbe, E. C., \& Sheep, M. L. 2006. Where is The “Me” Among the "We”? Identity Work and the Search for Optimal Balance. Academy of Management Journal, 49(5): 1031-1057.

Ladge, J. J., Clair, J. A., \& Greenberg, D. 2012. Cross-Domain Identity Transition during Liminal Periods: Constructing Multiple Selves as Professional and Mother during Pregnancy. Academy of Management Journal, 55(6): 1449-1471.

Lee, M. D., MacDermid, S. M., Dohring, P. L., \& Kossek, E. E. 2005. Professionals Becoming Parents: Socialization, Adaptation, and Identity Transformation. In E. Kossek and S. Lambert (Eds.), Work and Life Integration in Organizations, New Directions for Theory and Practice, 287-318. Mahweh, New Jersey: Lawrence Erlbaum Associates, Publishers.

Lee, M.D. 1993. Women's Involvement in Professional Careers and Family Life: Themes and Variations. Business and The Contemporary World, 5: 106- 127.

Levinson, D. J., \& Levinson, J. D. 1996. The Seasons of a Woman's Life. New York, NY: Random House.

Levinson, D. J., \& Darrow, C. N. 1978. The Seasons of a Man's Life. New York, NY: Random House. 
Lewis, S., \& Cooper, C. L. 1999. The Work-Family Research Agenda in Changing Contexts. Journal of Occupational Health Psychology, 4(4): 382-393.

Lips-Wiersma, M., \& Hall, D. T. 2007. Organizational Career Development Is Not Dead: A Case Study on Managing the New Career During Organizational Change. Journal of Organizational Behavior, 28(6) : 771-792.

Lobel, S.A., \& St. Clair, L. 1992. Effects of Family Responsibilities, Gender, and Career Identity Salience on Performance Outcomes. Academy of Management Journal, 35(5): 1057-1069.

Lobel, S. A. 1991. Allocation of Investment in Work and Family Roles: Alternative Theories and Implications for Research. Academy of Management Review, 16(3): 507-521.

Mainiero, L. A., \& Sullivan, S. E. 2006. The Opt-Out Revolt: Why People are Leaving Companies to Create Kaleidoscope Careers. Mountain View, CA: Davies-Black Publishing.

Mainiero, L., \& Sullivan, S. 2005. Kaleidoscope Careers: An Alternate Explanation for the "OptOut” Revolution. Academy of Management Executive, 19(1): 106-123.

Marcia, J.E. 2002. Identity and Psychosocial Development in Adulthood. Identity: An International Journal of Theory and Research, 2(1): 7-28.

Marcia, J. E. 1966. Development and Validation of Ego Identity Status. Journal of personality and social psychology, 3(5): 551-558.

Marshall, J. 1989. Re-visioning Career Concepts: A Feminist Invitation. In M. B., Arthur, D.T., Hall, \& B.S. Lawrence (Eds.), Handbook of Career Theory, 275-291. New York, NY: Cambridge University Press.

McAdams, D. P. 1993. The Stories We Live By: Personal Myths and the Making of the Self. New York, NY: The Guilford Press.

McAdams, D. 1999. Personal Narratives and the Life Story. In L.A. Pervin \& O.P. John (Eds.), Handbook of Personality: Theory and Research, 478-500. New York, NY: The Guilford Press.

Meiksins, P., \& Whalley, P. 2002. Putting Work in its Place: A Quiet Revolution. Ithaca NY: Cornell University Press.

Miller, J. B. 1976, 1986. Toward a New Psychology of Women. Boston, MA: Beacon Press.

Millward, L. J. 2006. The Transition to Motherhood in an Organizational Context: An Interpretative Phenomenological Analysis. Journal of Occupational and Organizational Psychology, 79(3): 315-333. 
Moen, P., \& Roehling, P. 2005. The Career Mystique: Cracks in the American Dream. Lanham, MD: Rowman \& Littlefield Publishers, Inc.

Moen, P., \& Sweet, S. 2004. From 'Work-Family’to ‘Flexible Careers’ A Life Course Reframing. Community, Work \& Family, 7(2): 209-226.

Musson, G., \& Duberley, J. 2007. Change, Change or be Exchanged: The Discourse of Participation and the Manufacture of Identity. Journal of Management Studies, 44(1): 143-164.

Ng, T. W., \& Feldman, D. C. 2007. The School to Work Transition: A Role Identity Perspective. Journal of Vocational Behavior, 71(1): 114-134.

Nippert-Eng, C. E. 1996. Home and Work: Negotiating Boudaries Through Everyday Life. Chicago IL: The University of Chicago Press.

O'Neil, D. A., \& Bilimoria, D. 2005. Women's Career Development Phases: Idealism, Endurance, and Reinvention. Career Development International, 10(3): 168-189.

Patton, M. Q. 2002. Qualitative Evaluation and Research Methods (3rd ed.). Newbury Park, CA: Sage.

Pentland, B. T. 1999. Building Process Theory with Narrative: From Description to Explanation. Academy of Management Review, 24(4): 711-724.

Petriglieri, G., \& Petriglieri, J. L. 2010. Identity Workspaces: The Case of Business Schools. Academy of Management Learning \& Education, 9(1): 44-60.

Phillips, S. D., \& Imhoff, A. R. 1997. Women and Career Development: A Decade of Research. Annual Review of Psychology, 48(1): 31-59.

Postmes, T., \& Jetten, J. 2006. Reconciling Individuality and the Group. In T. Postmes and J. Jetten (Eds.), Individuality and the Group: Advances in Social Identity, 258-269. London: Sage Publications, Inc.

Powell, G. N., \& Graves, L. M. 2003. Women and Men in Management. Thousand Oaks, California: Sage Publications, Inc.

Powell, G. N., \& Mainiero, L. A. 1992. Cross-Currents in the River of Time: Conceptualizing the Complexities of Women's Careers. Journal of Management, 18(2): 215-237.

Pratt, M., Rockmann, K., \& Kaufmann, J. 2006. Constructing Professional Identity: The Role of Work and Identity Learning Cycles in the Customization of Identity Among Medical Residents. Academy of Management Journal, 49(2): 235-262.

Pringle, J. K., \& Dixon, K. M. 2003. Re-Incarnating Life in the Careers of Women. Career Development International, 8(6): 291-300. 
Rapoport, R., \& Rapoport, R. N. 1971. Further Considerations on the Dual Career Family. Human Relations, 24(6): 519-533.

Rapoport, R., Bailyn, L., Fletcher, J., \& Pruitt, B. 2002. Beyond Work-Family Balance. Advancing Gender Equity and Workplace Performance. San Francisco, CA: Jossey-Bass View.

Reissman, C. K. 2008. Narrative Methods for the Human Sciences. Thousand Oaks, CA: Sage Publications, Inc.

Roberts, P., \& Newton, P. M. 1987. Levinsonian Studies of Women's Adult Development. Psychology and Aging, 2(2): 154-163.

Rothbard, N. P., \& Edwards, J. R. 2003. Investment in Work and Family Roles: A Test of Identity and Utilitarian Motives. Personnel Psychology, 56(3): 699-729.

Russell Sage Foundation. 2013. The Rise of Women: Seven Charts Showing Women's Rapid Gains in Educational Achievement (February 13, 2013). Retrieved from: http://www.russellsage.org/blog/rise-women-seven-charts-showing-womens-rapid-gainseducational-achievement

Schein, E. H. 1978. Career Dynamics: Matching Individual and Organizational Needs. Reading, MA: Addison-Wesley.

Shamir, B., House, R. J., \& Arthur, M. B. 1993. The Motivational Effects of Charismatic Leadership: A Self-Concept Based Theory. Organization Science, 4(4): 577-594.

Singer, J. A. 2004. Narrative Identity and Meaning Making Across the Adult Lifespan: An Introduction. Journal of Personality, 72(3): 437-460.

Slaughter, A.M. 2012. Why Women Still Can’t Have It All. Atlantic Monthly, July/August 2012

Snow, D. A., \& Anderson, L. 1987. Identity Work Among the Homeless: The Verbal Construction and Avowal of Personal Identities. American Journal of Sociology, 92(6): 1336-1371.

Somers, M. R. 1994. The Narrative Constitution of Identity: A Relational and Network Approach. Theory and Society, 23(5): 605-649.

Stone, P. 2007. Opting Out?: Why Women Really Quit Careers and Head Home. Berkeley, CA: University of California Press.

Strauss, A. \& Corbin, J. 1998. Basics of Qualitative Research. Techniques and Procedures for Developing Grounded Theory. Thousand Oaks, CA: Sage Publications. 
Stryker, S. 1968. Identity Salience and Role Performance: The Relevance of Symbolic Interaction Theory for Family Research. Journal of Marriage and the Family, 30(4): 558-564.

Stryker, S. 1980. Symbolic Interactionism: A Social Structural Version. Menlo Park, CA: The Benjamin/Cummings Publishing Company.

Stryker, S., \& Burke, P. J. 2000. The Past, Present, and Future of an Identity Theory. Social Psychology Quarterly, 63(4): 284-297.

Sullivan, S. E., \& Baruch, Y. 2009. Advances in Career Theory and Research: A Critical Review and Agenda for Future Exploration. Journal of Management, 35(6): 1542-1571.

Sullivan, S., \& Mainiero, L. 2007. The Changing Nature of Gender Roles, Alpha/Beta Careers and Work-Life Issues: Theory-Driven Implications for Human Resource Management. Career Development International, 12(3): 238-263.

Super, D. E., \& Hall, D. T. 1978. Career Development: Exploration and Planning. Annual Review of Psychology, 29(1): 333-372.

Super, D. E. 1980. A Life-Span, Life-Space Approach to Career Development. Journal of Vocational Behavior, 16(3): 282-298.

Sveningsson, S., \& Alvesson, M. 2003. Managing Managerial Identities: Organizational Fragmentation, Discourse and Identity Struggle. Human Relations, 56(10): 1163-1193.

Tajfel, H., \& Turner, J. 1985. The Social Identity Theory of Intergroup Behaviour. In S. Worchel and W. Austin (Eds.), Psychology of Intergroup Relations, 7-24. Chicago: Nelson Hall.

Volpe, E. H., \& Murphy, W. M. 2011. Married Professional Women's Career Exit: Integrating Identity and Social Networks. Gender in Management, 26(1): 57-83.

Voydanoff, P. 2005. Consequences of Boundary-Spanning Demands and Resources for Work-toFamily Conflict and Perceived Stress. Journal of Occupational Health Psychology, 10(4), 491.

Wallis, C. 2004. The Case for Staying Home. Time Magazine, 163(12): 50-59.

Watson, T. J. 2008. Managing Identity: Identity Work, Personal Predicaments and Structural Circumstances. Organization, 15(1): 121-143.

Wharton, A. S., \& Blair-Loy, M. 2006. Long Work Hours and Family Life A Cross-National Study of Employees' Concerns. Journal of Family Issues, 27(3): 415-436.

Yost, J. H., Strube, M. J., \& Bailey, J. R. 1992. The Construction of the Self: An Evolutionary View. Current Psychology, 11(2): 110-121. 
TABLE 1: PARTICIPANT DEMOGRAPHICS

\begin{tabular}{|c|c|}
\hline Age & $\begin{array}{c}\text { Range: } 31-45 \\
\text { Mean: } 37.5\end{array}$ \\
\hline Number of Children & $\begin{array}{l}\text { Range: } 1-4 \\
\text { Mean: } 2.1\end{array}$ \\
\hline Marital Status & $\begin{array}{l}\text { Married: } 33 \\
\text { Partnered: } 2\end{array}$ \\
\hline Annual Household Income & $\begin{array}{l}\text { Range: } \$ 50,000 \text { to } \$ 500 \mathrm{~K} \\
\text { Average: } \$ 200 \mathrm{~K}\end{array}$ \\
\hline Employment Status & $\begin{array}{l}\text { Full-time (15), Part-time (11) } \\
\text { Career break (9) }\end{array}$ \\
\hline Race & $\begin{array}{l}2 \text { Asian American, } 1 \text { African American, } \\
\text { 33 Caucasian }\end{array}$ \\
\hline $\begin{array}{l}\text { Degrees held } \\
\text { (number of participants*) }\end{array}$ & $\begin{array}{c}\text { BA/BS (5) } \\
\text { MA (4) } \\
\text { MBA (15) } \\
\text { MPA (2) } \\
\text { M. Eng. (2) } \\
\text { MSSW (1) } \\
\text { MD (1) } \\
\text { JD/LLM (4) } \\
\text { PhD (2) }\end{array}$ \\
\hline Titles & $\begin{array}{c}\text { Partner, Vice President, Director, Resident, } \\
\text { Professor, Researcher, Senior Manager, Senior } \\
\text { Counsel, Manager, Senior Analyst, Analyst, } \\
\text { Technician, Specialist }\end{array}$ \\
\hline Industry sectors & $\begin{array}{l}\text { Financial services, medical devices/supplies, } \\
\text { consulting, high tech, consumer goods, } \\
\text { pharmaceuticals, healthcare, education }\end{array}$ \\
\hline
\end{tabular}

*Total adds to 36 as one participant holds two master's degrees 
TABLE 2: REFLECTION ASSIGNMENT SELECTED EVENTS

\begin{tabular}{|l|c|}
\hline \multicolumn{1}{|c|}{ Significant event/turning point } & Number of informants \\
\hline Becoming a mother/having children & $\mathbf{2 9}$ \\
\hline $\begin{array}{l}\text { Pre-graduation from university event and/or starting first post- } \\
\text { university job }\end{array}$ & $\mathbf{2 0}$ \\
\hline $\begin{array}{l}\text { Combining career \& family (e.g., changing employment status, } \\
\text { changing employers/industries, having subsequent children, etc.) }\end{array}$ & $\mathbf{1 1}$ \\
\hline Getting engaged/married/moving in with a partner & $\mathbf{3 5}$ \\
\hline $\begin{array}{l}\text { Other (e.g., health scare, end of a romantic relationship, quitting a } \\
\text { job, being fired) }\end{array}$ & \\
\hline
\end{tabular}

\section{TABLE 3: ANALYTIC STEPS}

Four-Step Data Analysis Procedure:

- Step 1: Creating summaries and analytic memos

- Step 2: Creating chronological biographical accounts

- Step 3: Identifying within-case patterns and themes

- Step 4: Identifying between-case patterns and themes 
TABLE 4: Narrative Identity Work at the Early Career Transition

\begin{tabular}{|c|c|c|}
\hline $\begin{array}{c}\text { Form of } \\
\text { Identity Work }\end{array}$ & Definition & Example Quotes \\
\hline Searching & $\begin{array}{l}\text { Having yet to stake a } \\
\text { claim on a particular } \\
\text { identity. Considering } \\
\text { various paths and } \\
\text { possible selves }\end{array}$ & $\begin{array}{l}\text {...when I was graduating college I really wasn't sure } \\
\text { what I wanted to do in the long run. So I said, "Let me } \\
\text { go out and work. Let me go out and see what it would } \\
\text { be like." Not academia, because I kind of had a sense } \\
\text { of what that would be like. Not government, but in the } \\
\text { work world, in the corporate world, what could I do } \\
\text { with a PhD in economics? And I felt like I needed to } \\
\text { uncover what that was before I could decide. -US06 }\end{array}$ \\
\hline Shedding & $\begin{array}{l}\text { Letting go of an } \\
\text { identity adopted in } \\
\text { childhood/ } \\
\text { adolescence and } \\
\text { opening up to other } \\
\text { possible selves }\end{array}$ & $\begin{array}{l}\text { For as long as I could remember, my life was defined } \\
\text { solely by an academic purpose; ...however, after a } \\
\text { particularly tough personal year during my } 2 \text { nd year in } \\
\text { university, I decided that my life needed something } \\
\text { different.... I simply did not want to be, "Esther, the } \\
\text { lawyer." Having discovered this, I spent several years } \\
\text { wandering to find myself and my purpose. -CA02 }\end{array}$ \\
\hline Projecting & $\begin{array}{l}\text { Envisioning a future } \\
\text { self who realizes her } \\
\text { potential and/or } \\
\text { becomes financially } \\
\text { independent; often } \\
\text { inspired by a parent, } \\
\text { teacher, or mentor }\end{array}$ & $\begin{array}{l}\text { My career was always important to me. I think that's } \\
\text { the way I was raised. My mom always, you know, like } \\
\text { told me, "You know, you have to stand on your own } \\
\text { feet, like it's important to be independent, not only } \\
\text { emotionally but, you know, financially. Like you never } \\
\text { know what can happen in life." So I was really raised } \\
\text { that way. -CA11 }\end{array}$ \\
\hline Claiming & $\begin{array}{l}\text { Professing a } \\
\text { particular identity - a } \\
\text { clearly defined sense } \\
\text { of self }\end{array}$ & $\begin{array}{l}\text { I have always been very independent thinking, and the } \\
\text { ability to support myself without depending on anyone } \\
\text { but myself led to a very independent identity. -USO7 }\end{array}$ \\
\hline
\end{tabular}


TABLE 5: Narrative Identity Work at the Transition to Motherhood

\begin{tabular}{|c|c|c|}
\hline $\begin{array}{c}\text { Form of } \\
\text { Identity Work }\end{array}$ & Definition & Example Quotes \\
\hline \multirow[b]{2}{*}{ Revising } & $\begin{array}{l}\text { Modifying: Experiencing a } \\
\text { shift in one's sense of self } \\
\text { as the result of becoming } \\
\text { a mother; often involves a } \\
\text { de-prioritization of career/ } \\
\text { professional identity }\end{array}$ & $\begin{array}{l}\text { As expected, I wanted to be the best mother possible } \\
\text { (reading books, buying educational CDs, books, etc.) } \\
\text { with my aspirations as professional taking back seat. } \\
\text { I knew that I wanted to have } 3 \text { kids and I felt that } \\
\text { success for me would be having a JOB not a career } \\
\text { that would be satisfying and allow me to learn and } \\
\text { grow. -US03 }\end{array}$ \\
\hline & $\begin{array}{l}\text { Transforming: } \\
\text { Experiencing a dramatic } \\
\text { change in one's sense of } \\
\text { self as the result of } \\
\text { becoming a mother; often } \\
\text { entails the new mother } \\
\text { identity completely } \\
\text { overwhelming one's sense } \\
\text { of self as professional }\end{array}$ & $\begin{array}{l}\text { My work had been my whole identity up until I became } \\
\text { pregnant. I didn't even know there was a different } \\
\text { perspective to be had. I really valued work ethic and } \\
\text { achievement above all else. And then came (son's } \\
\text { name). I have to admit, even marrying my husband } \\
\text { didn't change the way I felt about myself or my values } \\
\text { or how I spent my time. My life didn't change that } \\
\text { much after I got married...it was just more cohesive. } \\
\text { But (son's name) rocked my world. -US19 }\end{array}$ \\
\hline Preserving & $\begin{array}{l}\text { Maintaining one's sense } \\
\text { of self as a professional } \\
\text { and an individual after the } \\
\text { birth of a first child - } \\
\text { often the story reveals a } \\
\text { desire to return to work } \\
\text { versus thoughts of } \\
\text { wanting to stay home }\end{array}$ & $\begin{array}{l}\text {...I remember just being very focused, like once it got } \\
\text { to be around seven weeks, I was like, "Oh my God, } \\
\text { she needs to be, I need to start getting..." I started } \\
\text { thinking about going back to work, and I was like, “I } \\
\text { need to get into a routine and a schedule at night." ... } \\
\text { I wanted her in her bedroom, in her crib. And like } \\
\text { have it planned so that I could get home from work, } \\
\text { get her to bed, and then still have some time to myself, } \\
\text { or with (my husband), so that it wouldn't be so } \\
\text { overwhelming. -US11 }\end{array}$ \\
\hline Interrogating & $\begin{array}{l}\text { Questioning a change in } \\
\text { one's sense of self, often } \\
\text { the loss of a previous } \\
\text { identity that accompanies } \\
\text { the addition of a "mother" } \\
\text { identity }\end{array}$ & $\begin{array}{l}\text { I was really struggling with: “Am I the old Talia? } \\
\text { Like am I...? Who is the new Talia?”-CA06 }\end{array}$ \\
\hline
\end{tabular}


TABLE 6: Narrative Identity Work in Combining Career \& Family

\begin{tabular}{|c|c|c|}
\hline $\begin{array}{c}\text { Form of } \\
\text { Identity Work }\end{array}$ & Definition & Example Quotes \\
\hline Enacting & $\begin{array}{l}\text { Performing an asserted sense } \\
\text { of self in how one combines } \\
\text { career and family }\end{array}$ & $\begin{array}{l}\text {...when I started working I was like, "Oh my God! He's going to be fulltime in the } \\
\text { daycare." It's not that I felt bad about it, because I knew that I needed to go back to } \\
\text { work. I was never going to be that person that was going to stay at home. -CA13 }\end{array}$ \\
\hline Experimenting & $\begin{array}{l}\text { Trying out various } \\
\text { "provisional selves”, such as } \\
\text { "stay-at-home” and "working } \\
\text { mom,” and/or exploring } \\
\text { various career paths in the } \\
\text { search for one that feels "right” }\end{array}$ & $\begin{array}{l}\text { During this whole time, my view of my upcoming role/identity kept shifting. ...I } \\
\text { partnered with (my husband) on the search fund, and also helped him identify } \\
\text { companies to apply to. ...but also constantly thinking about what I could do career- } \\
\text { wise or PhD-wise.... Whenever I had free time, I'd read as much as I could about } \\
\text { economics, my favorite research topic for a potential PhD, or about alternate jobs } \\
\text { for MBAs, ones that could potentially offer more flexibility. -US04 }\end{array}$ \\
\hline Grappling & $\begin{array}{l}\text { Struggling with a sense of } \\
\text { identity loss or conflicting } \\
\text { identities in combining career } \\
\text { and family }\end{array}$ & $\begin{array}{l}\text {...it has made me very uncomfortable and anxious and even depressed to think that } \\
\text { I can never be the person I'm pretending I am now... So I'm pretending that I can do } \\
\text { it all; that I can be patient and kind and Zen and professional, but not like a work } \\
\text { Nazi. And like a sweet and firm and proper mother without being like a controlling } \\
\text { bitch. It's like... I fall off that pedestal all the time. -CA15 }\end{array}$ \\
\hline
\end{tabular}


TABLE 7: Forms of Narrative Identity Work that Exemplify Three Identity Processes

\begin{tabular}{|c|c|c|c|c|}
\hline $\begin{array}{l}\text { Identity } \\
\text { Processes }\end{array}$ & Definition & $\begin{array}{c}\text { Early Career } \\
\text { Transition }\end{array}$ & $\begin{array}{l}\text { Transition to } \\
\text { Motherhood }\end{array}$ & $\begin{array}{c}\text { Transition to } \\
\text { Combining } \\
\text { Career \& Family } \\
\end{array}$ \\
\hline $\begin{array}{c}\text { Identity } \\
\text { Exploration }\end{array}$ & $\begin{array}{l}\text { Openly questioning one's sense } \\
\text { of self; imagining who one is } \\
\text { and/or who one wants to } \\
\text { be/become }\end{array}$ & Searching & Interrogating & $\begin{array}{c}\text { Grappling } \\
\text { Experimenting* }\end{array}$ \\
\hline $\begin{array}{c}\text { Identity } \\
\text { Adaptation }\end{array}$ & $\begin{array}{l}\text { Revising one’s self-concept by } \\
\text { recognizing and accepting a } \\
\text { change in one’s sense of self; } \\
\text { may involve letting go of a past } \\
\text { identity, adjusting one’s } \\
\text { priorities, and/or trying out } \\
\text { provisional selves }\end{array}$ & Shedding & $\begin{array}{l}\text { Revising: } \\
\text { Modifying } \\
\text { Transforming }\end{array}$ & Experimenting* \\
\hline $\begin{array}{c}\text { Identity } \\
\text { Expression }\end{array}$ & $\begin{array}{l}\text { Asserting one's sense of self; } \\
\text { presenting oneself in a manner } \\
\text { that reflects one’s commitment to } \\
\text { a clearly articulated self-concept. }\end{array}$ & $\begin{array}{l}\text { Claiming } \\
\text { Projecting }\end{array}$ & Preserving & Enacting \\
\hline
\end{tabular}

*Experimenting is the one form of narrative identity work that reflects two identity processes: identity exploration and identity adaptation. 
Figure 1: The Identity Process Patterns

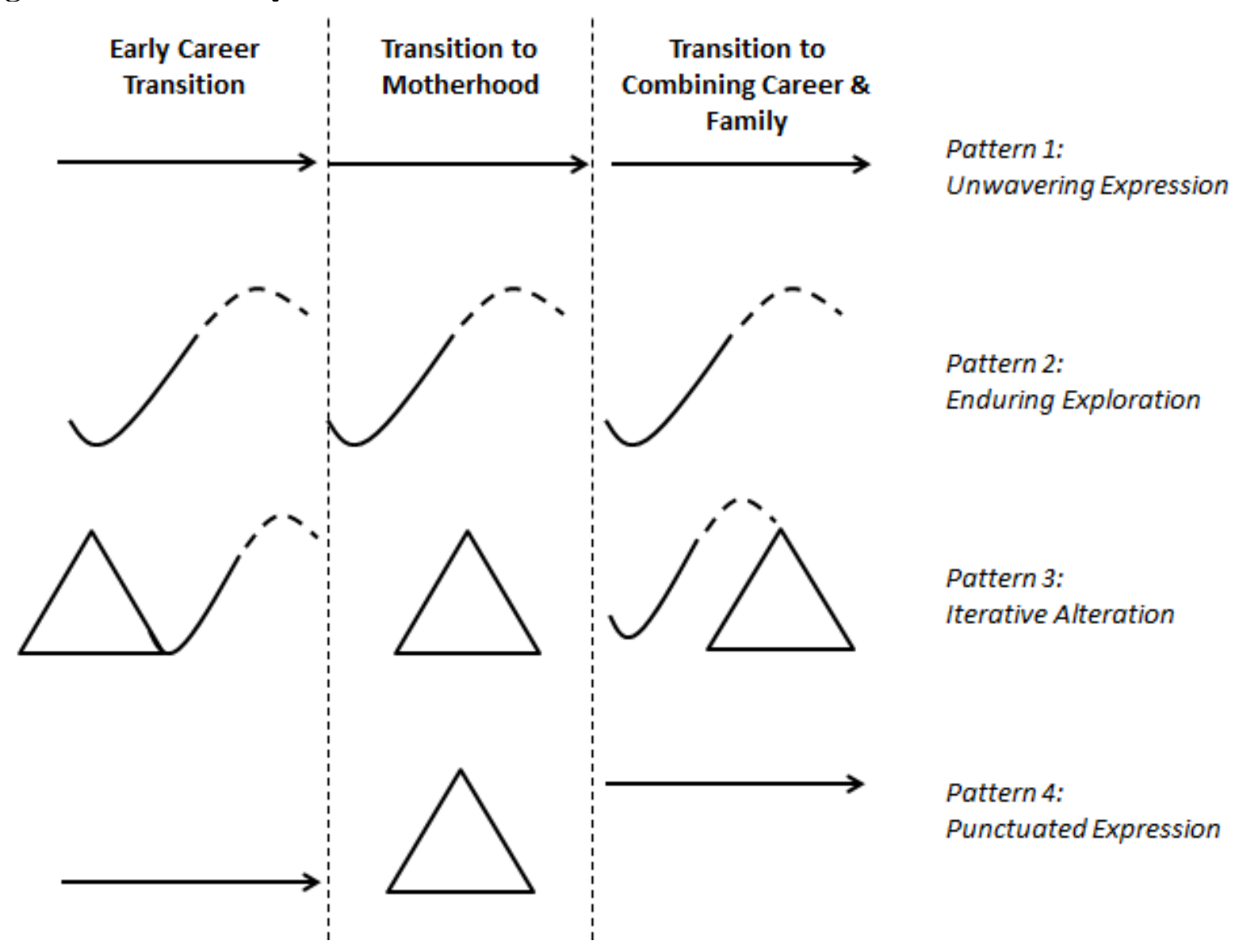




\section{APPENDIX A}

\section{Sample Recruiting Email of Women Professionals and Managers}

From: Christine Bataille

Sent: Mon /2011 11:54 AM

To: Personal Contacts

Subject: Help with Finding Participants for Work-Family Balance Study

Attached: Study Summary; Recruitment Flyer for Prospective Participants

Dear

I hope that all is well with you. I am writing to let you know that things are moving along with my doctoral program at McGill and to ask for your help in finding participants for my thesis research. My study is looking at how women professionals and managers combine career and family. In particular, I am interested in how these women develop a sense of personal identity while pursuing a career and raising a family.

I am looking for participants through a number of avenues, but I could use your help locating additional women to interview in the coming months. Attached is a brief summary of my study and a recruitment flyer. Would you mind taking a look and passing these on to anyone you know who may fit the participant profile? These women could then contact me directly for more information about participating in the study.

Thanks in advance for your time!

Kind regards,

\section{Christine}

Christine D. Bataille

Ph.D. Candidate \& Principal Investigator*

Organizational Behavior

Desautels Faculty of Management

McGill University

1001 Sherbrooke St. West

Montreal, Quebec

H3A 1G5 Canada

e-mail: christine.bataille@mail.mcgill.ca

tel.: 514-969-1453

* under the supervision of Dr. Mary Dean Lee, Desautels Faculty of Management, McGill University 


\section{Study Summary}

Combining career and family continues to pose serious challenges for women. The purpose of the present study is to understand how married/partnered professional and managerial women with young children combine career and family. Specifically, I hope to learn how careeroriented women feel about their combined work and family lives and to uncover the kinds of challenges they face in crafting and maintaining a sense of self while pursuing a career and raising a family. Investigating this "identity work" has the potential to improve how we approach career counselling and women's career development. Further, exploring how women conduct identity work as they make decisions about how to combine career and family may help career counsellors provide more appropriate support to their female clients. Moreover, the findings from this study may inform organizational efforts to create more individualized support systems that allow women to plan out and achieve both their career and family goals.

In order to attain these goals, the researcher will conduct two confidential interviews each with a sample of 25-30 women who are currently working full-time in either professional or managerial positions. Participants for this study must be either married or partnered, have at least one young child living at home, and live in Canada or the United States.

- Interviews will be conducted at a mutually convenient place and time and will last approximately 60 minutes each. The first interview will be in-person and will cover managing work, personal and family life on a day-to-day basis. In the second interview, participants will be asked about particular transition points in their lives, including starting their careers and becoming mothers. Participants will have the right to withdraw from the interview or decline to answer any specific question at any time.

\section{Benefits of Participating in the Study}

After all interviews are conducted, an Executive Feedback Report will be prepared and distributed to all participants. The research findings will protect the identity of participants, with all responses being reported anonymously.

If you would like to participate in this study, please contact the researcher directly at the phone number or email address provided below.

\footnotetext{
Christine D. Bataille, Ph.D. Candidate (Principal Investigator)* Organizational Behavior

Desautels Faculty of Management, McGill University

1001 Sherbrooke St. West, Montreal, Quebec, H3A 1G5 Canada

tel.: 514-969-1453 / e-mail: christine.bataille@mail.mcgill.ca

* under the supervision of Dr. Mary Dean Lee, Desautels Faculty of Management, McGill University
} 


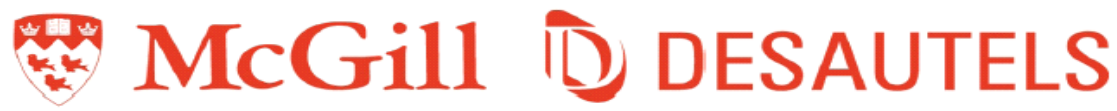

FACULTY OF MANAGEMENT • FACULTÉ DE GESTION

\section{WANTED FOR RESEARCH STUDY: Women Professionals and Managers with Young Children}

How do you manage building a career while raising a family?

As most of us are well aware, combining work and family continues to pose serious challenges for career-oriented women. The purpose of this study is to understand how professional and managerial women feel about pursuing a career while raising a family.

How do you really feel about your professional and personal life? How did you get to where you are and where are you headed?

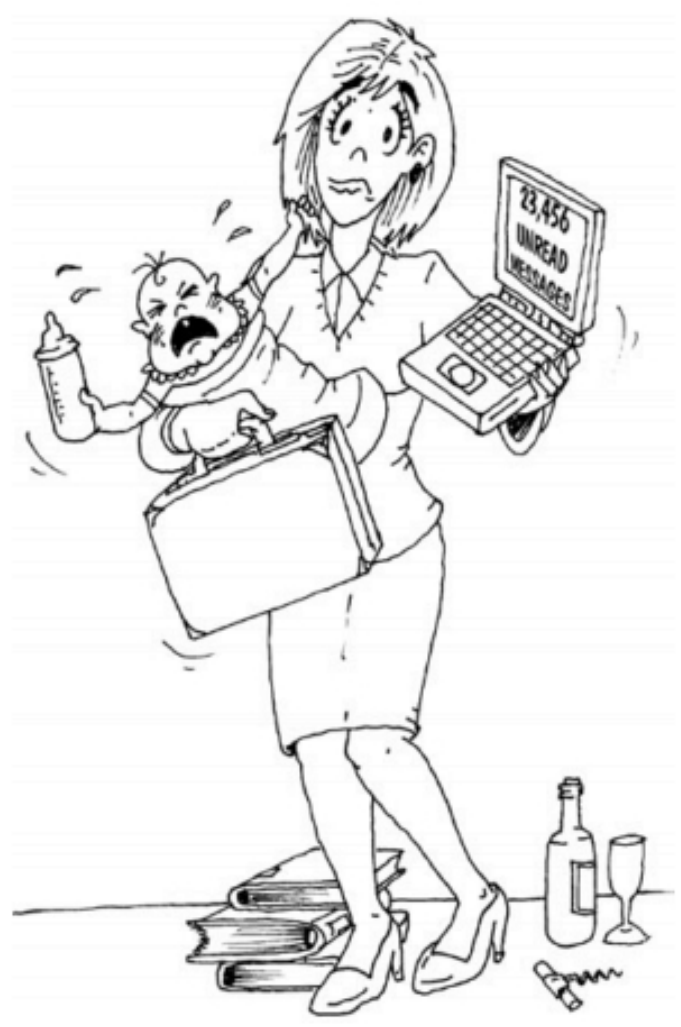

If you are a woman who is married or partnered, have a professional or managerial career and have at least one young child living at home, then I want to interview* you!

\author{
Christine D. Bataille \\ PhD Candidate, Organizational Behaviour \\ Desautels Faculty of Management \\ christine.bataille@mail.mcgill.ca
}

*Two interviews are required for participation in this study. Interviews are completely confidential and are expected to last no more than 60 minutes each. 


\section{APPENDIX B \\ PROFESSIONAL/MANAGERIAL WOMEN'S IDENTITY WORK STUDY: INTERVIEW PROTOCOL}

\section{Pre-Interview Dialogue}

1. Review purpose of study and focus of interview - answer questions.

Suggested Script: The goal of this study is to increase understanding of how women develop a sense of personal identity while pursuing a career and raising a family. This research is part of my $\mathrm{PhD}$ thesis and I will be conducting interviews with approximately 30-35 women in Canada and the United States. Today's interview consists of three parts: a) a brief history of your career and family life, b) how you are currently combining career and family and c) how you see yourself as a person today, and how you envision yourself in the future. At the end of the interview, I will ask you for some basic demographic information and then we will schedule a second interview. In preparation for our next meeting, I will also ask you to reflect upon and write about 3 to 4 significant/defining turning points or transitions in your life. During the second interview, I will ask you to tell me about these transitions, as well as other transitions that we know to be significant for women who pursue careers and raise a family. I will also ask you to describe yourself at different points in time.

Everything you tell me will be considered strictly confidential, and you may decline to answer any question or withdraw from the study at any time. In my analysis, I will focus on aggregate results and recurrent themes across all of those interviewed; the anonymity of each interviewee will be carefully protected. Once the study is completed, all of those who have participated in interviews in the study will receive a report describing a summary of my findings. Do you have any questions?

1. Collect signed Consent Forms and leave Interviewee 1copy with Interviewer signature, or provide a blank for signature.

2. If not already obtained and filled out below (which is ideal), get address, phone number, and email address (business card is good).

3. Check on time constraints (Interview time estimated to be 1-1.5 hours.)

4. Check recording equipment.

Name:

E Mail:

\section{Address:}

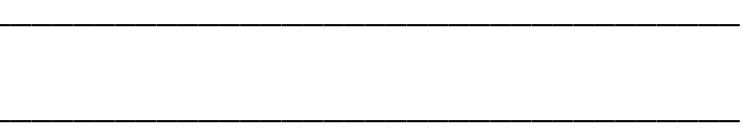

Current/Most Recent Job Title:

\section{Current/Most Recent Employer:}

\section{Phone \#:}

E Mail Contact for Exec. Report

2012-2013: 


\section{Interview 1:}

As I mentioned, today's interview consists of three parts:

A. Brief history of your career and family life

B. How you are currently combining career and family

C. How you see yourself as a person today, and how you envision yourself in the future

\section{A. Career/Family History}

1. Why don't we start with you giving me a high-level overview of your career, beginning with when you graduated from university.

a. Please include any significant life events, as well, such as when you got married, the birth of each child, etc.

b. How is your health? Any health issues in the past?

\section{B. Current Situation}

Thank you for the overview - it is very helpful for me to have a sense of your career and family history. Now, I would like to learn more about your current situation, in terms of work and family. (If the informant is not currently working, ask about last job held).

1. Are you currently working? Full/part-time?

- Where are/were you working?

- What is/was your position/title?

- On average, how many hours per week do/did you work?

- What's your (work) schedule like? How much flexibility do you have?

- How often do you travel?

- How long is/was your commute?

- Do/did you ever work from home?

- How fluctuating is/was your work load over a year's time? Give examples of high and low demand, hours per week, etc.

- Have/had you had any recent promotions OR are/were you expecting a promotion in the near future?

- How much do you enjoy the work that you do?

2. What does your husband/partner do?

- What is his work schedule like?

- How often does he travel?

- How is his health?

- What role does he play in the family?

3. How many children do you have? 
- Ages?

- Daycare/Preschool/School?

- Health?

- Activities?

4. Does anyone help you with caring for your children and taking care of your home?

- Who cares for your children when you are at work/engaged in personal activities?

- Do you have a nanny, babysitter, housekeeper?

- Do you get any childcare support from your family or neighbours?

- Who/what has been most helpful to you in combining work and family?

- Do you have any elder care responsibilities? If yes, please explain.

5. How do you spend your evenings and weekends?

- Describe a typical weekend in your family

6. Besides your (career and) family/home responsibilities, what other kinds of activities and/or organizations are you involved in?

- Other than your spouse/partner and child(ren), do you have certain friends/family members/colleagues that you make time for?

- How often do you see/speak to them?

- What kinds of activities do you do together?

- What do you do when you are alone?

- Describe your "alone time" in a typical week - what are you doing?

7. How do you feel about your current situation/how you are currently combining career and family? In other words, how close are you to having the kind of career and family life that you want?

- What are the best parts of your current situation? The worst?

- What are/were the most demanding aspects of combining your career and family life?

- If the present situation is challenging:

- How do you cope?/What gets you through the difficult times?

- Have you encountered any specific problems? Explain.

8. Thinking about your present situation, if you could wave a magic wand, what would be different? 


\section{Personal Identity}

Thank you for helping me to gain an in-depth understanding of your present situation. Everything you have shared with me is very helpful, as one of the important goals of this study is to understand how professional and managerial women with young children are combining career and family. The other important objective is to gain insight into how women develop a sense of personal identity as they pursue careers, raise families and engage in other activities. So, what I would like to do now is ask you a few questions about how you see yourself as a person.

1. Sitting here right now, how do you see yourself as a person?

- If you asked yourself the question, "Who Am I?” how would you answer?

- How would you describe yourself?

- Please give me an example/share a story that will help me to understand why you describe yourself as ?

- If you were talking to a long lost relative from a faraway place - on the phone (or skype) - what you say about yourself?

2. What would you like others to know about you?

- How would your friends describe you?

3. Where do you see yourself in 5-10 years, in terms of career, family and personal life?

\section{Wrap-up}

Is there anything else you would to add before our next interview - anything I did not ask you about but that you think is relevant?

\section{Preparation for Interview 2:}

In preparation for our next meeting, I would like to ask you to reflect upon 3 or 4 of most significant career/life transitions or turning points you have experienced since high school. These may include some of the transitions you mentioned when you gave me your career history, or maybe there are other transitions or events that stand out to you as particularly challenging or meaningful.

It would be great if you could write a little bit about each of the turning points/events you choose, as this will save us some time in Interview 2, but please do not spend more than an hour or so on this (unless you find the exercise particularly interesting and want to write more!).

I have prepared a form to help you write up your thoughts (be sure to give "Reflection Assignment” to informant).

\section{Interview 2:}

At the end of our last meeting, I asked you to reflect upon, and write about, 3 to 4 turning points/transitions since high school that stand out as particularly significant to you. What I would like to do in this second interview is to ask you some questions about a) the turning 
points/transitions that you identified and b) some specific transitions that have been identified in previous research as particularly important in women's lives. I will then ask you to tell me how you think the person you are today differs from/is similar to the person you were in university. Lastly, I will ask you to reflect upon the process of being involved in this study.

Why don't we begin with you naming the specific transitions you wrote about and telling me how old you were during each one (If you have not had a chance to complete the reflection assignment, why don’t we look at it now, together?):

Turning point/Transition 1:

Age:

Turning point/Transition 2: Age:

Turning point/Transition 3: Age:

Turning point/Transition 4: Age:

OK. Now, before I ask you to tell me about each of these turning points/transitions in more detail, I would like to tell you about the four transitions that I had planned to ask you about (if there is any overlap, name the transition(s) but acknowledge that the informant has already included it/them in her list), and ask you how old you were at each of these points in time:

- University to $1^{\text {st }}$ Job, Age:

- Getting married/Co-habiting, Age:

- Birth of your first child, Age:

- Going back to work/deciding not to return to work at the end of maternity leave

- $1^{\text {st }}$ maternity leave, Age:

- $2^{\text {nd }}$ maternity leave, Age:

- $3^{\text {rd }}$ maternity leave, Age:

What I would like to do now is ask you some specific questions about each of these turning points/transitions. We will go in chronological order, which means we will start with

\section{a. Transitions}

\section{Turning point/Transition 1:}

o Describe what happened 
o How would you describe yourself at this point in your life?

- Did this transition/event affect how you saw yourself in any way?

Turning point/Transition 2:

o Describe what happened

o How would you describe yourself at this point in your life?

- Did this transition/event affect how you saw yourself in any way?

Turning point/Transition 3:

o Describe what happened

o How would you describe yourself at this point in your life?

- Did this transition/event affect how you saw yourself in any way?

Turning point/Transition 4:

- Describe what happened

- How would you describe yourself at this point in your life?

o Did this transition/event affect how you saw yourself in any way?

\section{University to First Job}

- What did you study in university? How did you decide on this?

- What kinds of activities/organizations were you involved in?

- What kind of a career did you envision?

- What was your job search like? How did you decide which job to take?

- Tell me about your experience in your first job.

- How would you describe the person you were then?

\section{Getting married/Co-habiting}

- How did you decide to get married/move in together?

- What kind of a family life did you envision?

- How did you imagine you would combine career and family? What were your husband's/partners views on combining career and family?

- How would your husband describe the woman he married?

- How do you think getting married/partnering change who you were or how you thought about yourself?

a. How did your life change? 


\section{Becoming a Mother}

- What was going on in your life when you became pregnant with your first child?

- Tell me about your thoughts and feelings when you learned that you were going to have a baby.

- How did you tell your employer that you were pregnant?

- What plans did you make for maternity leave and returning to work?

- After your baby was born, what were the first few months like?

- How, if at all, did your relationship with your husband/partner change?

- How would you describe the person you were at this time?

- How do you think becoming a mother has affected you?

\section{Going back to work/deciding not to return to work at the end of maternity leave}

- What options did you consider when you thought about going back to work?

- How did you figure out what you wanted for yourself and your family?

o What was your husband's role in this decision? Your employer's

- If/when returned to work:

o How did you feel when you were at work?

o How did your supervisors and co-workers respond to you?

o How did you feel when you got home after work?

- How, if at all, did your thoughts feelings about having a career and a family change after you had your first baby?

o After the second, third?

\section{B. Reflections on identity}

- How do you think you are different today from the university student you described at the beginning of the interview? Similar to her?

9. How would you describe what you have gained by pursuing a career and having a family?

- Are there parts of yourself that you have given up/lost?

10. Given the present set-up of your life, how do you maintain a sense of who you are? 
11. If you were talking to a friend who has a high-potential career and is considering having children, what advice would you give?

\section{Reflections on the interview process}

- What was the process like, writing about these transition points/significant life events?

- Did anything surprise you?

- Has being part of this study had an impact on you in any way? If so, how?

- Is there anything that you might not have thought about before that occurred to you during this interview? Something I did not ask you about?

- Is there anything you would like to ask me?

\section{Follow-up}

- Do you know of anyone else who fits the study criteria and might be interested in participating?

- Would you be willing to pass on my study summary? 


\section{APPENDIX C}

Demographic Survey for Study Participants

Interviewee ID:

Age:

Highest degree obtained

Current employment status: __ Full-time __ Part-time ___ Currently not working

Approximate number of hours worked per week:

If you have worked less than full-time (excluding maternity leave), please specify the year(s) and approximate number of days/hours you worked per week:

\begin{tabular}{|l|l|l|l|l|}
\hline & Starting Mo/Yr & Ending Mo/Yr & Days per Week & Hours per Week \\
\hline Period 1 & & & & \\
\hline Period 2 & & & & \\
\hline Period 3 & & & & \\
\hline Period 4 & & & & \\
\hline
\end{tabular}

Marital status (check one): ___ Married ___ Partnered Age of spouse/partner:

Ages of children: Child 1:__ Child 2:__ Child 3:__ Child 4:

Spouse/Partner's employment status: __ Full-time ___Part-time ___ Currently not working

Spouse/Partner’s job title and employer:

Approximate hours spouse works per week:

Annual household income range: Please circle the number beside the income range that most closely represents your household's total, pre-tax annual income.

1. Less than $\$ 50,000$

6. $\$ 150,000$ - $\$ 174,999$

10. $\$ 275,000$ - $\$ 299,999$

2. $\$ 50,000$ - $\$ 74,999$

7. $\$ 175,000-\$ 199,999$

11. $\$ 300,000$ - $\$ 349$,

3. $\$ 75,000-\$ 99,999$

8. $\$ 200,000$ - $\$ 224,999$

12. $\$ 350,000$ - $\$ 399,999$

4. $\$ 100,000-\$ 124,999$

9. $\$ 225,000$ - $\$ 249,999$

13. $\$ 400,000-\$ 449,000$

5. $\$ 125,000-\$ 149,999$

10. $\$ 250,000$ - $\$ 274,999$

14. $\$ 450,000$ - $\$ 499,999$

15. More than $\$ 500,000$

Who is the primary earner in your family? Self Spouse/partner About equal What percentage of the household income comes from you?

If you are not currently working, or are working less than full time, what percentage of the household income came from you when you were working full time? 


\section{APPENDIX D \\ RFFLECTION ASSIGNMENT FOR INTERVIEW 2}

\section{Professional/Managerial Women's Narrative Identity Work Study:}

Reflecting back on your life since college/university, what are some of the career/life transitions or turning points that stand out in your mind as particularly significant, challenging and/or meaningful? For example: starting your first job, getting promoted, going back to school, changing jobs or employees, getting married, having your first/second/third child, going part-time, changing careers, losing a job, death of a loved one, etc.

Feel free to use the template below, or to write your thoughts down in a notebook or journal, or even type them up in a Word document. I will ask you to share what you have written the next time we meet.

\section{Turning point/Transition \#1}

a) Name the event:

b) What is it about this event/turning point that makes it stand out to you?

c) How did this event/turning point affect you/how you see yourself? 


\section{Turning point/Transition \#2}

a) Name the event:

b) What is it about this event/turning point that makes it stand out to you?

c) How did this event/turning point affect you/how you see yourself? 


\section{Turning point/Transition \#3}

d) Name the event:

e) What is it about this event/turning point that makes it stand out to you?

f) How did this event/turning point affect you/how you see yourself? 
Turning point/Transition \#4

a) Name the event:

b) What is it about this event/turning point that makes it stand out to you?

c) How did this event/turning point affect you/how you see yourself? 
APPENDIX E: Informed Consent for Interviews with Women Professionals and Managers

This study is in partial fulfillment of the requirements for the degree of Doctor of Philosophy.

Mailing Address for Researcher and Faculty Advisor:

\author{
McGill University \\ 1001 Sherbrooke, St. West \\ Montreal, Quebec H3A 1G5
}

Researcher: Christine Bataille

(514-969-1453)

Faculty Advisor: Mary Dean Lee

christine.bataille@mail.mcgill.ca

(514 398-4034)

marydean.lee@mcgill.ca

Purpose of the Research: The purpose of the present study is to understand how married/ partnered professional and managerial women with young children see themselves and their ongoing pursuit of career, family and personal life. Specifically, I hope to learn about how career-oriented women feel about their combined work and family lives and uncover the kinds of challenges they face in crafting and maintaining a sense of self while pursuing a career and raising a family.

What is Involved: Your participation in this study will involved being interviewed by the researcher on two separate occasions. During the first interview, I will be asking about your current day-to-day life. This will include questions about how you combine work and family. I will also inquire about how you envision yourself in the future and how your imagined future self compares with the person you are today. In preparation for the second interview, I will ask you to think about three specific transitions in your life: 1) when you left university and started in your first career job, 2) when you started your life with your husband/partner, and 3) when you had your first child and returned to work after maternity/parental leave. During the second interview, I will be asking you to tell me about these transitions and to describe the person you were at particular points in time. With your permission, the interview will be recorded, however you are free to ask me at any time to either temporarily or permanently stop the recording. Your participation is voluntary and you are free to not answer questions or to withdraw at any time. Your responses will remain confidential, and any quotations or examples that are used in the reports of results will protect your identity. Only the researcher will have access to the data, which will be stored in a locked office. The interviews are expected to last no more than 60 minutes each.

\title{
Please tick to confirm
}

I confirm that I have read and understood this consent form and that I allow the results of my two interviews to be used only within the scope of the present study, including the use of direct quotes under a pseudonym.

I consent to both interviews being audio-recorded.

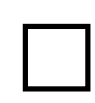

Date

Name (Family, Given)

Email address:

\section{Signature}

Phone: 
APPENDIX F: Analytic Memo Template

\begin{tabular}{|c|c|c|c|c|c|c|}
\hline $\begin{array}{l}\text { Informant ID: } \\
\text { Pseudonym: }\end{array}$ & $\begin{array}{l}\text { Employment } \\
\text { status: }\end{array}$ & $\begin{array}{l}\text { Current } \\
\text { Position: }\end{array}$ & Hours/week: & Age: & $\begin{array}{l}\text { Marital } \\
\text { Status: }\end{array}$ & $\begin{array}{l}\text { Number of Children: } \\
\text { Ages: }\end{array}$ \\
\hline \multicolumn{2}{|c|}{ Highest Degree Earned: } & \multicolumn{5}{|c|}{ Sector: } \\
\hline \multicolumn{2}{|c|}{ Health (self): } & \multicolumn{5}{|c|}{ Health (spouse): $\quad$ Health (Children): } \\
\hline \multicolumn{2}{|c|}{ HH Income: } & \multicolumn{5}{|c|}{ Percent contribution: $\quad$ Previous: FT: $\mathrm{PT}:$} \\
\hline \multicolumn{2}{|c|}{ Spouse Title/Organization: } & \multicolumn{2}{|c|}{ Spouse age: } & \multicolumn{3}{|c|}{ Spouse work hours: } \\
\hline
\end{tabular}

\begin{tabular}{|l|l|l|l|l|}
\hline $\begin{array}{l}\text { Major Career } \\
\text { segments }\end{array}$ & Year & Age & $\begin{array}{l}\text { Employment (including how found job, reason for } \\
\text { move from last job, time use, supports/hindrances) }\end{array}$ & $\begin{array}{l}\text { Major Personal Life events and activities } \\
\text { (marriage/divorce, children, etc.) }\end{array}$ \\
\hline & & & & \\
\hline & & & & \\
\hline & & & & \\
\hline & & & & \\
\hline
\end{tabular}

Themes (maximum 5-10 bullet points per theme)

\begin{tabular}{|l|c|}
\hline Present Identity & $\bullet$ \\
\hline Career sacrifices & $\bullet$ \\
\hline Career goals & $\bullet$ \\
\hline $\begin{array}{l}\text { Prioritizing spouse's } \\
\text { career }\end{array}$ & $\bullet$ \\
\hline Housework & $\bullet$ \\
\hline Childcare & $\bullet$ \\
\hline Activities & $\bullet$ \\
\hline Alone time & $\bullet$ \\
\hline $\begin{array}{l}\text { Flexible work } \\
\text { arrangements }\end{array}$ & $\bullet$ \\
\hline Stress & $\bullet$ \\
\hline $\begin{array}{l}\text { Fragility of current } \\
\text { situation }\end{array}$ & $\bullet$ \\
\hline
\end{tabular}




\begin{tabular}{|l|l|}
\hline $\begin{array}{l}\text { Most helpful to } \\
\text { combining career \& } \\
\text { family }\end{array}$ & $\bullet$ \\
\hline $\begin{array}{l}\text { Feeling about current } \\
\text { situation }\end{array}$ & $\bullet$ \\
\hline $\begin{array}{l}\text { Best part of current } \\
\text { situation }\end{array}$ & $\bullet$ \\
\hline $\begin{array}{l}\text { Worst part of current } \\
\text { situation }\end{array}$ & $\bullet$ \\
\hline Magic Wand Wish & $\bullet$ \\
\hline In 5 to 10 years... & $\bullet$ \\
\hline
\end{tabular}

\section{REFLECTION ASSIGNMENT}

\begin{tabular}{|l|l|l|l|}
\hline $\begin{array}{l}\text { Major Transitions/ } \\
\text { Turning Points }\end{array}$ & Age & Key Excerpts & Themes/Interpretive Comments \\
\hline & & & \\
\hline & & & \\
\hline & & & \\
\hline
\end{tabular}

\section{IDENTITY REFLECTIONS}

\begin{tabular}{|l|l|}
\hline Theme & Key Quotes \\
\hline $\begin{array}{l}\text { Different from university } \\
\text { student }\end{array}$ & $\bullet$ \\
\hline Similar to university student & $\bullet$ \\
\hline $\begin{array}{l}\text { Gains from combining career \& } \\
\text { family }\end{array}$ & $\bullet$ \\
\hline $\begin{array}{l}\text { Losses from combining career } \\
\text { \& family }\end{array}$ & $\bullet$ \\
\hline Maintaining a sense of self & $\bullet$ \\
\hline
\end{tabular}

